Aus der Klinik für Hämatologie und Medizinische Onkologie

(Prof. Dr. med. L. Trümper)

der Medizinischen Fakultät der Universität Göttingen

\title{
Einfluss der sauren und der neutralen Sphingomyelinasen auf Produktion und Zusammensetzung extrazellulärer Vesikel von Mamma-Karzinom-Zelllinien
}

\author{
INAUGURAL-DISSERTATION \\ zur Erlangung des Doktorgrades \\ der Medizinischen Fakultät der \\ Georg-August-Universität zu Göttingen
}

vorgelegt von

Daniel Köberle

aus

Wiesbaden-Dotzheim

Göttingen 2020 
Dekan: Prof. Dr. med. W. Brück

\section{Betreuungsausschuss}

Betreuerin: $\quad$ Prof. Dr. med. C. Binder

Ko-Betreuerin: $\quad$ Prof. Dr. med. C. Stadelmann-Nessler

\section{Prüfungskommission}

Referent/in: $\quad$ Prof. Dr. med. C. Binder

Ko-Referent/in: $\quad$ Prof. Dr. med. Stadelmann-Nessler

Drittreferent/in: $\quad$ Prof. Dr. med. R. Dressel

Datum der mündlichen Prüfung: $\quad$ 20.07.2021 
Hiermit erkläre ich, die Dissertation mit dem Titel "Einfluss der sauren und der neutralen Sphingomyelinasen auf Produktion und Zusammensetzung extrazellulärer Vesikel von Mamma-Karzinom-Zelllinien" eigenständig angefertigt und keine anderen als die von mir angegebenen Quellen und Hilfsmittel verwendet zu haben.

Göttingen, den 


\section{Inhaltsverzeichnis}

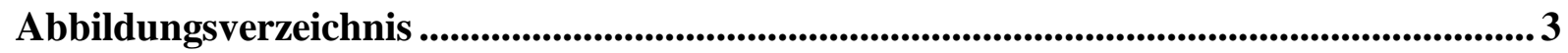

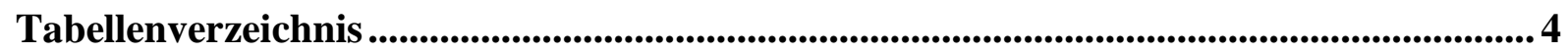

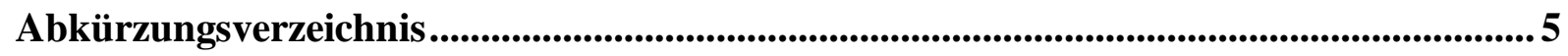

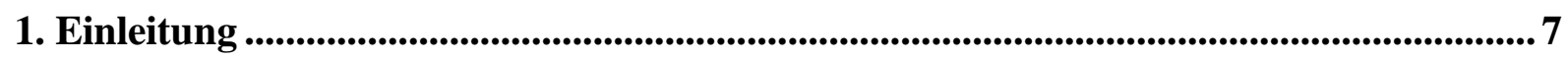

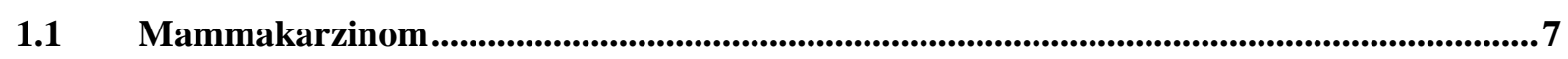

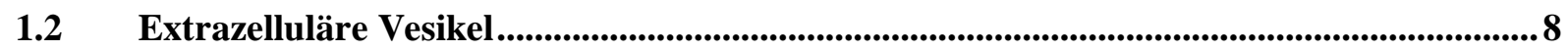

1.3 Sphingomyelinasen................................................................................................................................ 14

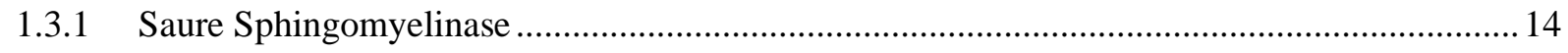

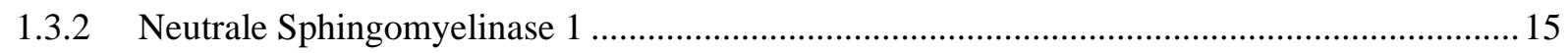

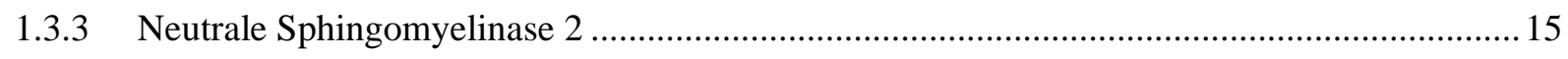

1.4 Sphingomyeline und Ceramide.............................................................................16

1.5 Extrazelluläre Vesikel und Sphingomyelinasen .............................................................18

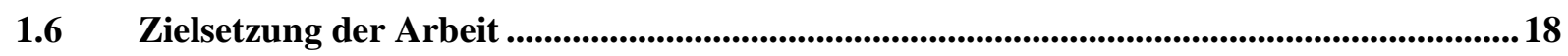

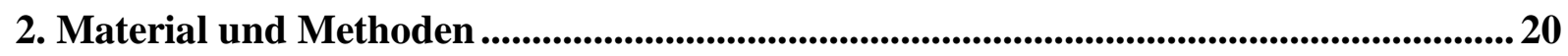

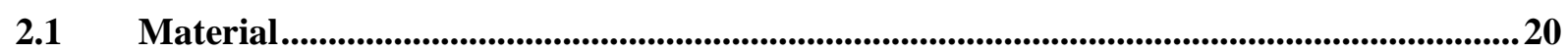

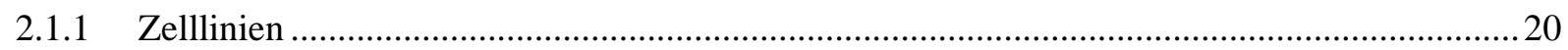

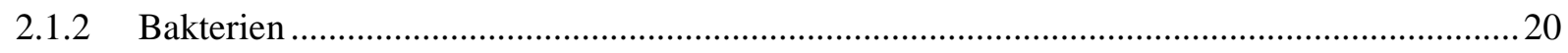

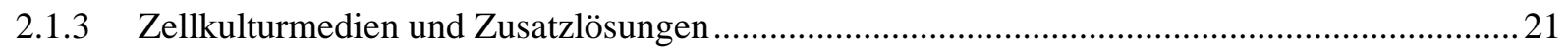

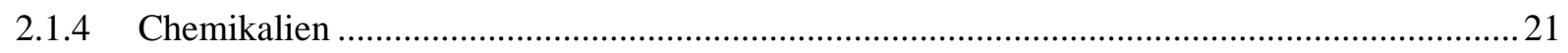

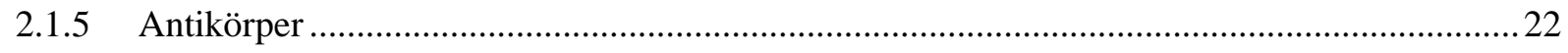

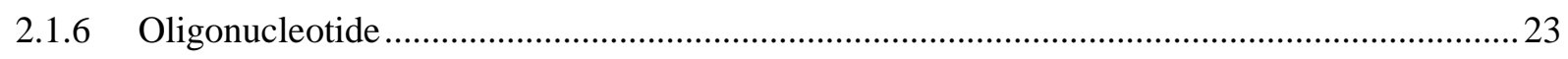

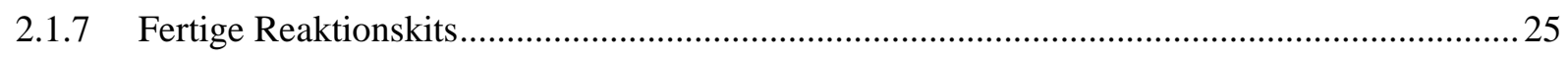

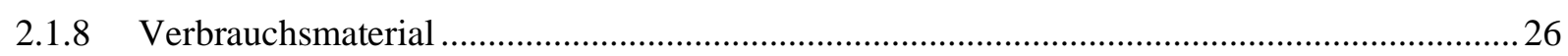

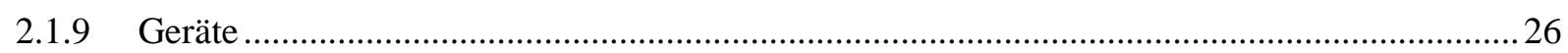

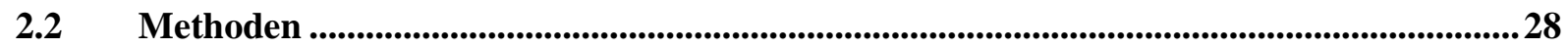

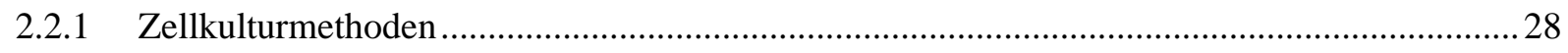

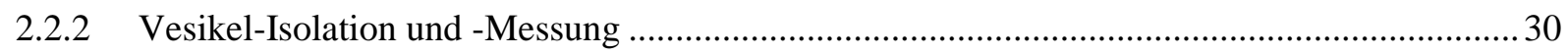

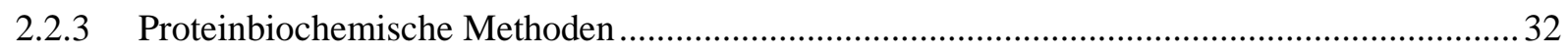

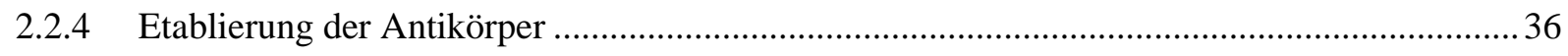

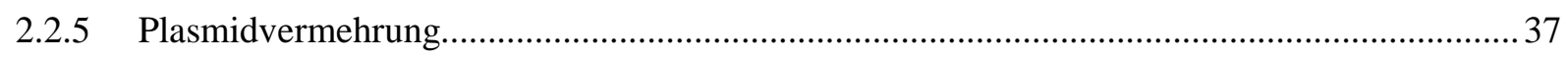

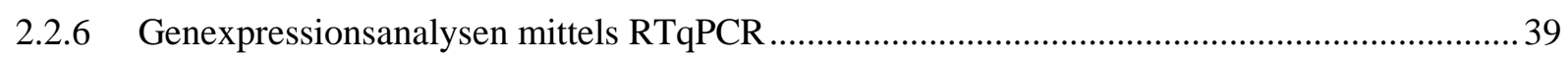

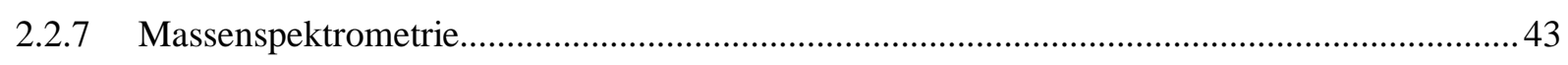

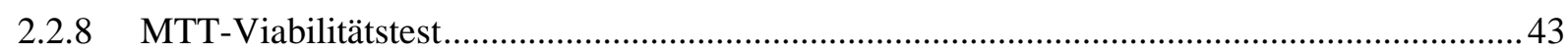


3. Ergebnisse ......................................................................................................................................... 45

3.1 SK-BR-3 exprimiert aSMase, nSMase1 und nSMase2 ...........................................................45

3.2 Etablierung und Optimierung der siRNA- Transfektion........................................................46

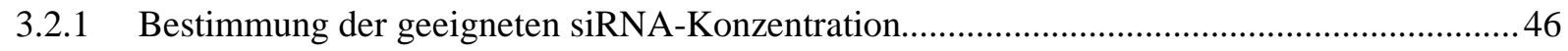

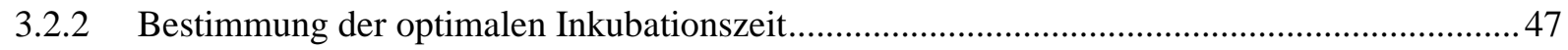

3.2.3 Keine Beeinträchtigung der Zellviabilität durch Knock-Down von SMPD1, SMPD2 und

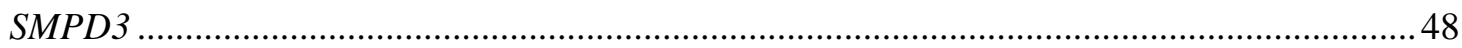

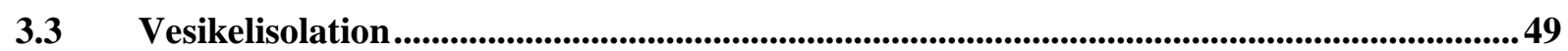

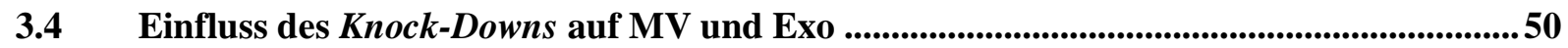

3.4.1 Einfluss des Knock-Downs auf MV- und Exo-Sekretion.......................................................50

3.4.2 Einfluss des Knock-Downs auf die MV- und Exo-Größe ........................................................51

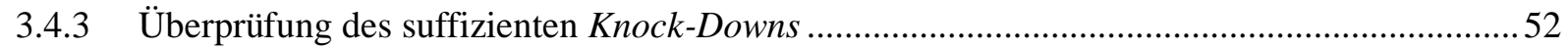

3.5 Kein Einfluss des Knock-Downs einer SMase auf die Expression anderer SMasen ..........53

3.6 Massenspektrometrische Analyse von Ceramiden und Sphingomyelinen .........................54

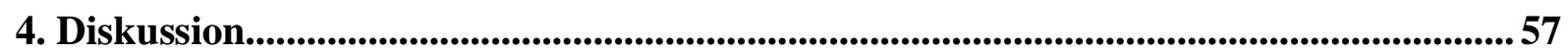

4.1 Bestimmung der Rahmenverhältnisse für die Transfektion ..............................................55

4.2 Sphingomyelinasen beeinflussen die Exo- und MV-Sekretion............................................58

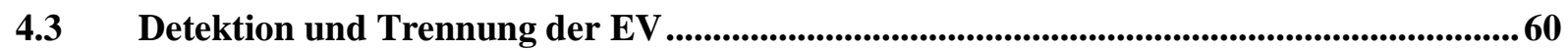

4.4 Knock-Down einer SMase scheint die Expression der anderen nicht zu beeinflussen......62

4.5 Knock-Down der aSMase senkt die Ceramidkonzentration......................................................62

4.6 Weitergehende Forschung...........................................................................................................63

4.7 Relevanz der Arbeit in Bezug auf angewandte Medizin.......................................................64

5. Zusammenfassung .................................................................................................................................. 66

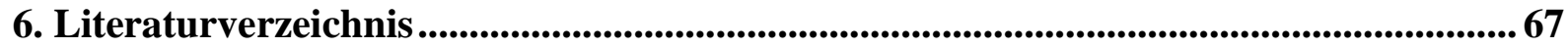




\section{Abbildungsverzeichnis}

Abbildung 1.1: Sekretion extrazellulärer Vesikel...................................................................... 9

Abbildung 1.2: $\quad$ Biogenese der extrazellulären Vesikel.................................................................. 10

Abbildung 1.3: $\quad$ Einflussnahme von Tumor-EV (tEV) auf ihre Umgebung..................................... 13

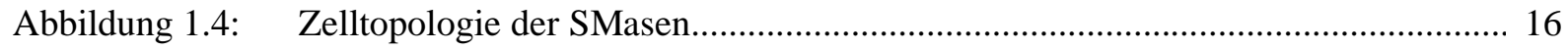

Abbildung 1.5: $\quad$ Rolle von Sphingolipiden in der Biologie.......................................................... 17

Abbildung 2.1: $\quad$ Prinzip der EV-Extraktion und Trennung in MV (P14) und Exo (P100)............... 30

Abbildung 3.1: Western-Blot aus Gesamtlysat verschiedener Zelllinien...................................... 44

Abbildung 3.2: $\quad$ Bestimmung der geeigneten siRNA-Konzentration............................................... 45

Abbildung 3.3: Bestimmung der geeigneten Inkubationszeit..................................................... 46

Abbildung 3.4: Bestimmung der Zellviabilität........................................................................... 48

Abbildung 3.5: $\quad$ Beispielhafte Kurve zur Konzentrations- und Größenverteilung.......................... 49

Abbildung 3.6: Einfluss des Knock-Downs auf die EV-Sekretion............................................... 50

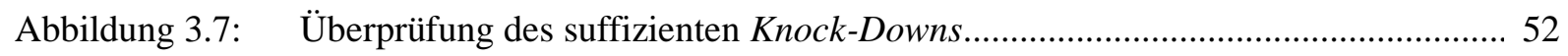

Abbildung 3.8: Einfluss des Knock-Downs einer SMase auf die Expression der anderen.............. 53

Abbildung 3.9: $\quad$ Messung des Ceramid- und Sphingomyelingehalts in SK-BR-3 nach

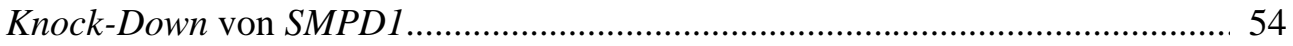

Abbildung 3.10: Messung des Ceramid- und Sphingomyelingehalts in SK-BR-3 nach

Knock-Down von SMPD2 


\section{Tabellenverzeichnis}

Tabelle $1.1 \quad$ Gen- und Protein-Namen der SMasen................................................................. 14

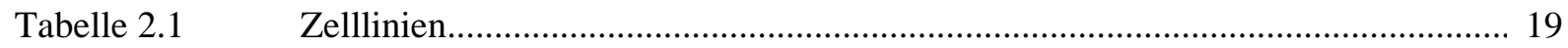

Tabelle 2.2 Zellkulturmedien und Zusatzlösungen............................................................. 20

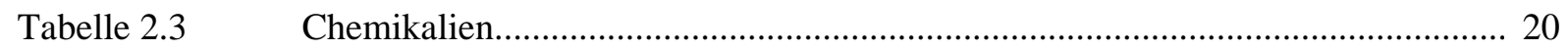

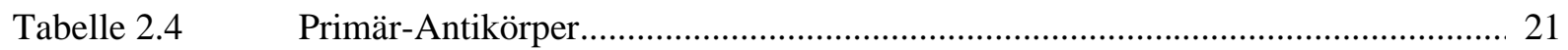

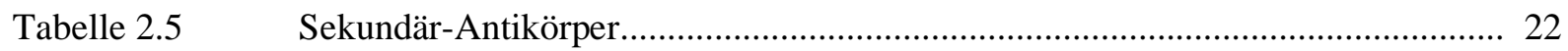

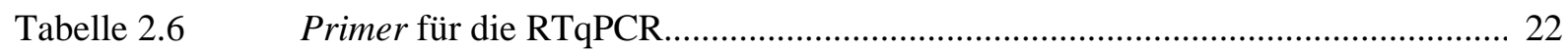

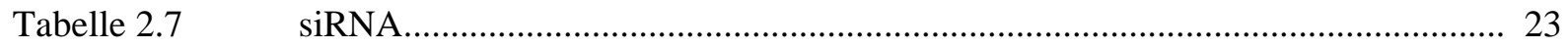

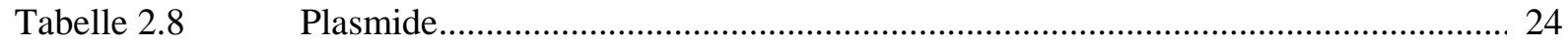

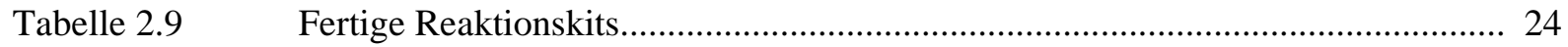

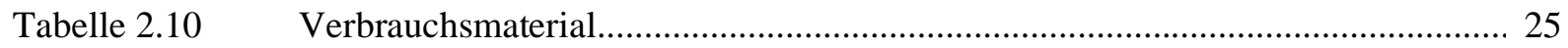

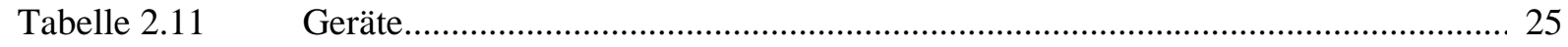

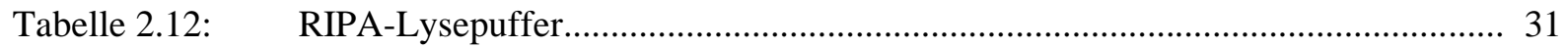

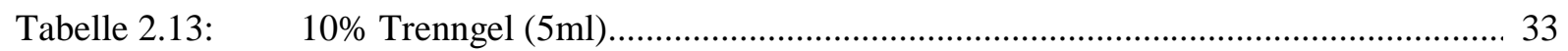

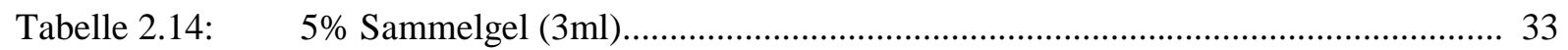

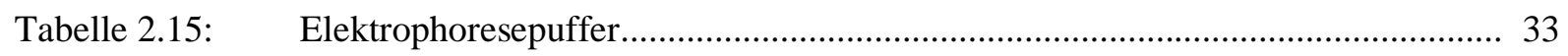

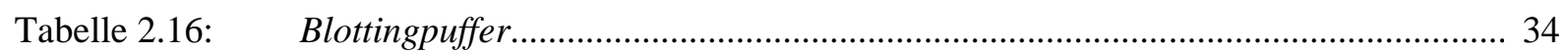

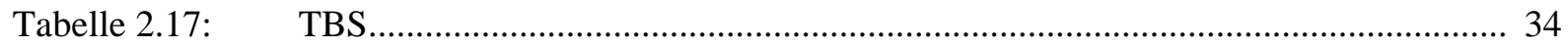

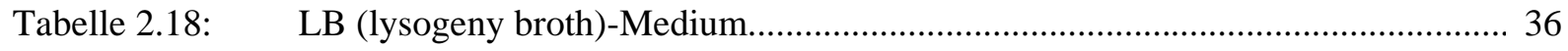

Tabelle 2.19: $\quad$ Reagenzien der reversen Transkription............................................................ 39

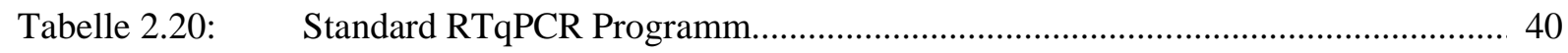

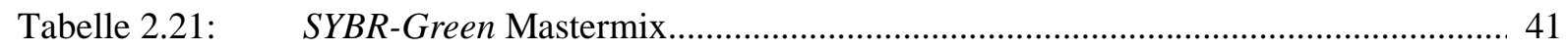

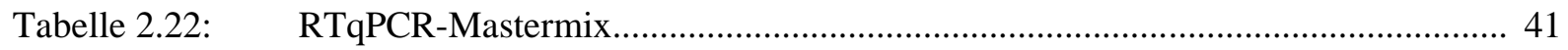




\section{Abkürzungsverzeichnis}

AGO Arbeitsgemeinschaft Gynäkologische Onkologie e.V.

alkSMase alkalische Sphingomyelinase

APS Ammoniumpersulfat

ARF-6 ADP-Ribosylierungsfaktor-6

aSMase $\quad$ saure Sphingomyelinase, acid sphingolyelinase

ATP Adenosintriphosphat

AUC Fläche unter der Kurve, area under curve

BSA Bovines Serumalbumin

CD Cluster of Differentiation

cDNA komplementäre DNA, complementary DNA

Ct Zyklusschwelle, Cycle Threshold

DMSO Dimethylsulfoxid

DNA Desoxyribunukleinsäure

ECL Elektrochemilumineszenz

EDTA Ethylendiamintetraacetat

ER Östrogenrezeptor, estrogen receptor

ESCRT endosomal sorting complexes required for transport

EV extrazelluläre(s) Vesikel

Exo Exosom(en)

Exo-siSMPD Exosomen von Zellen, die mit siSMPD transfiziert wurden

EZM extrazelluläre Matrix

FCS Fetales Kälberserum, fetal calf serum

FIASMA funktionelle Inhibitoren der sauren Sphingomyelinase

GOI gesuchtes Gen, gene of interest

Her2 humaner epidermaler Wachstumsfaktorrezeptor 2

ILV Intraluminale Vesikel

KD Knock-Down

MHC Haupthistokompatibilitätskomplex, major histocompatibility complex 
mRNA messenger-RNA

MTT 3-(4,5-Dimethylthiazol-2-yl)-2,5-diphenyltetrazoliumbromid

MV Mikrovesikel

MVE Multivesikuläres Endosom

MV-siSMPD Mikrovesikel von Zellen, die mit siSMPD transfiziert wurden

NCBI National Center for Biotechnology Information, Maryland (USA)

nSMase neutrale Sphingomyelinase

NTA Nanoparticle Tracking Analysis

P100 Pellet, das sich bei Ultrazentrifugation mit $100.000 \mathrm{~g}$ bildet; entspricht a. e. Exo

P14 Pellet, das sich bei Ultrazentrifugation mit 14.000g bildet; entspricht a. e. MV

PBS phosphatgepufferte Salzlösung, phosphate-buffered saline

PR Progesteronrezeptor

RISC RNA-induced silencing-Komplex

RTqPCR real-time quantitative Polymerase-Kettenreaktion

S1P Sphingosin-1-Phosphat

SD Standardabweichung, standard deviation

SDS Natriumlaurylsulfat, sodium dodecyl sulfate

SDS-PAGE Natriumdodecylsulfat-Polyacrylamidgelelektrophorese

siCtl Kontroll-siRNA

siRNA small interfering RNA

siSMPD siRNA, die gegen das Gen SMPD gerichtet ist (s. Zusatz 1,2,3)

SMase(n) Sphingomyelinase(n)

SNARE löslicher N-Ethylmaleimide-sensitiver-Factor Bindungsrezeptor, soluble $N$ ethylmaleimide-sensitive-factor attachment receptor

TBS trisgepufferte Salzlösung, tris-buffered saline

TBS-T TBS mit Tween 20

TEMED Tetramethylethylendiamin

tEV extrazelluläre(r) Vesikel aus Tumorzellen

ZfKD Zentrum für Krebsregisterdaten 


\section{Einleitung}

\subsection{Mammakarzinom}

Das Mammakarzinom ist das häufigste Karzinom der Frau und nach dem Bronchialkarzinom das zweithäufigste Karzinom insgesamt. Gleichzeitig stellt das Mammakarzinom die häufigste Krebstodesursache der Frau dar. In Deutschland erkrankten nach dem Zentrum für Krebsregisterdaten am Robert Koch-Institut in Deutschland im Jahr 2014 ca. 114 von 100.000 Frauen an einem Mammakarzinom, 23 von 100.000 Frauen starben daran (ZfKD 2019).

Es gibt verschiedene Risikofaktoren, die die Entstehung des Mammakarzinoms begünstigen. Ein wichtiger Faktor dabei ist ein langer Einfluss von Östrogen auf den Körper. Dieser kann sich durch verschiedene Konstellationen ergeben wie durch frühe Menarche oder späte Menopause, durch keine oder wenig Schwangerschaften, durch Adipositas und lange Einnahme von hormonellen Kontrazeptiva oder Hormonersatztherapien. Aber auch andere Risikofaktoren wie ein Diabetes mellitus Typ 2 und Nikotin- und Alkoholabusus sind bekannt (Rhiem und Schmutzler 2015).

Histologisch sind nahezu alle Mammakarzinome Adenokarzinome. Sie werden je nach ihrem Ursprungsgewebe in duktale (dem Milchgangsepithel entspringenden) und in lobuläre (den Milchdrüsenläppchen entspringende) Neoplasien eingeteilt. Außerdem ist vor allem therapeutisch relevant, ob es sich um ein invasives oder nichtinvasives Karzinom handelt. Unter die nichtinvasiven Karzinome fallen die Carcinomata in-situ, also Karzinome, die die Basalmembran ihres Ursprungsgewebes noch nicht überschritten haben. Bei den invasiven Karzinomen tritt das invasive Karzinom ohne speziellen Typ (früher invasiv-duktales Mammakarzinom) mit ca. 75\% am häufigsten auf. Den Rest bilden die sogenannten invasiven Karzinome mit speziellem Typ. Mit ca. 10-15\% ist hier das invasiv-lobuläre Karzinom das häufigste (Lebeau et al. 2014).

Für die Therapie und die Prognose ist, abgesehen von der Bestimmung des genauen Typs des Karzinoms, dessen Größe und die evtl. Ausbreitung in lokale Lymphknoten bzw. andere Organe von Relevanz. Dies wird durch die internationale TNM-Klassifikation beschrieben (AGO 2019). Hinzu kommt das sogenannte Grading, in das das Ausmaß der Entdifferenzierung bzw. der Zellteilungsrate eingehen.

Zur Standard-Diagnostik gehören darüberhinaus weitere Marker von prognostischer und prädiktiver Bedeutung, wobei letztere Marker eine Aussage über das eventuelle Ansprechen auf spezifische Therapien erlauben. So ist z. B. ein positiver Östrogen- (ER+) und Progesteronrezeptorstatus (PR+) sowohl mit einer besseren Prognose als auch mit einem guten Ansprechen auf eine antihormonelle Therapie assoziiert. Die Überexpression des Wachstumsfaktorrezeptors aus der Epidermal-GrowthFactor-Receptor-Familie Her2/neu hingegen kennzeichnet eine prognostisch ungünstige Subgruppe 
von Mamma-Karzinomen (Hashmi et al. 2018). Als prädiktiver Marker ist ein positiver Her2/neuStatus jedoch mit einem guten Ansprechen auf Trastuzumab, einem monoklonalen Antikörper, der gegen den Rezeptor gerichtet ist, verbunden (Figueroa-Magalhães et al. 2014).

Generell wird somit die Wahl der Therapie des Mammakarzinoms von diversen Faktoren (Staging, Grading, Alter der Patientin, Rezeptorprofil etc.) beeinflusst und muss in jedem individuellen Fall neu diskutiert werden. Dennoch beinhalten die gängigen Therapieregimes in der primären, kurativen Situation eine operative, meist brusterhaltende Therapie gefolgt von Nachbestrahlung und ggf. einer adjuvanten Systemtherapie mit Chemotherapie bzw. Antihormon- oder Antikörpertherapie (AGO 2019). In der metastasierten Situation steht i. d. R. die Systemtherapie im Vordergrund, angepasst an die Charakteristika des Tumors, den Allgemeinzustand der Patientin und die prinzipiell palliative Situation.

\subsection{Extrazelluläre Vesikel}

Zell-Zell-Kommunikation ist ein essenzieller Bestandteil der Biologie. Schon lange sind einige Mechanismen bekannt, wie Zellen beispielsweise via Gap junctions oder Hormonen und Signalmolekülen als Mediatoren kommunizieren. Mittlerweile ist jedoch eine weitere Möglichkeit der Zell-Zell-Kommuniktion, die der extrazellulären Vesikel (EV), Thema der aktuellen Forschung. Extrazelluläre Vesikel sind eine heterogene Gruppe von Partikeln, die von allen Säugetier-Zelltypen sezerniert und in vielen Körperflüssigkeiten nachgewiesen werden können (Yáñez-Mó et al. 2015). Grundsätzlich besteht ihre Funktion in der Zell-Zell-Kommunikation. Anders als bei direktem ZellZell-Kontakt kann mittels EV die Kommunikation über große Distanzen erfolgen (Turturici et al. 2014). Ihren Einfluss üben sie primär über die von ihnen transportierten Moleküle aus, wobei diese sowohl in löslicher Form intravesikulär als auch als integrale Membranbestandteile an der Vesikeloberfläche lokalisiert sein können. Je nach Mutter-Zelle und Vesikeltyp ist die Beladung sehr unterschiedlich.

Generell finden sich fast alle von Zellen produzierten Substanzklassen auch in EV wieder. So konnte in der Vergangenheit gezeigt werden, dass sowohl Proteine (Simpson et al. 2009), RNA (Ratajczak et al. 2006), DNA (Waldenström et al. 2012) als auch Lipide (Vidal et al. 1989) von Vesikeln transportiert werden. Diese Moleküle werden jedoch keineswegs zufällig in die Vesikel geschleust. Stattdessen gibt es verschiedene Mechanismen, die ganz gezielt Proteine, Nukleinsäuren und Fette auf die Vesikel verteilen und andere Moleküle gezielt nicht einschleusen (D'Souza-Schorey und Clancy 2012). Die Fachliteratur unterteilt die EV in Exosomen (Exo) mit 50-150 nm, Mikrovesikel (MV) mit 100-500 nm und Apoptosekörper mit 500-4000 nm. Diese Subpopulationen unterscheiden sich voneinander vor allem in ihrer Entstehung. Während Exo aus sogenannten Multivesikulären Endosomen (MVE) stammen (Raposo und Stoorvogel 2013), schnüren sich MV direkt von der 
Plasmamembran ab (Colombo et al. 2014). Apoptosekörper entstehen hingegen im Zuge des programmierten Zelltodes (Elmore 2007). Sie sind dadurch charakterisiert, Zellorganellen zu enthalten, was für MV und Exo nicht beschrieben ist. Für die drei Entstehungsarten werden verschiedene kontraktile Fusionsproteine wie SNARE-Komplexe oder Motorproteine wie Aktin und Myosin benötigt (Cai et al. 2007).

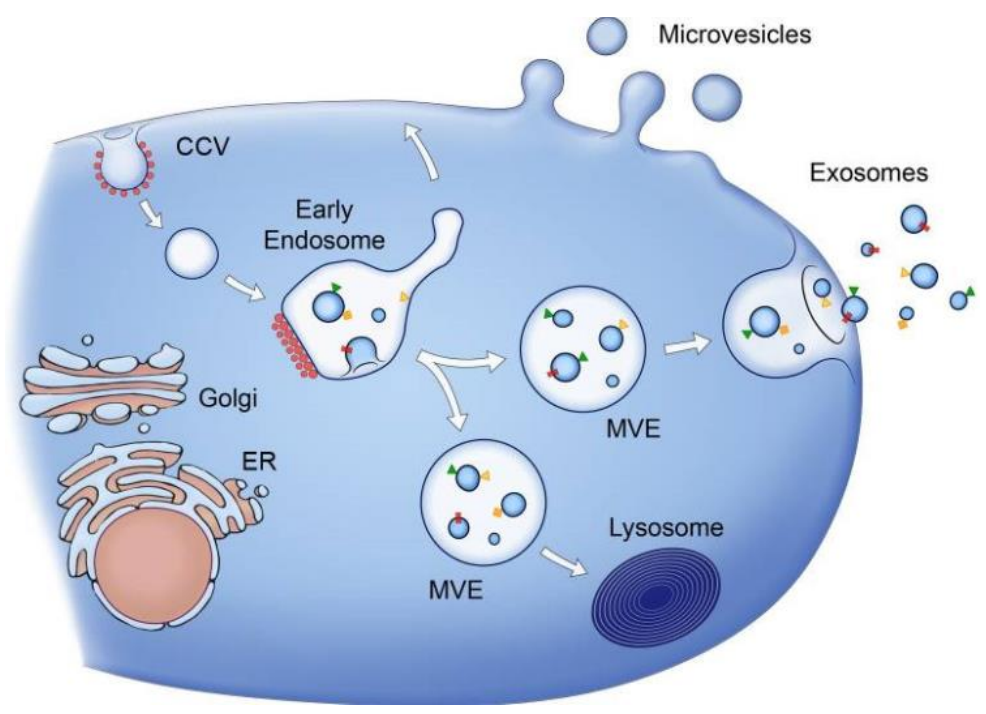

Abbildung 1.1: Sekretion extrazellulärer Vesikel. Die größeren Mikrovesikel schnüren sich direkt von der Plasmamembran ab, während die kleineren Exosomen aus sogenannten MVE stammen. Diese fusionieren entweder mit einem Lysosom oder mit der Plasmamembran, wodurch die Exo in die Zellperipherie entlassen werden. Die roten Punkte symboliseren Clathrin-coated-Vesikel oder Clathrin-coated-Endosomen, die Dreiund Rechtecke symbolisieren membranassoziierte Proteine und Transmembranproteine (Raposo und Stoorvogel 2013). Die Verwendung der Abbildung erfolgte mit freundlicher Genehmigung der Rockefeller University Press.

Die Entstehung von Exo ist bisher am besten untersucht worden. Hierfür schnüren sich zunächst Vesikel von Endosomen ab. Dabei gelangen die Vesikel in das Innere der Endosomen, welche dann als MVE bezeichnet werden. Die Vesikel innerhalb der MVE werden als Intraluminale Vesikel (ILV) bezeichnet. Die MVE und die darin enthaltenen ILV verschmelzen dann entweder mit Lysosomen, werden also degradiert. Andere MVE hingegen verschmelzen mit der Plasmamembran. Dabei werden die ILV, jetzt als Exo bezeichnet, in die Zellperipherie abgegeben. Die molekularen Mechanismen dahinter sind sehr komplex. Verschiedene sortierende Proteine, die spezifisch das Transportgut binden und auswählen, und Motorproteine, die die Membranfusionen bewirken oder den Transport der MVE bewerkstelligen, sind daran beteiligt (Raposo und Stoorvogel 2013; van Niel et al. 2018; Vidal 2019).

Eine wichtige Rolle übernehmen die sogenannten endosomal sorting complexes required for transport (ESCRT)-Komplexe. Sie sind zytosolische Proteinkomplexe, die bei der ILV Bildung und der 
spezifischen Beladung mit Transportgut unterschiedliche Aufgaben übernehmen. ESCRT-0, ESCRT-I und ESCRT-II und ihre akzessorischen Proteine (programmed cell death 6-interacting protein (Alix), tumor susceptibility gene (TSG) 101, charged multivesicular body protein (Chmp) 4) sind so beispielsweise an der Auswahl und Bildung der spezifischen Transportgüter beteiligt. Sie bilden eine Art Brücke zwischen ubiquitinierten Transmembranproteinen, den Transportgütern und zwischen den verschiedenen ESCRT-Komplexen untereinander (Babst 2005; Wollert und Hurley 2010). ESCRT-III ist an der eigentlichen Membraneinschnürung und damit Bildung der ILVs beteiligt (Wollert et al. 2009) (Abb. 1.2).

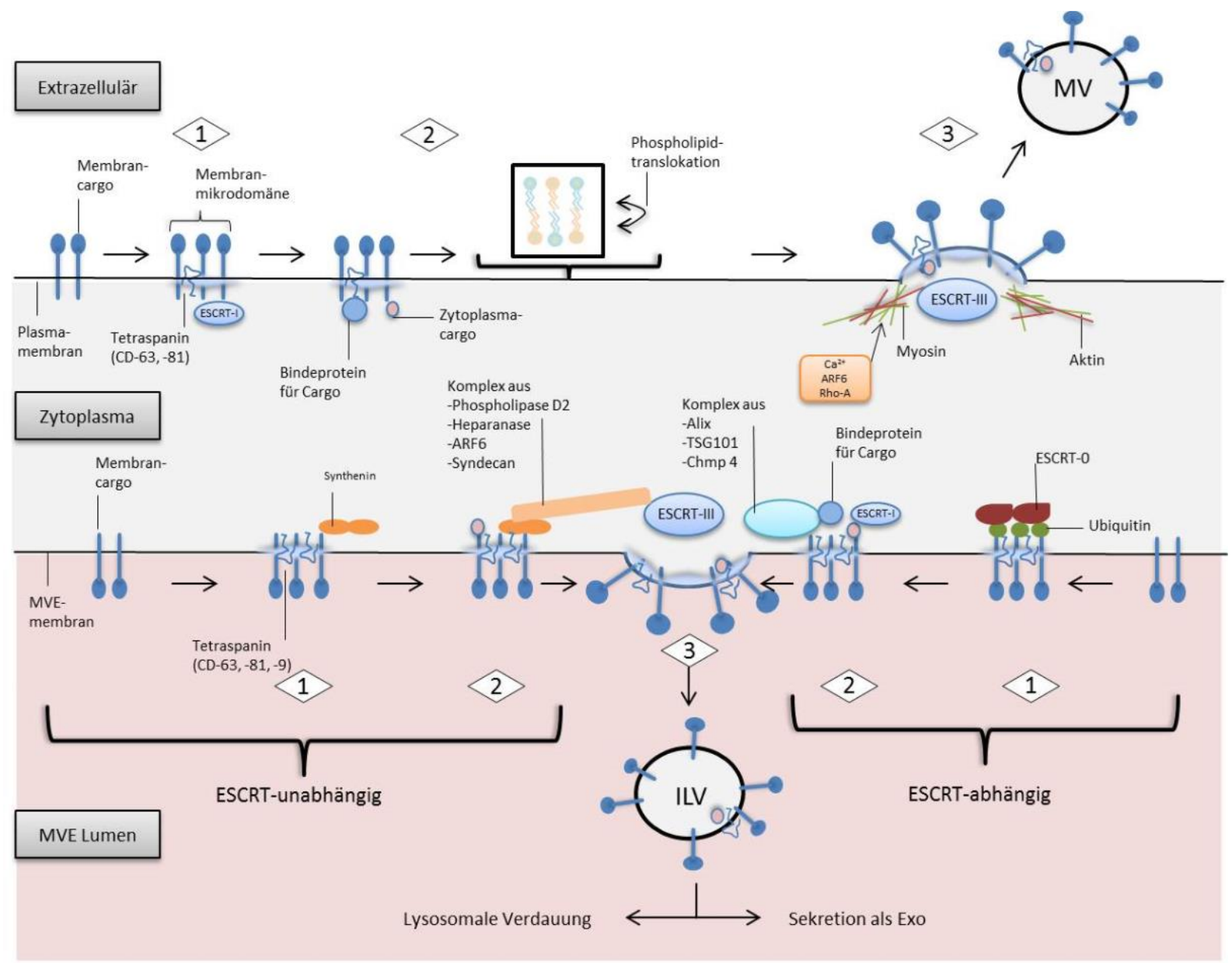

Abbildung 1.2: Biogenese der extrazellulären Vesikel. Verschiedene molekulare Mechanismen sind an der Entstehung der MV und der ILV (den späteren Exo) beteiligt. Zunächst werden Lipide und Transmembranproteine der Plasmamembran für MV (oben) und der MVE- Membran für Exo (unten) in Mikrodomänen zusammengefasst (Schritt 1). Diese Mikrodomänen sind auch an der Bindung und Auswahl der Transportgüter wie zytosolische Proteine und RNA beteiligt (Schritt 2). Die Bildung dieser Mikrodomänen zusammen mit der Hilfe von zusätzlichen Proteinkomplexen bewirkt die Membranwölbung nach extrazellulär (oben) und in das Lumen der MVE (unten) und letztlich die Abschnürung der MV oder ILV (Schritt 3). ESCRTIII wird für die eigentliche Abschnürung der Vesikel benötigt. Die Membranwölbung und die Auswahl der Transportgüter erfolgt auf einem ESCRT-abhängigen und einem ESCRT-unabhängigen Weg. Die Mechanismen, 
die zu MV Bildung führen sind noch nicht ganz verstanden. Interessanterweise scheinen die Mechanismen denen der Exo-Genese zu ähneln. Eine Ausnahme ist hier der Wechsel bestimmter Lipide von einer Plasmamembranschicht zur anderen; ein Mechanismus, der nur für die MV-Bildung beschrieben ist. ARF6, ADP-Ribosylierungsfaktor. Modifiziert nach van Niel et al. (2018).

Neben diesem Ubiquitin- bzw. ESCRT-abhängigen Weg gibt es noch einige Ubiquitin-unabhängige. Bei dem sogenannten Syndecan-Synthenin-Alix-Weg wird die ILV-Bildung über das Zusammenspiel von Heparanase, ADP-Ribosylierungsfaktor 6 (ARF-6), Phospholipase D2, Syndecan und Synthenin bewirkt (Baietti et al. 2012). Dieser Prozess wird durch die Bindung von Synthenin an Alix sowie durch die Anwesenheit von Tetraspanin-Proteinen wie CD63, CD81 und CD9 erleichtert. Aber auch die Funktion der neutalen Sphingomyelinasen scheint Einfluss auf die MVE-Bildung zu haben, da durch ihr Produkt Ceramid die Exo-Sekretion zuzunehmen scheint (Trajkovic et al. 2008).

Die unterschiedlichen Einflüsse und Mechanismen der MVE-Bildung scheinen neben der Komposition der MVE-Membran (Möbius et al. 2003) auch einen Einfluss darauf zu haben, ob die MVE mit Lysosomen verschmelzen und abgebaut werden (Baietti et al. 2012) oder durch Transport über das intrazelluläre Zytoskelett mit Hilfe von Motorproteinen wie Myosin, Dynein oder Kinesin zur Plasmamembran transportiert werden, wo sie über SNARE-Proteine dann mit der Plasmamembran fusionieren (Cai et al. 2007).

Die Entstehung der MV, welche sich direkt von der Plasmamembran abschnüren, ist anders als die der Exo noch nicht so gut verstanden. Wichtig scheint dabei einerseits die Komposition der Plasmamembranlipide einerseits, und das Zusammenspiel der Zytoskelettproteine Aktin und Myosin andererseits zu sein. So wird die Abschnürung der MV durch eine ATP-abhängige Kontraktion des Zytoskeletts vollzogen. Diese Kontraktion unterliegt wiederum verschiedenen Einflüssen. Sie ist zum Beispiel $\mathrm{Ca}^{2+}$-abhängig oder kann durch die Phosphorylierung der Myosin-Leichten-Kette durch die kleinen GTPasen ARF-6 und Rho-A herbeigeführt werden (Muralidharan-Chari et al. 2009). Die Komposition der Plasmamembran wird ihrerseits auch durch verschiedene Proteine beeinflusst. Sogenannte Aminophospholipidtranslokasen, welche die Translokation von Phospholipiden von der inneren Lipidschicht zur äußeren (oder anderes herum) katalysieren, scheinen so z. B. die Membranstruktur zu beeinflussen, was die MV-Biogenese erleichtert (Bevers et al. 1999). Aber auch Proteine der Tetraspanin-Familie, ESCRT-I und ESCRT-III scheinen eine wesentliche Rolle in der MV-Biogenese einzunehmen. All diese Vorgänge unterliegen des Weiteren verschiedenen Stimuli wie bspw. Hypoxie, die die MV-Sekretion steigert. Das Verständnis über die genauen molekularen Mechanismen der MV-Sekretion steht zur Zeit noch an seinen Anfängen und ist daher noch nicht ausreichend geklärt.

Die Proteine, die an der Biogenese der EV beteiligt und in EV gehäuft aufzufinden sind, werden als Marker für die Identifizierung der Exo und MV verwendet. Da manche Proteine aber sowohl in der 
Exo- als auch in der MV-Biogenese beteiligt und manche dieser Proteine auch z. T. in Apoptosekörpern zu finden sind, werden i. d. R. mehrere Marker gleichzeitig untersucht. Gängige Exo-Marker sind z. B. die ESCRT-Proteine TSG101 und Alix, aber auch Proteine aus der Tetraspaninfamilie Cluster of differentiation (CD) 63, CD 81 und CD 9 (Théry et al. 2006; Théry et al. 2009). Da die MV sich direkt von der Plasmamembran abschnüren, sind Transmembranproteine besonders hoch exprimiert. Demnach verwendet man als MV-Marker häufig Integrine und Selektine, obwohl diese auch auf Exo, wenn auch in geringerer Menge, nachzuweisen sind (Heijnen et al. 1999). Typischerweise finden sich die verwendeten Exo-Marker allerdings auch auf den MV. So konnten z. B. die Exo-Marker CD 63 und CD 81 auf MV nachgewiesen werden (Crescitelli et al. 2013). Um also EV mit Hilfe von Markern zu charakterisieren, ist dessen Nachweis ebenso wichtig wie das Fehlen von Markern anderer Populationen.

Die unterschiedliche Größe und Dichte ist ein nützlicher Faktor im Prozess der Trennung der EV voneinander. Exo sind mit 50-150 nm deutlich kleiner als die MV mit 100-500 nm. Das erlaubt die Trennung der EV z. B. durch Ultrazentrifugation (Raposo et al. 1996). Hierbei ist jedoch zu beachten, dass dadurch geringfügige Überlappungen entstehen und keine absolute Trennung in Exo und MV erreicht werden kann (Doyle und Wang 2019). Die oben beschriebenen Marker helfen dabei, zu überprüfen, ob die Trennung in einem ausreichenden Maße vollzogen wurde.

Die Funktionen von EV sind vielseitig. EV sind an den meisten Prozessen, die eine Zell-ZellKommunikation erfordern, beteiligt, insbesondere in komplexen Geweben. Beispiele für ihren Einfluss auf physiologische Vorgänge sind die Regulation von Proliferation, Differenzierung, Apoptose sowie die Modulation von Immunprozessen (Canals et al. 2011). EV können als SignalingKomplex wirken, Proteine zu Zielzellen transportieren und Zellen modifizieren, indem sie genetisches Material an ihre Nachbarzellen transferieren (Turturici et al. 2014). Dies geschieht über verschiedene Mechanismen. So können sie erstens mit anderen Zellen fusionieren und so ihr Transportgut in die jeweiligen Zellen absondern, zweitens via Endozytose aufgenommen werden und intrazellulär mit Lysosomen verschmelzen und drittens über Moleküle auf ihrer Oberfläche direkt Liganden-RezeptorInteraktionen mit anderen Zellen eingehen. Eine weitere Möglichkeit besteht darin, dass die EV bereits extrazellulär ihr Transportgut an die extrazelluläre Matrix beziehungsweise die jeweilige Körperflüssigkeit abgeben (Turturici et al. 2014).

Da die Hauptfunktion der EV in der Zell-Zell-Kommunikation liegt, verwundert es nicht, dass sie gerade im Immunsystem eine tragende Rolle übernehmen. So können sowohl pro- als auch antiinflammatorische Effekte ausgelöst werden, indem EV einerseits Antigene dendritischen Zellen präsentieren, um eine spezifische T-Zell-Antwort zu generieren, andererseits aber auch Signalstoffe wie tissue growth factor (TGF) $\beta$ oder Fas-Ligand transportieren (s. Abb. 1.3 D), wodurch die T-ZellAktivität durch verminderte Proliferation oder Apoptoseinduktion gehemmt wird (s. Abb. 1.3 B) (Bobrie et al. 2011). Auch im Gerinnungssystem spielen EV eine wichtige Rolle, da insbesondere den 
MV eine prokoagulatorische Kapazität zugesprochen wird (Yáñez-Mó et al. 2015). In der Organdifferenzierung und Embryogenese insbesondere bei der fetomaternalen Kommunikation haben EV eine wichtige Funktion. So bilden beispielsweise manche polare Zellen mit der Hilfe von EV einen Gradienten von verschiedenen Substanzen, die für die Differenzierung von Geweben unerlässlich sind (bspw. Hedgehog oder Wnt-Liganden) (Lakkaraju und Rodriguez-Boulan 2008; Gross et al. 2012; Gross und Zelarayán 2018). Da EV von Tumorzellen (tEV) funktionell eine ähnliche Einflussnahme auf ihre Umgebung haben wie EV von Nicht-Tumorzellen, ist in Abbildung 1.3 beispielhaft die tEVEinflussnahme abgebildet.

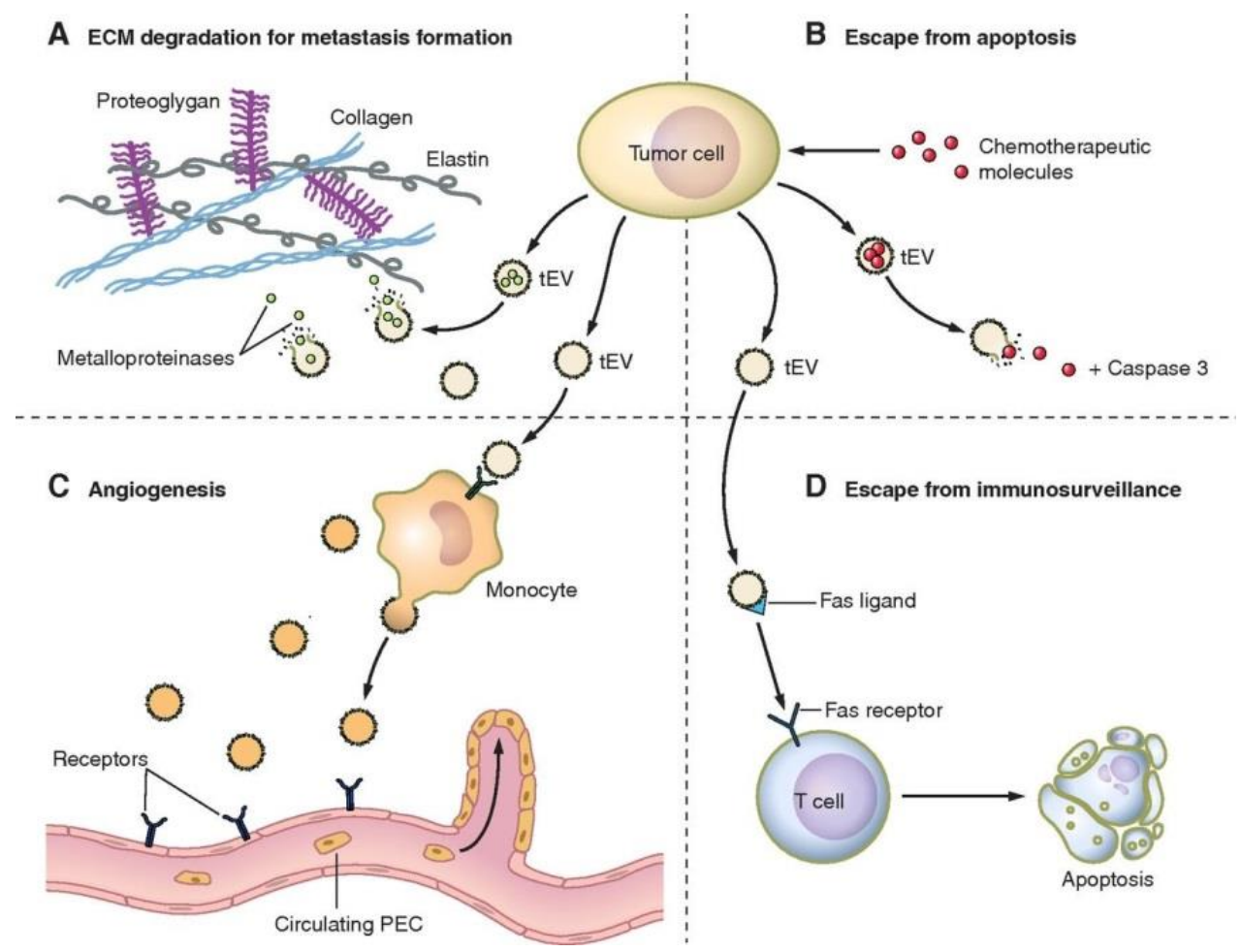

Abbildung 1.3: Einflussnahme von Tumor EV (tEV) auf ihre Umgebung. A: Sie transportieren Metalloproteinasen, um die extrazelluläre Matrix $\mathrm{zu}$ zersetzen und so die Invasion von Tumorzellen zu erleichtern. B: Durch das Ausschleusen von Chemotherapeutika und Caspase 3 mit Hilfe von tEV können Tumoren der Apoptose entgehen. C: Durch den Transport von proangiogenetischen Stimuli können tEV die Angiogenese beschleunigen. D: Durch auf tEV exprimierte Liganden können diese Immunzellen (z. B. TLymphozyten) zur Apoptose bringen (Turturici et al. 2014). Die Verwendung der Abbildung erfolgte mit freundlicher Genehmigung der American Physiological Society.

EV werden auch zu den wesentlichen Akteuren der Tumor-Progression und -Metastasierung gezählt (Vader et al. 2014). So enthalten EV z. B. unterschiedliche Proteasen, mit deren Hilfe sie die 
extrazelluläre Matrix (EZM) auflösen und so die Invasion von Tumoren erleichtern können (s. Abb. 1.3 A). Die Angiogenese beeinflussen EV u. a. durch den Transport proangiogenetischer Faktoren von Stromazellen an die Tumorzellen (s. Abb. 1.3 C) (Turturici et al. 2014). Da man EV in allen Körperflüssigkeiten finden kann, darunter Plasma, Urin, Liquor und Speichel (Vader et al. 2014) und sich die EV maligner Zellen hinsichtlich Zusammensetzung und Menge von denen gesunder Zellen unterscheiden(Ginestra et al. 1999), sind sie in letzter Zeit als mögliche Biomarker in den Fokus der Tumordiagnostik gerückt (Corrado et al. 2013).

\subsection{Sphingomyelinasen}

Die Sphingomyelinasen (SMase, Sphingomyelin-Phosphodiesterase) sind Enzyme, die die Hydrolyse von Sphingomyelinen in Ceramide und Phosphocholin katalysieren. Bislang konnten fünf verschiedene SMasen identifiziert werden. Darunter befinden sich eine saure SMase (aSMase), drei neutrale SMasen (nSMase1-3) und eine alkalische SMase (alkSMase). Sie sind zusammen mit ihren Gennamen in der folgenden Tabelle aufgeführt:

Tabelle 1.1: Gen- und Protein-Namen der SMasen

\begin{tabular}{l|l}
\hline Gen & Protein \\
\hline SMPD1 & aSMase \\
SMPD2 & nSMase1 \\
SMPD3 & nSMase2 \\
SMPD4 & nSMase3 \\
ENPP7 & alkSMase
\end{tabular}

Eine Einflussnahme auf Zellfunktionen erzielen die SMasen über ihre Substrate (Ceramide) und Produkte (Sphingomyeline), welche wichtige Moleküle des Sphingolipid-Signalings sind. Ceramide und Sphingomyeline und deren Einfluss auf Zellstoffwechselvorgänge werden im Kapitel 1.4 besprochen. Im Folgenden möchte ich zunächst auf die für meine Dissertation wichtigen Enzyme aSMase und nSMase1 und 2 näher eingehen.

\subsubsection{Saure Sphingomyelinase}

Die saure Sphingomyelinase ist ein Enzym, dass ubiquitär exprimiert wird und ein saures pH-Optimum besitzt (Zumbansen 2001). Ihr kodierendes Gen SMPDI befindet sich auf dem p-Arm von Chromosom 11 (Henry et al. 2013). Die Masse der aSMase beläuft sich auf $69 \mathrm{kDa}$. Sie ist 
bevorzugt intrazellulär im sauren Milieu der Lysosomen lokalisiert, wird jedoch auch extrazellulär sezerniert (Schuchman et al. 1992; UniProt Consortium 2019a). Verschiedene Stress-Stimuli, wie beispielsweise UV-Licht, Strahlung oder Chemotherapeutika aktivieren die aSMase (Hannun und Obeid 2008). Sie ist außerdem mit dem Morbus Niemann-Pick assoziiert. Dabei handelt es sich um eine autosomal-rezessiv vererbte Lipidspeicherkrankheit, bei der die aSMase fehlerhaft ist. Dadurch akkumuliert Sphingomyelin in diversen Geweben, so beispielsweise der Leber, dem Gehirn und dem Knochenmark. Die Klinik der Erkrankung ist sehr variabel, wodurch die Diagnosestellung meist erst sehr spät erfolgt. Dennoch sind neurologische Symptome wie zerebelläre Ataxie, Dysarthrie, Dysphagie und Demenz häufig nachweisbar (Vanier 2013).

\subsubsection{Neutrale Sphingomyelinase 1}

Die neutrale Sphingomyelinase 1 ist ein ubiquitär exprimiertes Enzym mit einem neutralen $\mathrm{pH}$ Optimum (NCBI 2019a). Sie ist ein integrales Protein der Plasmamembran und an der inneren Schicht der Lipiddoppelmembran lokalisiert (Canals et al. 2011). Mit einer Masse von 40-60 kDa ist sie das kleineste Enzym der SMase-Familie (UniProt Consortium 2019b). Verschiedene Studien vermuten die Funktion der nSMase1 in ihrer Reaktion auf Stress, denn gerade unter Stressstimulation, wie z. B. oxidativem Stress, konnte eine erhöhte nSMase1 Aktivität nachgewiesen werden (Verheij et al. 1996; Yabu et al. 2015). Knock-Out-Versuche in Mäusen zeigten jedoch keine Veränderungen im Phänotyp der Mäuse, sodass die physiologische Rolle der nSMase1 noch nicht abschließend geklärt ist (Zumbansen und Stoffel 2002; Wu et al. 2010).

\subsubsection{Neutrale Sphingomyelinase 2}

Die neutrale Sphingomyelinase 2 ist anders als die nSMase1 nicht ubiquitär vorhanden. Vor allem wird sie im Duodenum, Jejunum und im Ileum exprimiert. Das kodierende Gen befindet sich auf Chromosom 16 (NCBI 2019b). Mit 70 kDa hat nSMase2 nahezu dieselbe Masse wie die aSMase. Die nSMase2 ist einerseits an der Plasmamembran, andererseits an der Membran des Endoplasmatischen Retikulums lokalisiert (Canals et al. 2011). Welche Mechanismen die Zuordnung zu den verschiedenen Kompartimenten steuern, ist bislang unbekannt (Wu et al. 2010).

Die nSMase2 spielt eine wichtige Rolle in verschiedenen Prozessen des Körpers. So konnte ihre Mitwirkung bei Immunprozessen sowie bei allgemeinen Stressreaktionen von Zellen nachgewiesen werden, da ihre Aktivität unter bestimmten Stressoren wie Tumornektosefaktor (TNF) $\alpha$ oder Interleukin (IL)-1 erhöht wird. Interessanterweise überschneiden sich die aktivierenden Stimuli der nSMase2 sehr stark mit denen der aSMase (Marchesini et al. 2003; Karakashian et al. 2004). KnockOut-Versuche zeigten außerdem eine Rolle der nSMase2 bei malignen Erkrankungen. So finden sich 
bei 5\% der Akuten Myeloischen Leukämie und bei 6\% der Akuten Lymphatischen Leukämie Mutationen im SMPD3 Gen, ebenso konnte eine homozygote Deletion des SMPD3 Gens in murinen Osteosarkommodellen nachgewiesen werden (Wu et al. 2010).

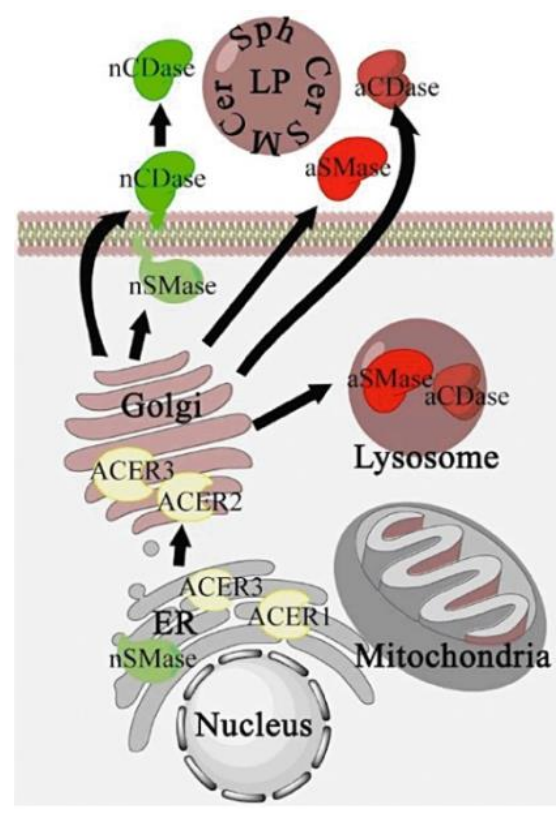

Abbildung 1.4: Zelltopologie der SMasen. nSMasen finden sich sowohl an der Plasmamembran sowie im Endoplasmatischen Retikulum, die aSMase wird einerseits in Lysosomen, andererseits extrazellulär gefunden. aCDase, saure Ceramidase; aSMase, saure Sphingomyelinase; nCDase, neutrale Ceramidase; nSMase, neutrale Sphingomyelinasen; Sph, Sphingosine (Canals et al. 2011). Die Verwendung der Abbildung erfolgte mit freundlicher Genehmigung des John Wiley and Sons-Verlags.

\subsection{Sphingomyeline und Ceramide}

Ceramide sind bioaktive Lipide und als Modulatoren verschiedener Vorgänge im Menschen bekannt. Unter die Vorgänge, in welche Ceramide involviert sind, zählen Zellwachstum, Apoptose, Seneszenzeinleitung, Autophagie und Stress- sowie Entzündungsreaktionen (Canals et al. 2011).

Ceramide können auf verschiedene Arten entstehen. Sie können entweder de-novo durch die CeramidSynthetase oder die Palmitoyltransferase synthetisiert werden. Außerdem können sie durch modulierende Enzyme wie den SMasen aus Sphingomyelinen entstehen. Ceramide können dann beispielsweise durch Ceramidasen $\mathrm{zu}$ Sphingosin und in einem weiteren Schritt durch Sphingosinkinasen zu ihrem Gegenspieler Sphingosin-1-Phosphat metabolisiert werden. Sphingosin1-Phosphat steuert Funktionen wie Zellmotilität und -proliferation, während Ceramide wie oben 
beschrieben die Apoptose, Autophagie und Seneszenzeinleitung regulieren (Hannun und Obeid 2008; Canals et al. 2011). Ceramide und die entsprechenden Derivate haben zwei Möglichkeiten, in den Stoffwechsel einzugreifen. Entweder handelt es sich um direkte Lipid-Lipid-Reaktionen, bei der die Membranstruktur von Zellen und Organellen entscheidend verändert wird, oder via Lipid-ProteinReaktionen, bei denen das Lipid die Aktivität der Proteine entscheidend verändert. Unter den vielen möglichen Reaktionen sei nur ein Beispiel für den möglichen Einfluss von Ceramiden auf Stoffwechselvorgänge genannt: Ceramide können durch ihre biochemische Struktur mit der Ceramidactivated-Ser-Thr-Phosphatase (CAPP) interagieren, welche durch die Aktivierung wiederum andere Proteine wie beispielsweise die Proteinkinase $\mathrm{C} \alpha$ dephosphoryliert. Die Proteinkinase $\mathrm{C} \alpha$ selbst ist wiederum Teil eines sehr komplexen Systems von aktivierenden und deaktivierenden Enzymen, die ganz grundlegend in den Stoffwechsel, wie Zellwachstum und Proliferation einwirkt (Lee et al. 1996). Weitere Ansatzpunkte und die daraus folgenden zellbiologischen Antworten sind in der folgenden Abbildung 1.5 zusammengefasst.

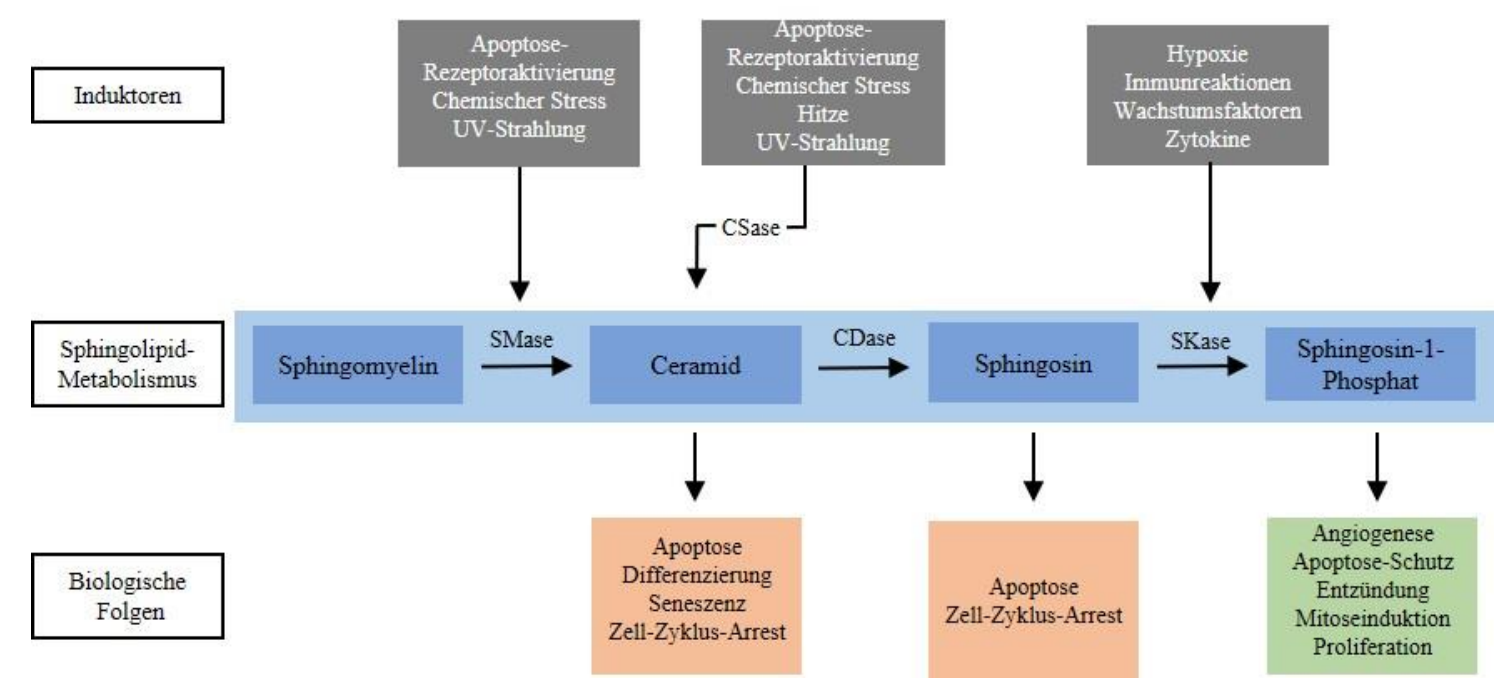

Abbildung 1.5: Rolle von Sphingolipiden in der Biologie. Das Schema zeigt den möglichen Einfluss der bioaktiven Lipide Ceramid, Sphingosin und Sphingosin-1-Phosphat auf zellbiologische Vorgänge. Demnach können Ceramide entweder durch Ceramidsynthasen (CSase) de-novo synthetisiert oder aus Sphingomyelinen durch SMasen gebildet werden. Beide Wege können durch verschiedene Stimuli angestoßen werden (graue Boxen). Sphingosin und Sphingosin-1-Phosphat können von Ceramidasen (CDase) oder Sphingosinkinasen (SKase) generiert werden. All diese Metabolite interagieren mit bestimmten Proteinen wie bspw. Phosphatasen, Kinasen und G-Proteinen, welche letztlich einen Einfluss auf den Zellmetabolismus besitzen. Modifiziert nach Hannun und Obeid (2008). 


\subsection{Extrazelluläre Vesikel und Sphingomyelinasen}

Die Sekretion von MV und Exo wird wie die meisten Vorgänge des Körpers stark reguliert. Verschiedene Enzyme und Rezeptoren fungieren als Stimulatoren, Inhibitoren oder Modulatoren. Ein Beispiel für solche Modulatoren stellt die Enzymfamilie der SMasen dar. Ihr Einfluss auf die Anzahl der sezernierten EV wurde in der Vergangenheit mehrfach bewiesen.

So konnte z. B. gezeigt werden, dass die Stimulation des ATP-Rezeptors $\mathrm{P}_{2} \mathrm{X}_{7}$ in Mikrogliazellen und Astrozyten die aSMase aktiviert, was letztlich in einer Zunahme der MV-Sekretion resultiert. Der Knock-Out der aSMase in Astrozyten reduzierte die Menge der sezernierten MV (Bianco et al. 2009).

In einer Studie von Trajkovic et. al. (2008) konnte ein Einfluss der nSMase1 auf die Sekretion von Exo in Oligodendrozyten nachgewiesen werden. Dabei nahm die Menge der sezernierten Exo durch die chemische Inhibition der nSMase ab (Trajkovic et al. 2008). Menck et. al. konnten 2017 zum ersten Mal nachweisen, dass auch in Mammakarzinom-Zelllinien durch die Inhibition mit GW4869 (Bisdihydroimidazolphenylphenylenbisacrylamid-Dihydrochlorid), einem nSMase1 und 2 Inhibitor, bzw. durch den Knock-Down von nSMase1 und 2 (SMPD2/SMPD3) die MV-Sekretion gesteigert wurde, während die Exo-Sekretion abnahm. Die Überexpression von SMPD2 und SMPD3 induziert den gegenteiligen Effekt, nämlich eine Abnahme in der MV-Sekretion bei gleichzeitiger Zunahme der Exo-Sekretion. Damit konnte zum ersten Mal nachgewiesen werden, dass die Abschnürung der MV von der Plasmamembran und die Sekretion der Exo aus MVE miteinander verknüpft sind (Menck et al. 2017).

\subsection{Zielsetzung der Arbeit}

Ziel dieser Arbeit ist es, zu untersuchen, inwiefern Karzinom-Zellen auf den Knock-Down sowohl der aSMase/ SMPD1 als auch der nSMasen1 und 2/ SMPD2,SMPD3 in Bezug auf die Exosomen- und die MV-Sekretion reagieren. Hintergrund dessen ist der Versuch, alle wesentlichen SMasen, die einen nachgewiesenen Einfluss auf die EV-Sekretion haben, an nur einer Zelllinie und nach dem gleichen Schema zu testen.

Geplant sind folgende Versuche:

(1) Identifikation einer geeigneten Zelllinie für die Versuche. (2) Transfektion dieser Zelllinie mit siRNA gegen die Gene der neutralen und sauren Sphingomyelinase SMPD1-3 und Optimierung der Transfektion in Bezug auf siRNA-Konzentration und Inkubationszeit mittels quantitativer realtime Polymerase-Kettenreaktion (RTqPCR) und Western-Blot. (3) Überprüfung der Viabilität nach Transfektion mit Hilfe des MTT-Tests. (4) Trennung der von den transfizierten Zellen produzierten EV in Exo und MV und Quantifizierung der EV mittels Nanoparticle Tracking Analysis (NTA). 
(5) Massenspektrometrische Untersuchung auf die Ceramid- und Sphingomyelinkonzentration nach Knock-Down der SMasen.

Damit soll die Frage beantwortet werden, welche SMase entscheidend für die EV-Sekretion ist, und/oder ob ein genereller Effekt durch das Aktivieren bzw. Hemmen des Ceramid-Signaling ersichtlich wird. 


\section{Material und Methoden}

\subsection{Material}

\subsubsection{Zelllinien}

Die in dieser Arbeit verwendeten Zelllinien sind in Tabelle 2.1 abgebildet

Tabelle 2.1: Zelllinien

\begin{tabular}{l|llll}
\hline Name & Gewebe & Besonderheit & Herkunft & Referenz \\
\hline HEK293T & Humane embryonale & SV 40-Large- & Prof. Dr. med. G. & (DuBridge et al. 1987) \\
MCF-7 & Tumor Antigen+ & Wulf, Göttingen & \\
& Humanes & ER+, PR+, & DSMZ, & (Soule et al. 1973) \\
Mammakarzinom & Her2/neu - & Braunschweig & \\
MDA-MB231 & Humanes & ER-, PR-, & ATCC, Wesel & (Cailleau et al. 1974) \\
& Mammakarzinom & Her2/neu - & & \\
& Humanes & ER-, PR-, & ATCC, Wesel & (Trempe 1976) \\
& Mammakarzinom & Her2/neu+ & &
\end{tabular}

Die Zelllinie SK-BR-3, welche primär in dieser Arbeit verwendet wurde, findet seit 1970 ihre Verwendung in der Forschung. Sie wurde von Germain Trempe und Lloyd Old vom Memorian Sloan Kettering Cancer Center in New-York kultiviert. Bei der Spenderin der Tumorzelle handelt es sich um eine 43-Jährige Kaukasierin mit malignem Adenokarzinom der Brust. SK-BR-3 überexprimiert das Genprodukt Her2/neu, das als Indkikator für eine schlechtere Prognose und als prädiktiver Marker für eine spezifische Therapie benutzt wird (Memorial Sloan Kettering 2019; Fogh et al. 1977).

\subsubsection{Bakterien}

Die Transformation (s. Kap. 2.2.5.1) erfolgte mit kompetenten Bakterien des E.coli-Stammes DH5- $\alpha$ von Invitrogen life technologies, Carlsbad, USA. 


\subsubsection{Zellkulturmedien und Zusatzlösungen}

Alle in der Zellkultur verwendeten Medien und Zusätze sind in Tabelle 2.2 abgebildet

Tabelle 2.2 Zellkulturmedien und Zusatzlösungen

Medium/Zusatz Hersteller

\begin{tabular}{l|l}
\hline Ampicillin & $\begin{array}{l}\text { Carl Roth, Karlsruhe } \\
\text { EDTA }\end{array}$ \\
Fetales Kälberserum (FCS) & $\begin{array}{l}\text { Sigma-Aldrich, München } \\
\text { Gibco, life technologies, Carlsbad (USA) } \\
\text { OptiMEM }\end{array}$ \\
Penicillin/Streptomycin & Sigma-Aldrich, München \\
Phosphat gepufferte Salzlösung (PBS) & Anprotec, Bruckberg \\
Roswell Park Memorial Institute- & Gibco, life technologies, Carlsbad (USA) \\
Medium (RPMI 1640) & \\
S.O.C Medium & Invitrogen, Darmstadt \\
Trypsin & Biochrom, Berlin
\end{tabular}

\subsubsection{Chemikalien}

Alle in dieser Arbeit verwendeten Chemikalien sind in Tabelle 2.3 aufgelistet. Ihre Verwendung wird in Abschnitt 2.2 Methoden erläutert.

\section{Tabelle 2.3 Chemikalien}

\begin{tabular}{l|l}
\hline Produkt & Hersteller \\
\hline Albumin Fraktion V & $\begin{array}{l}\text { Carl Roth, Karlsruhe } \\
\text { Sigma, Steinheim }\end{array}$ \\
Ammoniumpersulfat (APS) & $\begin{array}{l}\text { Roche, Mannheim } \\
\text { Carl Roth, Karlsruhe }\end{array}$ \\
Isopropanol & $\begin{array}{l}\text { Carl Roth, Karlsruhe } \\
\text { Lämmli-Puffer, Roti Load 1 K929.1 }\end{array}$ \\
LB-Medium & $\begin{array}{l}\text { Carl Roth, Karlsruhe } \\
\text { Invitrogen, Darmstadt }\end{array}$ \\
Lipofectamine, RNA iMax Reagent &
\end{tabular}




\begin{tabular}{l|l}
\hline Produkt & Hersteller \\
\hline Meliseptol & B. Braun, Melsungen \\
Milchpulver & Bio Rad, München \\
MTT-Lösung & Sigma, Steinheim \\
Natriumacid $\left(\mathrm{NaN}_{3}\right)$ & Merck, Darmstadt \\
Natriumclorid $(\mathrm{NaCl})$ & Carl Roth, Karlsruhe \\
Natriumlaurylsulfat, $S D S$ & TH. Geyer, Hamburg \\
PhosStop Phosphatase Inhibitor & Merck, Darmstadt \\
Ponceau S & Merck, Darmstadt \\
Sybr green & Roche, Mannheim \\
Tetramethylenethylendiamin (TEMED) & Sigma, Steinheim \\
Tris-Base & Fisher Scientific, Schwerte \\
Tween & PanReac AppliChem, Darmstadt
\end{tabular}

\subsubsection{Antikörper}

\subsubsection{Primär-Antikörper}

Die den Tabellen 2.4 und 2.5 aufgelisteten Primär- und Sekundär-Antikörper wurden in dieser Arbeit verwendet. Die Verdünnung wurde stets in 5\% Milchpulver TBS-T (für die Zusammensetzung s. Kapitel 2.2.3.3.2) angesetzt.

Tabelle 2.4 Primär-Antikörper

\begin{tabular}{l|lll}
\hline Target & Spezies/Bezeichnung & Verdünnung im Western-Blot & Hersteller \\
\hline aSMase & Maus, & $1: 1000$ & \#MAB5348, \\
monoklonal & & R\&D Systems, \\
& & & Wiesbaden \\
GAPDH & Maus, & $1: 5000$ & \#SC-32233, \\
& monoklonal & & Santa Cruz, \\
& & & Heidelberg
\end{tabular}




\begin{tabular}{l|lll}
\hline Target & Spezies/Bezeichnung & Verdünnung im Western-Blot & Hersteller \\
\hline HSP90 & Maus & $1: 1000$ & \#SC13119, \\
& monoklonal & & Santa Cruz, \\
& & & Heidelberg \\
nSMase1 & Kaninchen, & $1: 500$ & \#HPA018125, \\
& polyklonal & & Sigma, \\
& & & Steinheim \\
nSMase2 & Maus, & $1: 1000$ & \\
& monoklonal & & \#SC166637, \\
& & & Santa Cruz, \\
& & & Heidelberg
\end{tabular}

\subsubsection{Sekundär-Antikörper}

Tabelle 2.5 Sekundär-Antikörper

\begin{tabular}{l|lll}
\hline Target & Spezies/Label & Verdünnung im WB & AK-Nummer/Hersteller \\
\hline Kaninchen & Ziege/HRP & $1: 10.000$ & \#SC2004, Santa Cruz, \\
& & & Heidelberg \\
& Ziege/HRP & $1: 10.000$ & \#SC2005, Santa Cruz, \\
Maus & & & Heidelberg
\end{tabular}

\subsubsection{Oligonucleotide}

\subsubsection{Primer für die RTqPCR}

Für das Primer-Design wurde das Program PerlPrimer (Marshall 2004) verwandt. Alle Primer wurden von der Firma Iba in Göttingen hergestellt. GNB2L1 und HPRT1 sind beides Houskeepinggene, die in Kapitel 2.2.6.3 näher erläutert werden.

Tabelle 2.6 Primer für die RTqPCR

\begin{tabular}{l|ll}
\hline Gen & Primer & Sequenz \\
\hline GNB2L1 & hsGNB2L1fwd84 & AACCCTATCATCGTCTCCT \\
& hsGNB2L1rv84 & CAATGTGGTTGGTCTTCAG \\
& &
\end{tabular}




\begin{tabular}{l|ll}
\hline Gen & \multicolumn{1}{l}{ Primer } & Sequenz \\
\hline HPRT1 & $\begin{array}{l}\text { hsHPRT1fwd89 } \\
\text { hsHPRT1rv89 }\end{array}$ & TATGCTGAGGATTTGGAAAGG \\
CATCTCCTTCATCACATCTCG & \\
hsSMPD1fwd94 & GGAGCTGGAATTATTACCGA \\
hsSMPD1rv94 & GAAGACCCAAATTCATCCAC \\
hMPD3 & hsSMPD2rv139 & ATGATCCATCATGGTGACTG \\
& CGATGTGCTAGGTAGATGTC \\
hsSMPD3fwd91 & CATTTGACGTCGTCTGTGG \\
& hsSMPD3rv91 & CCTGTAGTGGGTGAACAGG
\end{tabular}

\subsubsection{SiRNA}

Die in Tabelle 2.7 aufgelisteten siRNA wurden bei Dharmacon (Lafayette, USA) erworben und nach Herstellerangaben in siRNA Puffer von Dharmacon aliquotiert.

Tabelle $2.7 \quad$ siRNA

\begin{tabular}{l|ll}
\hline siRNA-Name & Produktname & Produktnummer \\
\hline siSMPD1 & siGENOME siRNA - SMARTpool, SMPD1 & M-006676-01-0010 \\
& & \\
siSMPD2 & siGENOME siRNA - Individual, SMPD2 & D-006677-01-0005 \\
& & D-006677-02-0005 \\
& & D-006677-03-0005 \\
& & D-006677-04-0005 \\
siSMPD3 & siGENOME siRNA - Individual, SMPD3 & D-006678-01-0005 \\
& & D-006678-04-0005 \\
& & D-006678-17-0005 \\
& & D-006678-18-0005 \\
si-Non-Targeting & siGENOME Non-Targeting-siRNA & D-001210-03-20
\end{tabular}




\subsubsection{Plasmide}

Die in Tabelle 2.8 aufgelisteten Plasmide wurden von Sino Biological (Wayne, USA) erworben. Nach Herstellerangaben wurden DH5- $\alpha$ E. coli Bakterien mit den Plasmiden zur weiteren Verwendung transformiert.

Tabelle 2.8 Plasmide

\begin{tabular}{l|lll}
\hline Plasmid & Plasmid-Gerüst & Resistenz & Referenz \\
\hline pCMV3 & pCMV3-hsSMPD3-untagged & Ampicillin & Dr. rer. nat. K. Menck, \\
& $\begin{array}{l}\text { (hsSMPD3 ausgeschnitten von } \\
\text { Kpn I und Xba I) }\end{array}$ & & UMG Göttingen \\
pCMV3-hsSMPD1 & pCMV3-untagged & Ampicillin & Sino Biological \\
pCMV3-hsSMPD2 & pCMV3-untagged & Ampicillin & Sino Biological \\
pCMV3-hsSMPD3 & pCMV3-untagged & Ampicillin & Sino Biological
\end{tabular}

\subsubsection{Fertige Reaktionskits}

Alle Reaktionskits wurden nach Herstellerangaben verwendet. Nähere Erläuterungen finden sich unter Abschnitt 2.2 Methoden.

Tabelle 2.9 Fertige Reaktionskits

\begin{tabular}{l|l}
\hline Produkt & Hersteller \\
\hline$D_{C}$ Protein Assay Kit & Bio Rad, München \\
ECL Prime Western Blotting Detection Reagent & GE Healthcare, Braunschweig \\
Fugene HD & Promega, Mannheim \\
High Pure RNA-Isolation Kit & Roche, Grenzach-Mannheim \\
iSCRIPT cDNA Synthese Kit & Bio Rad, München \\
Nucleo Bond Xtra Midi EndoFree & Machery-Nagel, Düren \\
Precision Plus Protein Dual Core & Bio Rad, München \\
Signal Fire ECL Reagent & Cell Signaling, Denvers (USA)
\end{tabular}




\subsubsection{Verbrauchsmaterial}

Tabelle 2.10 Verbrauchsmaterial

\begin{tabular}{|c|c|}
\hline Produkt & Hersteller \\
\hline 10cm Zelladhäsionsplatte & Cellstar, Greiner Bio-One, Frickenhausen \\
\hline $175 \mathrm{~cm}^{2}$ Zellkulturflasche & Sarstedt, Nümbrecht \\
\hline 24-Well Zelladhäsionsplatte & Cellstar, Greiner Bio-One, Frickenhausen \\
\hline 6-Well Zelladhäsionsplatte & Sarstedt, Nümbrecht \\
\hline $75 \mathrm{~cm}^{2}$ Zellkulturflasche & Sarstedt, Nümbrecht \\
\hline 96-Well Photometerplatte & Sarstedt, Nümbrecht \\
\hline Auslaufpipette $(5 \mathrm{ml}, 10 \mathrm{ml}, 25 \mathrm{ml})$ & Sarstedt, Nümbrecht \\
\hline Eppendorfcups $(0,5 \mathrm{ml} ; 1,5 \mathrm{ml} ; 2 \mathrm{ml})$ & Sarstedt, Nümbrecht \\
\hline Falcon-Tube (15ml, 50ml) & Sarstedt, Nümbrecht \\
\hline Filtropur S0,2 Sterilfilter & Sarstedt, Nümbrecht \\
\hline Glaspasteurpipette & Labsolute, Renningen \\
\hline Microplatte RTqPCR 348-Well & Greiner Bio-One, Frickenhausen \\
\hline Nitrozellulosemembran & Heinemann, Schwäbisch Gmünd \\
\hline Omnifix-Spritzen (10ml) & B. Braun, Melsungen \\
\hline Pipettenspitzen & Sarstedt, Nümbrecht \\
\hline Zellschaber $(16 \mathrm{~cm}, 25 \mathrm{~cm})$ & Sarstedt, Nümbrecht \\
\hline
\end{tabular}

\subsubsection{Geräte}

Die in Tabelle 2.11 aufgelisteten Geräte fanden in dieser Arbeit ihre Verwendung. Nähere Erläutungen finden sich in Abschnitt 2.2 Methoden.

Tabelle 2.11 Geräte

\begin{tabular}{l|l}
\hline Produkt & Hersteller \\
\hline Autoklav Varioklav & Thermo Scientific, Bonn \\
Biometra Fastblot & Analytic Jena AG, Jena
\end{tabular}




\begin{tabular}{|c|c|}
\hline Produkt & Hersteller \\
\hline $\mathrm{CO}_{2}$-Inkubator Hera cell & Heraeus Thermo Fisher Scientific, Bonn \\
\hline Elektrophoresekammer Minigel Twin & Biometra, Göttingen \\
\hline Feinwaage Analytic AC 210P & Sartorius, Göttingen \\
\hline Magnetrührer IKA Mag Reo & IKA Labortechnik, Staufen \\
\hline Mikroskop Telval 31 & Zeiss, Oberkochen \\
\hline Nanodrop ND-1000 UV/Vis & Peqlab, Erlangen \\
\hline Nanosight NS-300 & Malvern Panalytical, Kassel \\
\hline Photometer Infinite F50 & Tecan, Crailsheim \\
\hline Pipettus Pipetboy 2 & Integra biosciences, Hudson (USA) \\
\hline Powersupply PowerPack P25 & Biometra, Göttingen \\
\hline Powesupply EPS600 & Pharmacia Biotech, Uppsala (Schweden) \\
\hline Scanner CanoScan 5600F & Canon, Willich \\
\hline Taqman-Cycler ABI 7900HT & Thermo Fisher, Bonn \\
\hline Thermocycler T300 & Biometra, Göttingen \\
\hline Thermomixer 5437 & Eppendorf, Hamburg \\
\hline Ultrazentrifuge Optima LE-80K & Beckmann Coulter, Krefeld \\
\hline Ultrazentrifuge TL100 & Beckmann Coulter, Krefeld \\
\hline UV-Transluminator T13 & Biometra, Göttingen \\
\hline Vortex VF2 & IKA-Labortechnik, Staufen \\
\hline Wasserbad Köttermann & Uetze, Hänigsen \\
\hline Werkbank Lamin Air HB 2448 & Thermo Fisher Scientific, Dreieich \\
\hline Zentrifuge Centrifuge 5415 D & Eppendorf, Hamburg \\
\hline Zentrifuge Fresco 21 & Thermo Fisher Scientific, Bonn \\
\hline Zentrifuge Multifuge 2L-R & Heraeus Thermo Fisher Scientific, Bonn \\
\hline Zentrifuge Multifuge X3R & Heraeus Thermo Fisher Scientific, Bonn \\
\hline
\end{tabular}




\subsection{Methoden}

\subsubsection{Zellkulturmethoden}

\subsubsection{Zellkultivierung}

Für die Zellkultivierung wurde unter sterilen Bedingungen an einer Werkbank mit Abzug gearbeitet. Es wurden ausschließlich autoklavierte oder desinfizierte Materialien oder werkseitig steril verpackte Produkte verwendet. Die SK-BR-3-Zellen wurden bei $37^{\circ} \mathrm{C}, 90 \%$ Luftfeuchtigkeit und $5 \% \mathrm{CO}_{2}$ in einem abgedunkelten Inkubator kultiviert. Dazu wurde der je nach Größe der Zellkulturflasche 10-20 ml RPMI 1640-FCS (Fetales Kälberserum) Medium (FCS zu RPMI im Verhältnis von 1:10) hinzugegeben.

Dieses Medium wurde alle drei bis fünf Tage gewechselt, es sei denn, die optische Konfluenz der Zellen überstieg ca. 80\%. In diesem Fall wurden die Zellen von der Zellkulturflasche abgelöst und in neue Flaschen aufgeteilt. Hierzu wurde das RPMI 1640 /FCS Medium zunächst abgesaugt und der Zelldetruitus in einem nächsten Schritt durch Waschung mit 3-5 ml PBS entfernt. Im Folgenden wurde je nach Größe der Zellkulturflasche 1-2 ml einer Trypsin/EDTA-Lösung (0,05\% Trypsin, 0,02\% EDTA in PBS im Verhältnis 1:10 in Reinstwasser verdünnt) auf die Zellen gegeben und diese im Inkubator für 10 min inkubiert. Nach Ablösung der Zellen durch das Trypsin konnten diese wieder in 1-5 ml RPMI 1640/FCS-Medium aufgenommen werden, wodurch das Trypsin inaktiviert wurde. Je nach Bedarf konnten die suspendierten Zellen dann abhängig von der gewünschten Zellkonfluenz in Zellkulturflaschen aufgeteilt oder für Versuche in $10 \mathrm{~cm}$ Petrischalen gegeben werden. Die Zellkulturflaschen wurden zuletzt noch mit RPMI 1640/FCS-Medium auf die gewünschte Menge aufgefüllt (175 $\mathrm{cm}^{2}$-Flasche, $23 \mathrm{ml}$ Medium; $75 \mathrm{~cm}^{2}$-Flasche, $10 \mathrm{ml}$ Medium).

\subsubsection{Zellzahlbestimmung}

Zur Bestimmung der Zellzahl bzw. der Zellkonzentration wurden ca. $200 \mu 1$ der frisch abtrypsinierten und in RPMI-FCS gelösten Zellsuspension entnommen und unter unsterilen Bedingungen zum Färben mit Trypanblau (1:10) versetzt. Diese Lösung wurde anschließend auf eine Neubauer-Zählkammer aufgetragen. Durch das Zählen der Zellen in vier Quadranten (definiertes Volumen von $0,1 \mathrm{~mm}^{3}$ pro Quadranten) und durch anschließende Bildung des arrhythmetischen Mittels konnte unter Berücksichtigung möglicher Verdünnungsfaktoren die Zellkonzentration und damit auch die absolute Zellzahl mathematisch ermittelt werden. 


\subsubsection{Transiente Transfektion mit siRNA}

Small Interfering (si)-RNA sind nichtkodierende Oligonukleotide (20-25 Basen), die komplementär zu einer Messenger (m)-RNA sind. Ihre Funktion besteht im sogenannten Posttranskriptionellen Silencing, eine Möglichkeit der Genregulation, bei dem die mRNA und siRNA mit verschiedenen Proteinen einen RNA-induzierten silencing-Komplex (RISC) bildet. Dieser RISC schneidet die mRNA, wodurch die Translation ausbleibt und die Expression des Proteins abnimmt oder ganz versiegt. In dieser Arbeit wurde siRNA verwendet, um die Aktivität von verschiedenen Genen zu reduzieren (Knock-Down).

Die folgenden Mengenangaben beziehen sich immer auf Versuche in $10 \mathrm{~cm}$ Zelladhäsionsplatten (Cellstar, Greiner Bio-One), die Werte in Klammern hingegen auf Versuche in 6-WellZelladhäsionsplatten (Sarstedt).

Für die si-Transfektion wurden SK-BR-3-Zellen zunächst wie oben beschrieben kultiviert. Nach Absaugen des Mediums und Waschung mit PBS und wurde Trypsin/EDTA (0,05\% Trypsin, 0,02\% EDTA in PBS im Verhältnis 1:10 in Reinstwasser verdünnt) zu den Zellen gegeben und für ca. 10 min im Inkubator inkubiert, um deren Adhäsion zu lösen (Mengen abhängig von der Größe der Kulturflaschen). Die Zellen wurden danach in RPMI 1640 Medium resuspendiert und nach oben beschriebener Methodik quantifiziert. Gleichzeitig wurden zwei Mastermixe vorbereitet. In Mastermix 1 wurden $10 \mathrm{nM}$ siRNA in $300 \mu \mathrm{l}(100 \mu \mathrm{l})$ Optimem (Gibco) Medium gelöst. Im Mastermix 2 wurde 12,5 $\mu \mathrm{l}(6 \mu \mathrm{l})$ Lipofectamin RNAiMax (Thermo-Fisher) in $300 \mu \mathrm{l}$ (100 $\mu$ l) Optimem-Medium gelöst. Lipofectamin ist ein Transfektionsreagenz, das die Effizienz der Transfektion steigert, indem es mit der siRNA Liposomen bildet, welche mit der Plasmamembran lebender Zellen fusioniert. Die in den Liposomen befindliche siRNA kann so die Plasmamembran überwinden. Nach kurzem Vortexten beider Mastermixe wurden diese zusammenpipettiert und für 5 min bei Raumtemperatur inkubiert. Nachdem der die Mastermixmischung (Mastermix $1+2$ ) dann auf die Adhäsionsplatte gegeben wurde, folgte die Zugabe von $5 \cdot 10^{6}\left(1 \cdot 10^{6}\right)$ Zellen SK-BR-3. Die Adhäsionsplatte wurde, auf ein Endvolumen von $10 \mathrm{ml}(2 \mathrm{ml})$ mit RPMI 1640 Medium aufgefüllt, im Inkubator inkubiert. Bei jedem Transfektionsversuch wurde auch eine Negativ-Kontroll-siRNA transfiziert, die zu keinem menschlichen Gen komplementär ist und somit auch keine mRNA binden und herunterregulieren kann.

\subsubsection{Transiente Transfektion mit Plasmiden}

Plasmide sind kleine ringförmige DNA-Moleküle. Sie besitzen verschiedene Gene wie Promotoren, Antibiotikaresistenzgene, das gene-of-interest (GOI) und Enhancer. Mithilfe von Transfektionsreagenzien, z. B. FugeneHD (Promega) kann das Plasmid in die Zelle gelangen und die Effizienz der Transfektion gesteigert werden. Ziel der Transfektion mit Plasmiden ist die 
Überexpression bestimmter Gene, in dieser Arbeit SMPD3. Die folgenden Mengenangaben beziehen sich immer auf Versuche in $10 \mathrm{~cm}$ Zelladhäsionsplatten. Die Werte in Klammern hingegen auf Versuche in 6-Well-Zelladhäsionsplatten.

Hierfür wurden die SK-BR-3-Zellen zunächst wie bei der Transfektion mit siRNA (s. Kapitel 2.2.1.1) trypsiniert und gezählt und danach jedoch gleich $3 \cdot 10^{6}\left(1 \cdot 10^{6}\right)$ Zellen auf die Adhäsionsplatte gebracht. Die Konfluenz soll ca. 50-60\% sein. Die Zellen wurden dann für 4 h im Inkubator inkubiert. Währenddessen wurde der Transfektionsmix vorbereitet. Dieser bestand aus $500 \mu \mathrm{l}(200 \mu \mathrm{l})$ Optimem, $3 \mu \mathrm{g}(1 \mu \mathrm{g})$ Plasmid-DNA und 12,5 $\mu \mathrm{l}(4,5 \mu \mathrm{l})$ FugeneHD. Dieser Mix wurde mit dem Vortex gemischt, kurz herunterzentrifugiert und für 5 min bei Raumtemperatur inkubiert. Vor der eigentlichen Transfektion wurde noch das Zellmedium abgesaugt und durch 1\% Penicillin/Streptomycin-RPMI1640 Medium getauscht. Nun wurde der Transfektionsmix zu den Zellen gegeben. Das Endvolumen betrug $10 \mathrm{ml}(2 \mathrm{ml})$. Nach Transfektion wurden die Zellen wieder im Inkubator inkubiert. Bei jedem Transfektionsversuch wurde auch eine Kontrolle transfiziert.

\subsubsection{Vesikel-Isolation und -Messung}

\subsubsection{Isolation von Mikrovesikeln und Exosomen}

Die EV-Isolierung erfolgte stets aus adhärenten Zellen. Je zwei $10 \mathrm{~cm}$ Zelladhäsionsplatten wurden wie in Kapitel 2.2.1.3 beschrieben mit siRNA transfiziert und für $72 \mathrm{~h}$ inkubiert. Danach folgte die Aspiration des Mediums und zweimalige Waschung mit PBS. Nach $24 \mathrm{~h}$ Inkubation der Zellen in partikelfreiem RPMI 1640 Medium mit 10\% partikelfreiem FCS wurde die Isolation der EV und Auftrennung in MV und Exo begonnen.

Hierbei machte man sich die unterschiedlichen Sedimentationskoeffizienten der EV zunutze, sodass ein differentielles Zentrifugationsprotokoll angewendet werden konnte (Abb 2.1). Zunächst wurde der Zellkulturüberstand aus den zwei Adhäsionsplatten abgenommen und gepoolt. Es folgte erst eine Zentrifugation für $5 \mathrm{~min}$ bei $750 \mathrm{~g}$, dann eine für $15 \mathrm{~min}$ bei $1500 \mathrm{~g}$, um Zellen und Detruitus aus der Probe zu pelletieren. Das Pellet wurde verworfen. Die Proben wurden daraufhin für 35 min bei $14.000 \mathrm{~g}$ und $4^{\circ} \mathrm{C}$ ultrazentrifugiert (Ultrazentrifuge Optima L80M mit Ausschwingrotor SW $32 \mathrm{Ti}$, Beckman Coulter), um die MV zu pelletieren (Pellet $14.000 \mathrm{~g}$, P14). Der Überstand wurde für die Exosomenpräparation verwendet. Das P14 wurde in $100 \mu 1$ PBS resuspendiert und für eine Waschung erneut bei $14.000 \mathrm{~g}$ und $4^{\circ} \mathrm{C}$ für 35 min zentrifugiert. Nach Resuspension wurden die MV bei $-20^{\circ} \mathrm{C}$ eingefroren.

Für die Exosomenpräparation wurde der Überstand bei der P14 Herstellung verwendet. Dieser wurde nach Filtrierung in einem 0,2 $\mu \mathrm{m}$-Sterilfilter (Filtropur S0,2, Sarstedt) bei $100.000 \mathrm{~g}$ und $4^{\circ} \mathrm{C}$ für $2 \mathrm{~h}$ zentrifugiert. Das Pellet (P100) wurde in $100 \mu$ PBS resuspendiert und durch erneute Zentrifugation 
bei $100.000 \mathrm{~g}$ und $4^{\circ} \mathrm{C}$ für weitere $2 \mathrm{~h}$ gewaschen. Nach Resuspendierung dieser P100 in $25 \mu \mathrm{PBS}$ wurden die Proben bei $-20^{\circ} \mathrm{C}$ eingefroren.

Bei jeder EV-Isolation wurden aus den EV-produzierenden Zellen Proteinlysate für Kontroll-WesternBlots, sowie Zellpellets für massenspektrometrische Analysen gewonnen. Vor Generierung der Zellpellets wurde zum besseren Normalisieren der MV- und Exo-Konzentration die Zellzahl bestimmt.

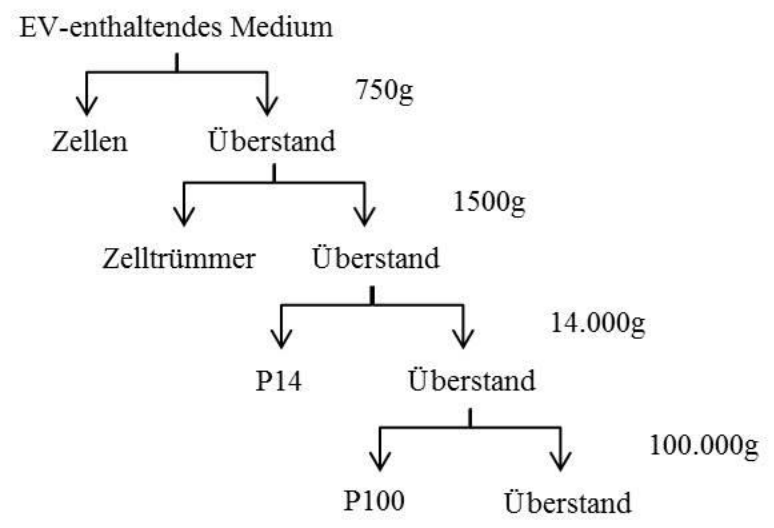

Abbildung 2.1:Prinzip der EV-Extraktion und Trennung in MV (P14) und Exo (P100). P, Pellet

\subsubsection{Nanoparticle Tracking Analysis}

Die Nanoparticle Tracking Analysis (NTA) gibt Auskunft über die Konzentration und Größe von Partikeln und kann für Teilchen mit einem Durchmesser von 10-1000 nm verwendet werden. Grundlage für die NTA ist die Brown'sche Bewegung, eine unregelmäßige Wärmebewegung von kleinen Partikeln, welche in Flüssigkeiten gelöst sind, und die Eigenschaften der Lichtstreuung. Ein Laserstrahl wird auf die Probe gerichtet und von den Partikeln gestreut. Durch Detektion der Streustrahlen mit einem Mikroskop und Aufzeichnung durch eine Kamera werden die Partikel visualisiert. Eine spezielle Software kann dann die Videoaufnahmen analysieren. Dazu werden einzelne Partikel verfolgt und ihre Brown'sche Bewegung vermessen. Über die Strokes-EinsteinGleichung kann dann der hydrodynamische Durchmesser des Partikels bestimmt werden. Letztlich ist es möglich, eine genaue Größenverteilung anzugeben (Filipe et al. 2010; Malvern 2019).

In dieser Arbeit erfolgte die NTA mit dem Gerät Nanosight NS-300 (Malvern). Die in PBS gelösten MV und Exo wurden zunächst mit PBS verdünnt (i. d. R. 1:20 bis 1:40), da laut Herstellerangaben die Partikelmenge pro Frame nicht über 20-70 liegen sollte, um Messungenauigkeiten zu verhinden. Mit einer $1 \mathrm{~mL}-$ Spritze (Braun, Melsungen) wurde die Probe auf die Messzelle des Nanosight gegeben und der Lauf gestartet. Je Probe wurden drei technische Replikate generiert. 


\subsubsection{Proteinbiochemische Methoden}

\subsubsection{Proteinisolation}

Für die Herstellung von Gesamtproteinlysaten zuvor inkubierter Zellen wurde aus den 6-Well-Platten oder $10 \mathrm{~cm}$ Zelladhäsionsplatten zunächst das Medium abgesaugt und die Zellen mit $500 \mu \mathrm{lbzw} .1 \mathrm{ml}$ PBS gespült. Um die Zellen zu lysieren, wurde $80 \mu \mathrm{l}$ (6-Wellplatte) oder $200 \mu \mathrm{l}$ (10cmZelladhäsionsplatte) RIPA-Lysepuffer (s. Tabelle 2.12) auf Eis hinzugegeben. Nach 10 min wurden die Zellen mit einem Zellschaber manuell von den Platten gelöst, in ein Eppendorfgefäß überführt und für weitere $10 \mathrm{~min}$ auf Eis belassen. Danach wurden die Eppendorfgefäße für $10 \mathrm{~min}$ bei $14.000 \mathrm{rpm}$ in einer Umgebungstemperatur von $4^{\circ} \mathrm{C}$ zentrifugiert, um die Proteine von Zelldetruitus und DNA zu pelettieren, und der Überstand mit einer Pipette in ein neues Eppendorfgefäß überführt. In diesem Überstand befindet sich das Gesamtproteinlysat. In einem nächsten Schritt kann dann entweder direkt die Proteinkonzentration gemessen (s. Kapitel 2.2.3.2) oder das Proteinlysat wird bei $-20^{\circ} \mathrm{C}$ zunächst eingefroren werden.

Tabelle 2.12: RIPA-Lysepuffer

\begin{tabular}{l|l}
\hline Substanz & Menge/Verhältnis \\
\hline Tris, pH 7,2 & $50 \mathrm{nM}$ \\
$\mathrm{NaCl}$ & $150 \mathrm{mM}$ \\
$\mathrm{SDS}$ & $0,1 \%$ \\
Na-Deoxycholat & $0,5 \%$ \\
Triton X-100 & $1 \%$
\end{tabular}

Dem RIPA-Lysepuffer wurde der Proteaseinhibitor-Mischung „Cocktail“ und ein Phosphataseinhibitor „PhosStop“ (beide Roche) hinzugefügt.

\subsubsection{Messung der Proteinkonzentration}

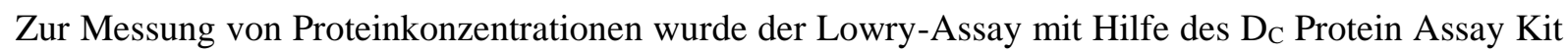
nach Herstellerangaben verwendet. Hierbei macht man sich die Eigenschaft von Substanzen zunutze, die bei der Reaktion mit Proteinen ihre Extinktion (detektierbar im Photometer) verändern. Diese Extinktion kann mit Lösungen verglichen werden, bei der die genaue Proteinkonzentration bereits bekannt ist. Um eine solche Eichkurve zu bekommen, werden Kalibratoren mit je 0, 25, 125, 250, 500, 750 und $1000 \mu \mathrm{g} / \mathrm{ml}$ Protein erstellt und bei jeder Konzentrationsmessung zweifach neu aufgetragen und mit den zu messenden Proteinlysaten verglichen.

Zunächst wurde die zu messende Lösung mit dem Vortex gemischt, um eine gleichmäßige Proteinverteilung zu erzielen. Davon wurde je $2 \mu \mathrm{l}$ in $8 \mu 1 \mathrm{H}_{2} \mathrm{O}$ verdünnt und anschließend mit $50 \mu \mathrm{l}$ 
der Stammlösung A versetzt. Nach Zugabe von $400 \mu 1$ der Stammlösung B wurden je zweimal $150 \mu 1$ der Lösung (Proteinlösung + Stammlösung A + Stammlösung B) entnommen und auf eine 96-WellPlatte übertragen. Diese blieb für $15 \mathrm{~min}$ nach Auftragung der Lösungen ohne Lichteinfluss bei Raumtemperatur. Mit einem Photometer wurde die Extinktion bei $750 \mathrm{~nm}$ Wellenlänge gemessen und berechnet. Nach Bildung des Mittelwertes der beiden Extinktionen ließen sich dann Rückschlüsse auf die Proteinkonzentration ziehen.

\subsubsection{Immunoblot}

Die Proteinlysate wurden mittels Western-Blot analysiert. Hierbei werden die Proteinlysate zunächst per SDS-PAGE (Natriumdodecylsulfat-Polyacrylamid-Gelelektrophorese) in Proteinbanden getrennt und anschließend auf eine Nitrozellulosemembran übertragen (Blotting). Für die Immundetektion einzelner Proteine bietet sich die Markierung mit spezifischen Antikörpern an.

\subsection{SDS-PAGE}

Das Prinzip der SDS-PAGE ist es, die Proteine ihrem spezifischen Molekulargewicht (in kDa) und ihrer Ladung nach aufzutrennen. Dafür wird über das Polyacrylamidgel eine Spannung gelegt, sodass die Proteine von der einen Gel- zur anderen Gelseite wandern und sich trennen. Abhängig vom Proteingewicht werden unterschiedlich stark konzentrierte Gele verwendet, um so die optimale Auftrennung innerhalb eines bestimmten Gewichtes zu erreichen.

Um das Gel zu erstellen, wird zuerst eine Form angefertigt, in der das Gel aushärten kann. Die Form besteht aus zwei Glasplatten, die mit Isopropanol gereinigt und mit $\mathrm{H}_{2} \mathrm{O}$ gespült werden. Zunächst wird das Trenngel (für Konzentrations- und Mengenverhältnis s. Tabelle 2.13) angemischt. Dieses wird in die Form gegeben und mit Isopropanol überschichtet, damit keine Lufteinschlüsse zurückbleiben. Nach der Polymerisation des Trenngels und Auswaschen des Isopropanols kann das Sammelgel (für Konzentrations- und Mengenverhältnis s. Tabelle 2.14) vorbereitet und auf das Trenngel in der Glasform gegeben werden. Durch Einbringen eines 10- oder 16-zähnigen Kamms entstehen Taschen, in die später das Protein gegeben wird. Der Sinn hinter unterschiedlichen Konzentrationen von Trenn- und Sammelgel ist, die Proteine im Sammelgel zunächst anzukonzentrieren. Dadurch gelingt eine genauere Auftrennung der Proteine.

Die Proben werden nach einem bestimmten Verdünnungsschema vorbereitet. Dieses ist je Probe unterschiedlich und richtet sich nach der genauen Proteinkonzentration. Es werden je nach Fragestellung 20-50 $\mu$ g Protein eingesetzt und mit einem Viertel des Gesamtvolumens (i. d. R. 56,5 $\mu \mathrm{l}$ ) Lämmli-Puffers (Carl Roth, Karlsruhe) versetzt. (Der Lämmlipuffer besteht aus SDS, Bromphenolblau, $\beta$-Mercaptoethanol, Glycerin und Tris/HCl.) Nach kurzem Herunterzentrifugieren 
und Denaturieren bei $95^{\circ} \mathrm{C}$ für 5 min kann die Probe auf das Gel gegeben werden. Grund für LämmliPuffer (v. a. das darin enthaltene 2-Mercaptoethanol) und Hitzedenaturierung ist das Aufbrechen von Wasserstoffbrückenbindungen. Dadurch liegt das Protein in seiner Primärstruktur vor.

Nach Auftragung der Proben in die entsprechenden Taschen des Polyacrylamidgels wird unter Zuhilfenahme eines Elektrophoresepuffers (s. Tabelle 2.15) eine Spannung von 90 V angelegt. Die negativ geladenen Proteine wandern nun von der Kathode zur Anode. Nach Durchlaufen des Sammelgels (ca. $30 \mathrm{~min}$ ) kann die Spannung erhöht werden (140 V), um die Auftrennung zu beschleunigen. Da man zusätzlich zu den Proben noch einen vorgefärbten Größenmarker Precision Plus Protein Dual Core (BioRad) auf das Gel aufträgt, kann man schon während der Elektrophorese erkennen, wie gut die Proteine voneinander getrennt sind. Der Versuch wird beendet, wenn die Trennung im gewünschten Bereich ausreichend erfolgt ist. Das Gel kann dann aus der Glasform herausgelöst und geblottet werden.

Tabelle 2.13: $10 \%$ Trenngel $(5 \mathrm{ml})$

\begin{tabular}{l|l}
\hline Substanz & Menge \\
\hline Aqua dest. & $2,03 \mathrm{ml}$ \\
Acrylamid & $1,67 \mathrm{ml}$ \\
Trenngelpuffer $^{1}$ & $1,25 \mathrm{ml}$ \\
$10 \%$ Ammoniumpersulfat (APS) & $50 \mu 1$ \\
Tetramethylethylendiamin (TEMED) & $5 \mu 1$
\end{tabular}

${ }^{1} 1,5 \mathrm{M}$ Tris $+10 \%$ SDS $(\mathrm{pH} 8,8)$

Tabelle 2.14: $\quad$ 5\% Sammelgel (3ml)

\begin{tabular}{l|l}
\hline Substanz & Menge \\
\hline Aqua dest. & $2,13 \mathrm{ml}$ \\
Acrylamid & $0,5 \mathrm{ml}$ \\
Sammelgelpuffer ${ }^{1}$ & $0,38 \mathrm{ml}$ \\
$10 \%$ Ammoniumpersulfat (APS) & $30 \mu \mathrm{l}$ \\
Tetramethylethylendiamin (TEMED) & $3 \mu \mathrm{l}$ \\
${ }^{1} 1,5 \mathrm{M}$ Tris +10\% SDS (pH 6,8) & \\
& \\
Tabelle 2.15: Elektrophoresepuffer & \\
\hline Substanz & Menge \\
\hline Tris-Base & $3 \mathrm{~g}$ \\
Glycin & $14,4 \mathrm{~g}$ \\
SDS & $1 \mathrm{~g}$ \\
$\mathrm{H}_{2} \mathrm{O}$ & 1,11
\end{tabular}




\subsection{Blotting}

Ziel des Blottings ist es, die im Gel getrennten Proteine möglichst vollständig auf eine neue Trägermembran zu übertragen. Dafür kann man verschiedene Blottingmethoden (Kapillartransfer, Diffusionstransfer, Elektrotransfer) verwenden. In dieser Arbeit wurden alle Proteine im Immunoblot mit einem sogenannten Semi-Dry-Blot per Elektrotransfer übertragen.

Hierzu wurde das Gel nach dem Herauslösen aus der Glasform zunächst in den Blottingpuffer (s. Tabelle 2.16) überführt und auf die Nitrozellulosemembran gelegt (diese kann Proteine binden). Um die elektrische Leitfähigkeit zu gewährleisten und um das Gel vor dem Austrocknen zu schützen, wurden in Blottingpuffer getränkte Filterpapiere um Gel und Membran gelegt und diese Einheit in den Biometra Fastblot (Jena Analytik) gespannt. Der Fastblot hält eine Spannung von $10 \mathrm{~V}$ für 1,5 h aufrecht, wonach die Proteine vom Gel auf die Nitrozellulosemembran übergetreten sind. Zur Kontrolle, ob die Proteine tatsächlich auf die Membran übertragen wurden, wurde die Membran nach dem Blotten für 2-3 min mit Ponceau-Farbe gefärbt. Proteine färben sich rot. Durch anschließendes Entfärben mit TBS-T (s. Tabelle 2.17) kann die Membran für die Immunfärbung verwendet werden.

Tabelle 2.16: Blottingpuffer

\begin{tabular}{l|l}
\hline Substanz & Menge \\
\hline Tris-Base & $3,028 \mathrm{~g}$ \\
Glycin & $14,414 \mathrm{~g}$ \\
Aqua dest. & 0,81 \\
Methanol & 0,21
\end{tabular}

Tabelle 2.17: TBS

\begin{tabular}{l|l}
\hline Substanz & Menge \\
\hline Tris-Base & $2,42 \mathrm{~g}$ \\
$\mathrm{NaCl}$ & $8 \mathrm{~g}$ \\
Aqua dest. & 1,11 \\
$\rightarrow \mathrm{pH} 7,6$ austitrieren mit $\mathrm{HCl}$ &
\end{tabular}

Für TBS-T Zusatz von 1\% Tween (Pan Reac, AppliChem, Darmstadt).

\subsection{Immunfärbung}

Durch die Immunfärbung können gezielt Proteine sichtbar gemacht werden. Dafür macht man sich das spezfische Bindungsprofil von Antikörpern zunutze. Ein erster Antikörper bindet an das gesuchte Protein. Ein zweiter Antikörper, der, an den eine Peroxidase geknüpft ist, bindet den ersten. Gibt man 
nun eine auf Acridin basierende Substanz hinzu, wird diese von der Peroxidase reduziert. Dabei entsteht nur an der Stelle des gesuchten Proteins eine detektierbare elektromagnetische Strahlung. Dieses Phänomen nennt man Chemilumineszenz.

Damit keine weiteren Proteine nach dem Blotting mehr auf die Membran gelangen, wodurch die Antikörper unerwünschte unspezifische Färbungen erzeugen könnten, wurden alle bislang unbesetzten Stellen der Nitrozellulosemembran mit für den Antikörper nicht erkennbaren Proteinen blockiert. Dazu eignet sich Milchpulver oder Bovines Serumalbumin (BSA). In dieser Arbeit wurde die Blockierung vornehmlich mit fünfprozentigem Milchpulver in TBS-T für eine Stunde unter ständiger Bewegung bei Raumtemperatur vollzogen. Im Folgenden wurde der entsprechende Antikörper verdünnt und gelöst in TBS-T mit BSA bzw. Milchpulver bei $4^{\circ} \mathrm{C}$ über Nacht auf einem Schütteltisch inkubiert. Nach mehrmaliger gründlicher Waschung der Membran am nächsten Tag mit TBS-T folgte die Inkubation des Sekundärantikörpers bei Raumtemperatur für eine Stunde. Auch der Sekundärantikörper wurde in fünfprozentiger Milchpulver-TBS-T-Lösung verdünnt und gelöst. Nach erneutem mehrmaligen Waschen der Membran, konnte diese mit dem ElektrochemilumineszenzReagenz in Verbindung gebracht (entweder Signal Fire ECL Reagent, Cell signaling; oder Amersham ECL Prime Western Blotting Detection Reagent, GE Healthcare) und im Luminescent Image Analyzer LAS-400 (Fujifilm) entwickelt werden. Die auf der Membran erscheinenden Banden lassen Rückschlüsse auf den Proteingehalt des gesuchten Proteins im untersuchten Proteinlysat zu.

\subsection{Quantifizierung der Western-Blots}

Um die Western-Blots zu quantifizieren, wurden die detektierten Banden mit dem Open-Source Programm Image J (imagej.nih.gov/ij) analysiert. Dabei misst man die optische Dichte der Banden und vergleicht diese mit einer Kontrolle, um die relative Expression als quantitative Daten angeben zu können. Es konnten nur die Western-Blot Aufnahmen verwendet werden, bei denen noch keine Sättigung der Bande eingetreten ist, andernfalls wird die Messung fehlerhaft und ungenau. Hierfür wurden die verschiedenen Aufnahmen nach unterschiedlicher Belichtungszeit miteinander verglichen. Fiel hier keine Veränderung mehr auf, war die Bande gesättigt. Nach Subtraktion der Hintergrunddichte und Messung der Bandendichte konnte diese mit der Kontrolle verglichen werden und gab Aufschluss über die relative Expression.

\subsubsection{Etablierung der Antikörper}

Die bestellten Antikörper müssen vor ihrer Verwendung getestet werden. Dazu wurden auf biogps.org Zelllinien ausgewählt, die das Protein besonders stark exprimieren, gegen das der Antikörper gerichtet ist. Die Webseite biogps.org ist ein Internetkatalog, in dem die Expression von Genen in bestimmten 
Zellen angegeben sind. Nach Gewinnung von entsprechenden Proteinlysaten wurden Western-Blots durchgeführt. Zeigten sich im erwarteten Größenspektrum Banden, konnte der Antikörper verwendet werden und war etabliert.

\subsubsection{Plasmidvermehrung}

\subsubsection{Transformation kompetenter Bakterien mit Plasmiden}

Um Plasmide zu vermehren, wurden kompetente Bakterien, d. h. Bakterien, die in der Lage sind, freie DNA aus ihrer Umgebung aufzunehmen, mit Plasmiden der Firma Sino Biological transformiert. Eine auf den Plasmiden vorhandene Antibiotikaresistenzkassette ermöglicht die Anzucht nur von jenen Bakterien, die das Plasmid aufgenommen haben.

Ausgangsmaterial waren sogenannte DH5- $\alpha$ E. coli Bakterien. $100 \mu 1$ der Bakterien wurden mit 100 ng des entsprechenden Plasmides versetzt und für 30 min auf Eis inkubiert. Ein 45-sekündiger Hitzeschock bei $42^{\circ} \mathrm{C}$ ermöglichte dem Plasmid, die Zellmembran der Bakterien zu überwinden. Nach zweiminütiger Inkubation auf Eis wurde $150 \mu$ SOC-Medium (Invitrogen) hinzugegeben und die Bakterien anschließend für 45 min bei $37^{\circ} \mathrm{C}$ unter ständiger Bewegung angezüchtet.

Um die Bakterien zu selektieren, die das Plasmid aufgenommen haben, wurden zuvor Ampicillinhaltige Agarplatten gegossen. Da die Plasmide eine Sequenz mit einer Ampicillin-Resistenz besitzen (Amp R), konnten nur diese Bakterien überleben, die das Plasmid exprimierten. Dazu wurde eine 1,5\% Agarlösung in LB-Medium (s. Tabelle 2.18) angesetzt und erhitzt. Nach Zugabe von $1 \mu \mathrm{g} / \mathrm{ml}$ Ampicillin wurde die Agarlösung in $21,5 \mathrm{~cm}^{2}$ Petrischalen ausgegossen. Die abgekühlten AgarAmpicillin-Platten konnten dann in einem nächsten Schritt mit den transformierten Bakterien beimpft werden. Hierzu wurde eine gebogene sterile Pasteurpipette verwendet. Während einer Inkubation bei $37^{\circ} \mathrm{C}$ bildeten sich über Nacht in den kopfüber positionierten Agarplatten (die Position verhindert das Betropfen der Bakterien durch Kondenswasser) Bakterienkulturen, die am nächsten Tag gepickt werden konnten.

Tabelle 2.18: LB (lysogeny broth)-Medium

\begin{tabular}{l|l}
\hline Substanz & Menge/Verhältnis \\
\hline Hefeextrakt & $5 \mathrm{~g} / \mathrm{l} \mathrm{H} \mathrm{H}_{2} \mathrm{O}$ \\
Trypton & $10 \mathrm{~g} / 1 \mathrm{H}_{2} \mathrm{O}$ \\
Natriumchlorid & $0,5 \mathrm{~g} / 1 \mathrm{H}_{2} \mathrm{O}$ \\
\multicolumn{2}{l}{ Es handelt sich bei dieser LB-Medium Formulierung um die LB-Luria. }
\end{tabular}




\subsubsection{Amplifikation der Plasmide}

Um die Plasmide zu amplifizieren, wurden die transformierten Bakterien zunächst vermehrt. Hierfür wurden zunächst einige (ca. vier bis zehn) Bakterienkolonien mit einer Pipette von der AgarAmpicillin-Platte entnommen und in $4 \mathrm{ml}$ Ampicillin-haltigen LB-Medium $(1: 1000)$ bei $37^{\circ} \mathrm{C}$ für $4 \mathrm{~h}$ unter ständiger Bewegung von 200 rpm kultiviert. Diese Starterkultur wurde dann in die Stammkultur überführt. Diese besteht aus $200 \mathrm{ml}$ des Ampicillin-haltigen LB-Mediums und wurde für ca. $16 \mathrm{~h}$ unter ständiger Bewegung $(200 \mathrm{rpm})$ bei $37^{\circ} \mathrm{C}$ inkubiert.

\subsubsection{Plasmidpräparation (Midiprep)}

Damit die amplifizierten Plasmide für die Transfektion der SK-BR-3-Zellen benutzbar werden, muss diese aus den Bakterien gewonnen und aufgereinigt werden. Hierfür wurde das Nucleo Bond Xtra Midi EF (Machary-Nagel) Präparationskit nach Herstellerangaben verwendet. Grundlage für die DNA-Gewinnung ist die Anionen-Austausch-Chromatografie und die alkalische Lyse. Hierbei wird durch Zugabe von SDS und Natriumhydroxid eine alkalische Verseifung der Lipide bewirkt, die letztlich die Bakterien lysiert. Die Plasmide, welche sich in den Bakterien befinden, werden an ein Siliciumdioxid-Anionenharz gebunden und die restlichen Substanzen der Zelle (Protein, Lipide, RNA etc.) durch verschiedene Waschungen beziehungsweise durch Enzyme (RNase A) entfernt. Die gebundene DNA kann im Anschluss durch Hinzugabe von Lösungen hoher Salzkonzentration aus dem Harz gelöst und mit Isopropanol letztlich gefällt werden.

Hierfür wurde die zuvor angesetzte Stammkultur (s. Kapitel 2.2.5.2) zentrifugiert $\left(4600 \mathrm{rpm}, 4^{\circ} \mathrm{C}\right.$, 10 min), um das Medium von den Bakterien zu trennen. Das Bakterienpellet wurde zunächst in einem Resolutions-Puffer resuspendiert und durch Zugabe von Lysepuffer lysiert und nach 5 min Inkubationszeit neutralisiert. Nach Äquilibrierung der Filter (NucleoBond Xtra Columns) mit einem speziellen Äquilibrierungspuffer wurden die Lysate auf den Filter gegeben. Es folgten drei Waschschritte, um Zelldebris, Proteine etc. zu entfernen. Dann folgte die Elution der Plasmide durch einen Elutionspuffer und letztlich die Fällung durch Isopropanol. Nach Zentrifugation der gefällten Plasmide (4600 rpm, $4^{\circ} \mathrm{C}, 10 \mathrm{~min}$ ) - die Plasmide wurden pelletiert - folgte eine Resuspension dieser in $70 \%$ Ethanol als Waschschritt. Die Plasmid-Ethanollösung wurde ein weiteres Mal zentrifugiert (4600 rpm, $4^{\circ} \mathrm{C}, 10 \mathrm{~min}$ ) und das entstandene Pellet in $\mathrm{H}_{2} \mathrm{O}$ aufgenommen. Alle Schritte wurden nach Herstellerangaben durchgeführt, die entsprechenden Mengen der eingesetzten Puffer entsprachen der Empfehlung des Herstellers.

Die gereinigten Plasmidproben wurden dann auf ihre DNA-Konzentration im NanoDrop ND-100 (Nano Drop Technologies) überprüft und zur Kontrolle sequenziert. 


\subsubsection{Bestimmung der Nukleinsäurekonzentration im Nanodrop}

Plasmid-DNA für die Transfektion und Proben-RNA für die RTqPCR wurden mittels NanoDrop ND1000 (Nano Drop Technologies) auf ihre Konzentration gestestet. Hierfür wurde nach Herstellerangaben zunächst das Gerät mit $1 \mu 1 \mathrm{H}_{2} \mathrm{O}$ gestartet und mit weiteren $1 \mu \mathrm{H}_{2} \mathrm{O}$ kalibriert. Die zu untersuchende Probe wurde durch Vortexen gemischt und je $1 \mu \mathrm{l}$ auf die Ansaugstelle des Nano Drops gegeben und die Nukleinsäurekonzentration ermittelt.

\subsubsection{Genexpressionsanalysen mittels RTqPCR}

Die quantitative real-time Polymerase-Kettenreaktion (RTqPCR) ist eine Methode zur Quantifizierung von DNA. Sie beruht auf den Mechanismen der herkömmlichen Polymerase-Kettenreaktion, bei der unter Zuhilfenahme von RNA-Primern ein ausgewählter Abschnitt der DNA durch DNA-Polymerasen vervielfältigt wird. Bei der RTqPCR wird zusätzlich ein Fluoreszenzfarbstoff (SYBR Green) hinzugegeben, der mit der DNA interkaliert. Da mit jedem Vervielfältigungszyklus auch die Menge der DNA zunimmt, steigt auch die Fluoreszenzintensität an. Durch das Messen dieser Intensität und durch den Vergleich mit einer Kontrolle und den sogenannten Houskeeping-Genen (Erklärung s. Kapitel 2.2.6.3) können dann Rückschlüsse auf die relative Quantität der DNA in der untersuchten Probe gewonnen werden.

\subsubsection{Extraktion von RNA aus kultivierten Zellen}

Für die Extraktion von RNA aus kultivierten Zellen wurde das High Pure RNA Isolation Kit (Roche) nach Herstellerangaben verwendet.

Ca. 1.000.000 Zellen wurden hierfür zunächst auf einer 6-Well-Platte ausgesät und je nach Fragestellung behandelt. Für die RNA-Extraktion wurde das Medium der Zellen abgesaugt, die Zellen mit PBS gewaschen und in $200 \mu$ PBS resuspendiert. Durch Zugabe des Lysepuffers (u.a. enthält dieser Guanidiniumthiocyanat) und anschließendem Vortexen für $15 \mathrm{sec}$ wurden die Zellen permeabilisiert und Proteine denaturiert (v. a. RNAsen müssen denaturiert werden, um die empfindliche RNA nicht zu zerstören). Die lysierten Proben wurden auf eine Filtersäule aufgetragen, welche die RNA bindet. Der Zelldetruitus passiert durch Zentrifugation bei $8000 \mathrm{~g}$ für $15 \mathrm{sec}$ den Filter und kann verworfen werden. Um DNA, welche ebenso vom Filter gebunden wird, zu eliminieren, wurde dieser mit DNaseI für 15 min bei Raumtemperatur inkubiert. Nach dreimaligem Waschen des Filters konnte die RNA eluiert werden. Hierzu wurde der $\mathrm{H}_{2} \mathrm{O}$ auf den Filter gegeben und dieser bei $8000 \mathrm{~g}$ für eine min zentrifugiert. Nach Auffangen der im Wasser gelösten RNA wurde die Konzentration entweder direkt mit dem Nanodrop ND-1000 UV/Vis gemessen oder die Probe zunächst bei $-80^{\circ} \mathrm{C}$ eingefroren. 


\subsubsection{Reverse Transkription}

Damit RNA auch mit der RTqPCR quantifiziert werden kann, muss sie zuerst in komplementäre DNA (cDNA, von englisch complementary) umgeschrieben werden. Hierbei wurde das iScript cDNA Synthesekit (Bio-Rad) nach Herstellerangaben verwendet.

Die reverse Transkription wird durch die reverse Transkriptase, eine RNA-abhängigen DNAPolymerase, vollzogen. Als Primer werden zufällige Hexameroligonucleotide und Oligodesoxythymidin(dT)nukleotide (zum Binden des Polyadenylatschwanzes von mRNA) verwendet. Sie hybridisieren an die RNA und ermöglichen so die Bildung eines komplementären DNA-Stranges durch die reverse Transkriptase.

Damit die Primerhybridisierung und Enlongation der cDNA unter optimalen Bedingungen ablaufen können, wurde das untenstehende Temperaturprotokoll im Thermocycler T3000 (Biometra) angewendet.

Thermoprotokoll: $\quad 5 \mathrm{~min}$ bei $25^{\circ} \mathrm{C} \rightarrow 30 \mathrm{~min}$ bei $42^{\circ} \mathrm{C} \rightarrow 5 \mathrm{~min}$ bei $85^{\circ} \mathrm{C}$

Tabelle 2.19: Reagenzien der reversen Transkription

\begin{tabular}{l|l}
\hline Substanz & Menge \\
\hline iScript Reaktionsmix & $4 \mu \mathrm{l}$ \\
Reverse Transkriptase & $1 \mu \mathrm{l}$ \\
RNA-Probe & $1 \mu \mathrm{g}^{1}$ \\
${ }^{1}$ Die Menge ist abhängig von der RNA-Konzentration. Das Endvolumen von $20 \mu \mathrm{l}$ wurde mit $\mathrm{H}_{2} \mathrm{O}$ aufgefüllt.
\end{tabular}

\subsubsection{RTqPCR}

Für die RTqPCR wurde die SYBR-Green-Methode gewählt. Das Prinzip der RTqPCR entspricht der herkömmlichen PCR, die sich in mehrere Abschnitte gliedert. Nach Aktivierung der Taq-Polymerase, eine hitzestabile DNA-Polymerase, folgen 40 Zyklen der Denaturierung, des Annealings und letztlich der Elongation. Im Unterschied zur herkömmlichen PCR wird bei der RTqPCR der Farbstoff SYBR hinzugefügt. Dieser sendet fluoreszierende Signale, wenn er mit der DNA interkaliert. Da bei jedem Zyklus der RTqPCR mehr DNA entsteht, nimmt das Fluoreszenzsignal mit jedem Zyklus zu. Dem Amplifikationszyklus, bei dem die Fluoreszenz exponentiell über die Hintergrundfluoreszenz ansteigt, wird Cycle Threshold (Ct) genannt. Je mehr cDNA des gene of interest (GOI) in der Probe vorliegt, desto schneller kommt es zu Fluoreszenzsignalen und desto niedriger ist der Ct-Wert. Normalisiert man den Ct-Wert der GOI mit dem Mittelwert zweier Houskeeping-Gene (HRPT1, GNB2L1), welche 
unabhängig von äußeren Einflüssen exprimiert werden und somit eine konstante Expression besitzen, erhält man den sogenannten $\Delta \mathrm{Ct}$-Wert, der die Expression verglichen mit den Houskeepern angibt. Vergleicht man diesen $\Delta$ Ct-Wert dann mit der unbehandelten biologischen DNA-Kontrolle, erhält man den $\Delta \Delta$ Ct-Wert, welcher Auskunft über die veränderte Expression durch die Behandlung der Proben gibt. Die relative Expression kann dann mit der untenstehenden Formel berechnet werden.

$$
\text { Relative Expression }=2^{-\Delta \Delta \mathrm{Ct}}
$$

Um eine der kultivierten Zellen auf das GOI zu untersuchen, wurde zuerst, wie oben beschrieben, RNA extrahiert und in cDNA transkribiert. Jede dieser Verdünnungen wurde außerdem noch 1:1 mit $\mathrm{H}_{2} \mathrm{O}$ verdünnt (um Pipettierfehler zu minimieren) und als Triplikat mit je $2 \mu 1$ auf eine 384-Well-Platte aufgetragen. Außerdem wurde je ein Triplikat No-Template-Control (NTC) pipettiert, welches anstatt der cDNA nur $\mathrm{H}_{2} \mathrm{O}$ beinhaltet. Dies dient dazu, mögliche Verunreinigungen zu detektieren.

$\mathrm{Zu}$ jedem cDNA-Triplikat und zu der NTC wurden je $8 \mu$ l eines Mastermixes 1 (s. Tabelle 2.22) hinzugegeben. Dieser besteht aus dem Primerpaar (foreward, fwd; reverse rev) und dem SYBR-Mix (s. Tabelle 2.21), welcher den Farbstoff und Nukleotidbasen (dNTP) für die Enlongation während der RTqPCR enthält. Der Mastermix 2 für die No-Primer-Control (NPC) bestand lediglich aus dem SYBRMix und $\mathrm{H}_{2} \mathrm{O}$ ohne Primer. Dieser wurde für die Detektion von möglichen Verunreinigungen als Triplikat statt des Mastermix zu der cDNA gegeben. Im NTC und im NPC wird keine DNA-Detektion erwartet.

Nach abgeschlossener Pipettierung wurde die 384-Well-Platte kurz herunterzentrifugiert und die RTqPCR am Taqman ABI PRISM 7900 HAT detection system (Applied Biosystems) unter Standardbedingungen (s. Tabelle 2.20) gestartet.

Die Auswertung der Rohdaten erfolgte mit dem Programm SDS2.4 (Applied Biosystems). Waren NTC und NPC auffällig, konnten die restlichen Daten nicht verwendet werden und die RTqPCR musste wiederholt werden. Nach der Subtraktion möglicher Ausreißer in den Amplifikationskurven der untersuchten Proben wurden die Ct-Werte und daraufhin die relative Expression berechnet.

Tabelle 2.20: Standard RTqPCR Programm

\begin{tabular}{l|l|l}
\hline Schritt & Dauer & Temperatur \\
\hline Aktivierung der Taq-Polymerase & $12 \mathrm{~min}$ & $95^{\circ} \mathrm{C}$ \\
Denaturierung & $15 \mathrm{sec}$ & $95^{\circ} \mathrm{C}^{1}$ \\
Annealing und Enlongation & $1 \mathrm{~min}$ & $60^{\circ} \mathrm{C}^{1}$ \\
& &
\end{tabular}


Schmelzkurvenanalyse

$15 \mathrm{sec}$

$95^{\circ} \mathrm{C}^{2}$

${ }^{1}$ Nacheinander 40 Zyklen

${ }^{2} 2^{\circ} \mathrm{C} / \mathrm{min}$ von $60-95^{\circ} \mathrm{C}$

Tabelle 2.21: SYBR-Green Mastermix

\begin{tabular}{l|l}
\hline Substanz & Menge \\
\hline PCR Puffer $^{1}$ & $2,5 \mathrm{ml}$ \\
$25 \mathrm{nM} \mathrm{MgCl}_{2}$ & $3 \mathrm{ml}$ \\
SYBR green (1:100) & $31,3 \mu \mathrm{l}$ \\
$20 \mathrm{nM}$ dNTP mix & $250 \mu \mathrm{l}$ \\
$5 \mathrm{U} / \mu \mathrm{l}$ Taq Polymerase & $100 \mu \mathrm{l}$ \\
$10 \%$ Triton X-100 & $652 \mu \mathrm{l}$ \\
$1 \mathrm{M}$ Trehalose & $7,5 \mathrm{ml}$ \\
${ }^{1} 0,75 \mathrm{M}$ Tris-HCl pH 8,8; 0,2 M Ammoniumsulfat; 0,1\% Tween-20
\end{tabular}

Tabelle 2.22: RTqPCR-Mastermix

\begin{tabular}{l|l}
\hline Substanz & Menge \\
\hline SYBR-Green Mastermix & $5,6 \mu \mathrm{l}$ \\
fw-Primer $(10 \mu \mathrm{M})$ & $0,3 \mu \mathrm{l}$ \\
rv-Primer $(10 \mu \mathrm{M})$ & $0,3 \mu \mathrm{l}$ \\
Nuklease freies $\mathrm{H}_{2} \mathrm{O}$ & $1,8 \mu \mathrm{l}$
\end{tabular}

\subsubsection{Primerdesign und Primereffizienz-Analyse}

Die Transkripte des zu untersuchenden Gens (GOI) wurde aus der Gendatenbank ncbi.nlm.nih.gov/gene ermittelt. Mithilfe dieser Basensequenz wurden die Primerpaare für die RTqPCR mit dem Program PearlPrimer Version 1.1.20 entworfen und die Effektivität des Primers ermittelt.

Dazu wurde über die Proteindatenbank biogps.org eine Zelle gesucht, die das GOI besonders stark exprimiert (Positivkontrolle). Bei der Effizienztestung des Primers hsSMPD3-91 wurde die Positivkontrolle durch Überexpression (s. Kapitel 2.2.1.4) von SMPD3 in SK-BR-3 erzeugt. Aus dieser Zelle wurde, wie oben beschrieben, RNA extrahiert und in cDNA transkribiert. Um die Primereffizienz zu testen, wurde eine Standardverdünnungsreihe der Positivkontroll-cDNA benötigt, bestehend aus Proben mit 25 ng, 12,5 ng, 3,125 ng, 0,78125 ng und 0,1953125 ng DNA. Die weiteren Schritte entsprachen der der RTqPCR, wie oben beschrieben. Die Auswertung der Rohdaten erfolgte mit dem Programm SDS2.4 (Applied Biosystems). Waren NTC und NPC auffällig, konnten die restlichen Daten nicht verwendet werden und die RTqPCR musste wiederholt werden. 
Das Programm berechnete die Ct-Werte, Kurvensteigung (slope) und Triplikatgenauigkeit R2. Durch Anwenden der untenstehenden Formel ergab sich die Primereffizienz.

$$
\text { Effizienz }[\%]=\left(10^{\wedge}(-1 / \text { slope })\right)-1
$$

R2 soll möglichst um den Wert 1,00 liegen. Primer mit einer Effizienz von 90\%-110\% wurden für weitere Versuche verwendet.

\subsubsection{Massenspektrometrie}

Die Massenspektrometrie (MS) ist eine Methode, um das Masse-zu-Ladungs-Verhältnis von Ionen zu analysieren und die Ionen in einem weiteren Schritt zu quantifizieren. Um diese Methode auch bei ungeladenen Molekülen anwenden zu können, werden diese zunächst z. B. mit Elektronen beschossen, wodurch auch sehr spezifische Fragment-Ionen entstehen können. Durch ein elektrisches Feld werden die ionisierten Moleküle dann beschleunigt und in einem Analysator vermessen.

Da die Fragment-Ionen sehr spezifisch sind, ist es möglich, bestimmte Moleküle, z. B. Ceramide oder Sphingomyeline, aus einer Probe zu analysieren und deren Gesamtmenge an Ceramiden und Sphingomyelinen mit anderen Proben zu vergleichen.

In dieser Arbeit wurden bei jedem siRNA-Transfektionsversuch nach der Isolierung der EV Zellen (wie in Kapitel 2.2.1.2) von ihrer Zelladhäsionsplatte abtrypsiniert und gezählt. Durch Zentrifugation der Zellen bei Raumtemperatur für 5 min bei $750 \mathrm{~g}$ wurde ein Zellpellet erstellt und der Überstand verworfen. Um das Zellpellet aufzuarbeiten, wurde dieses zunächst in $200 \mu$ l Acetonitril resuspendiert und die Zellen durch dreimaliges Einfrieren bei $-150^{\circ} \mathrm{C}$ und Auftauen lysiert. Nach weiterer Zentrifugation wurde der Überstand an die Metabolomics Core Facility (Dr. Frank Streit) der UMG Göttingen übergeben, welche die Proben im Rahmen einer Kooperation analysierte.

\subsubsection{MTT-Viabilitätstest}

Da durch Knock-Down (KD) einiger Gene die Zellviabilität verändert wird, wurde mit Hilfe des MTTViabilitätstests überprüft, inwiefern die Viabilität der SK-BR-3-Zellen durch KD von SMPD1, SMPD2 und SMPD3 beeinträchtigt ist.

Der Test beruht auf der Konversion des gelben löslichen Tetrazoliumsalzes MTT in ein unlösliches violettes Formazan. Diese chemische Reaktion wird von einer mitochondrialen Reduktase katalysiert und kann folglich nur von vitalen Zellen umgesetzt werden. Die Reaktion verläuft proportional zur Anzahl vitaler Zellen. Bei gleicher Zellzahl, gleichem Volumen und gleicher Inkubationszeit kann 
durch Messung der Extinktion und Normalisierung auf eine biologische Kontrollgruppe die Zellviabilität verschiedener Bedingungen (z. B. KD von SMPD1) ermittelt werden.

Dazu wurden in je zwei Wells einer 96-Wellplatte pro Bedingung 50.000 SK-BR-3-Zellen ausgesät und mit $10 \mathrm{nM}$ siRNA (bzw. siKontrolle) (3 $\mu$ l RNA iMax, 100 ml OptiMEM, 900 ml RPMI 1640 pro Well) transfiziert. Nach entsprechender Inkubationszeit (24-96 h) wurde das Medium abgesaugt, die Zellen mit $1 \mathrm{ml}$ PBS gewaschen und $500 \mu \mathrm{l}$ der 1:10 verdünnten MTT-Lösung Thiazol Blue Tetrazolium Bromide (Sigma-Aldrich) hinzugegeben. Während einer Inkubationszeit von $4 \mathrm{~h}$ konnten die Zellen das MTT verstoffwechseln, sodass sich violette Kristalle im Inkubator bildeten. Nach Absaugen der MTT-Lösung wurden $500 \mu \mathrm{l}$ des MTT-Lysepuffers auf das Well gegeben und dieser für 5-10 min auf dem Schütteltisch inkubiert, um alle Kristalle gleichmäßig zu lösen. Der MTTLysepuffer besteht aus 5\% Methansäure in zwei Teilen Isopropanol und einem Teil Dimethylsulfoxid (DMSO). Aus jedem Well wurden in Dreifachbestimmung je $100 \mu \mathrm{l}$ auf eine Photometerplatte pipettiert und die Extinktion bei $550 \mathrm{~nm}$ Wellenlänge analysiert. Durch Bildung des arithmetischen Mittels und anschließender Normalisierung auf die Kontrolle ergab sich die Zellviabilität. 


\section{Ergebnisse}

\subsection{SK-BR-3 exprimiert aSMase, nSMase1 und nSMase2}

Zunächst musste eine geeignete Zelllinie für die Versuchsreihe gewählt werden, die alle zu untersuchenden Enzyme (aSMase, nSMase1 und nSMase2) exprimiert. Dazu bot es sich an, durch Internetrecherche nach potenziellen Zellinien zu schauen, um diese danach per Western-Blot auf die Enzymexpression zu untersuchen. Die Wahl fiel auf vier verschiedene Zelllinien: (1) Die humane Brustkrebszelle MCF-7, (2) die humane Brustkrebszelle MDA-MB23, (3) die HEK-293T eine embryonale Nierenzelle, die mit einem T-Antigen transformiert wurde und (4) die SK-BR-3 Brustkrebszelllinie. Zur Überprüfung, ob die Zellen die gesuchten Enzyme exprimieren, wurden Proteinlysate der jeweiligen Zelle, welche die Arbeitsgruppe bereits hergestellt hatte, mittels einer Gelelektrophorese getrennt und mit zuvor etablierten Antikörpern markiert. Dabei stellte sich heraus, dass alle vier Zelllinien in ausreichendem Maße aSMase und nSMase1 exprimieren. Die nSMase2, fand sich in SK-BR-3 und HEK-293T, konnte allerdings für die geplanten Versuche nur in SK-BR-3 ausreichend detektiert werden. Die Wahl fiel somit auf die Mammakarzinomzelllinie SK-BR-3.

A

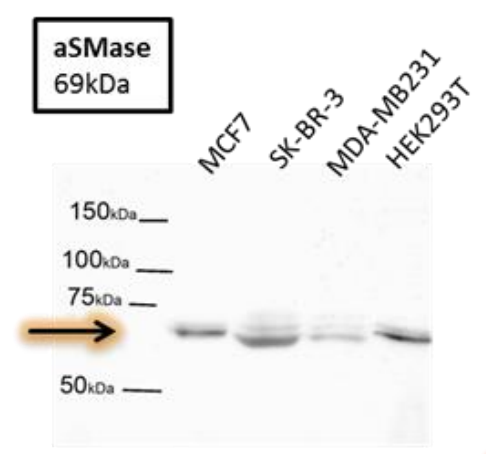

B

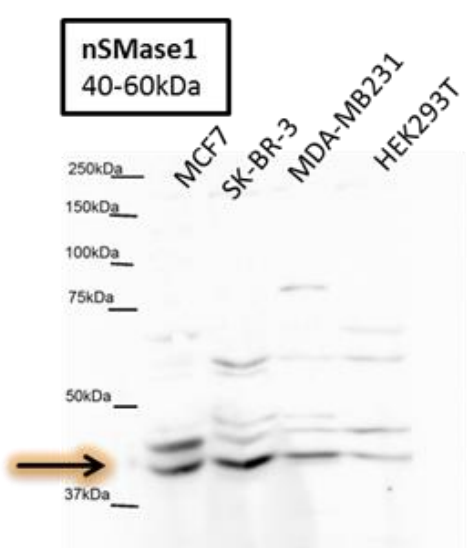

$\mathrm{C}$

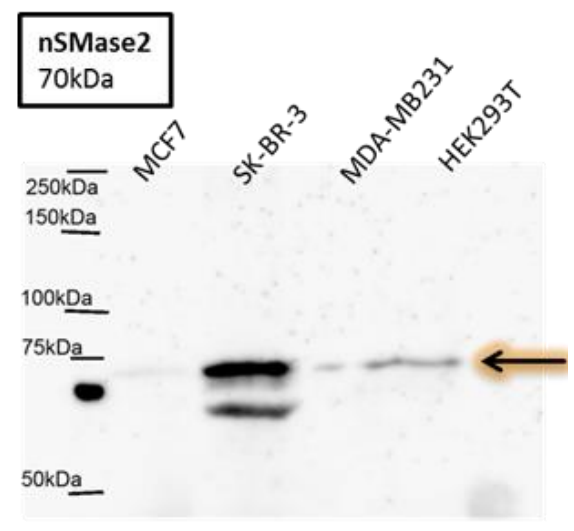

Abbildung 3.1: Western-Blot aus Gesamtlysat verschiedener Zelllinien. A: aSMase; B: nSMase1; C: nSMase2 


\subsection{Etablierung und Optimierung der siRNA- Transfektion}

\subsubsection{Bestimmung der geeigneten siRNA-Konzentration}

Um zu untersuchen, wie wirksam die käuflich erworbene siRNA gegen SMPD1-3 ist, und um gleichzeitig zu ermitteln, welche siRNA-Konzentration nötig ist, um einen suffizienten KD zu erreichen, wurden je 700.000 SK-BR-3-Zellen in 6-Well-Platten ausgesät und mit ansteigenden Konzentrationen von siRNA sowie einer Kontroll-si-RNA (siCtl) transfiziert. Nach $48 \mathrm{~h}$ wurden die Zellen lysiert. Im Western-Blot für aSMase und nSMase1 und 2 wurden die entsprechenden Proteine detektiert und die Expression quantifiziert (Abb 3.2: A). Es konnte nachgewiesen werden, dass bereits $10 \mathrm{nM}$ siRNA für alle drei SMPDs einen ausreichenden KD erzielten (Abb 3.2: B). Dies wurde auch mittels RT-qPCR bestätigt (s. Kapitel 3.2.2.2). Aufgrund dieser zusammengefassten Ergebnisse wurde die einzusetzende siRNA-Konzentration auf $10 \mathrm{nM}$ für die späteren Versuche festgelegt.

A

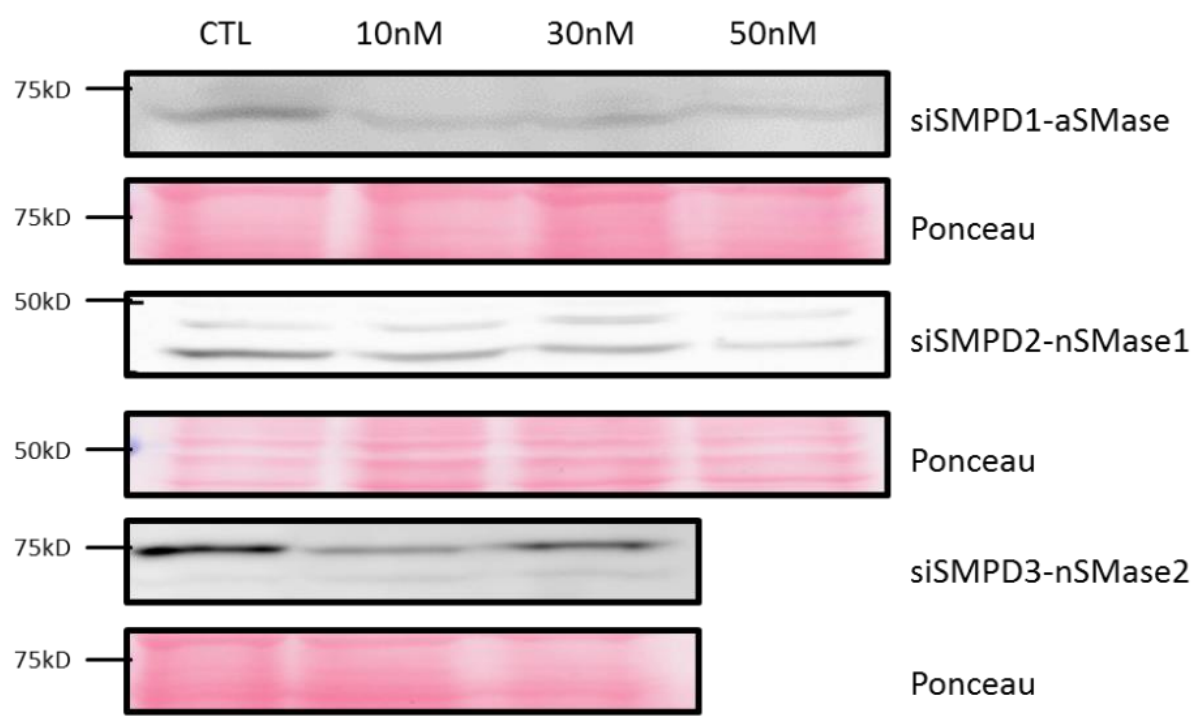

B

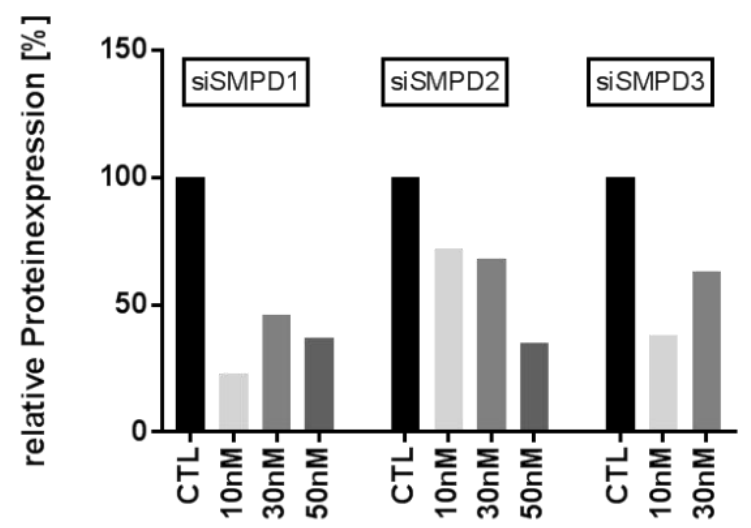


Abbildung 3.2: Bestimmung der geeigneten siRNA A: SMasen-Western-Blot nach KD von SMPD1, SMPD2 und SMPD3. Effekt unterschiedlicher si-RNA-Konzentrationen. B: Relative Proteinexpression nach KD von SMPD1, SMPD2 und SMPD3 mit verschiedenen Konzentrationen von siRNA gemessen im Western-Blot. Die Bandendichte aus Abb. 3.2A wurde mit Image J quantifiziert und auf die Kontrolle normalisiert. $(\mathrm{n}=1)$

\subsubsection{Bestimmung der optimalen Inkubationszeit}

\subsubsection{Messung der Proteinexpression nach Knock-Down im Western-Blot}

Zur Klärung der Frage, nach welcher Inkubationszeit die SK-BR-3-Zellen die siRNA aufgenommen haben und diese ihre volle Wirkung erreicht, wurde ein Zeitreihenversuch durchgeführt. Hierbei wurden erneut SK-BR-3-Zellen in 6-Well-Platten ausgesät. Da 700.000 Zellen, optisch betrachtet, im letzten Versuch als zu wenig erschien, wurde die Zellzahl auf 1.000.000 Zellen pro Well erhöht. Die Zellen wurden im Anschluss mit $10 \mathrm{nM}$ siRNA transfiziert. Für jede transfizierte siRNA (siSMPD1, siSMPD2, siSMPD3) wurde nach je 24 h, 48 h, 72 h und 96 h der Versuch beendet und Proteinlysate hergestellt. Im Western-Blot zeigte sich ein suffizienter KD bereits nach $24 \mathrm{~h}$, der aber auch nach $96 \mathrm{~h}$ noch erhalten blieb (Abb. 3.3). Die späteren Versuche konnten also in einem Zeitraum von bis zu vier Tagen mit guter Aussagekraft durchgeführt werden.

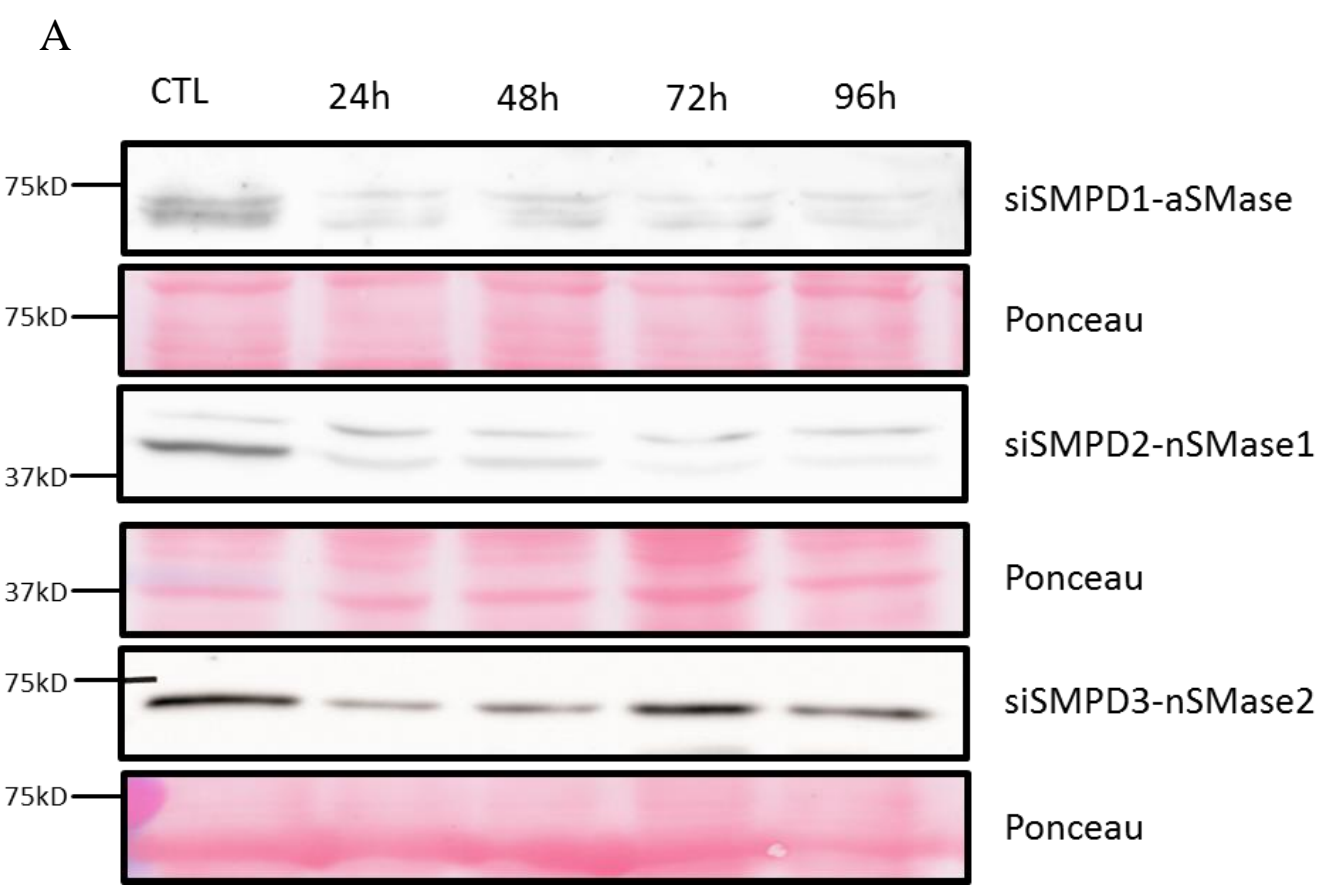


B

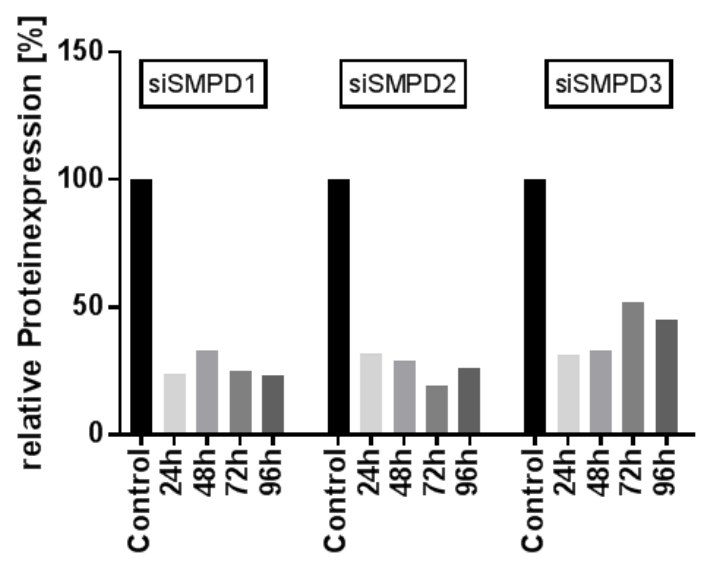

$\mathrm{C}$

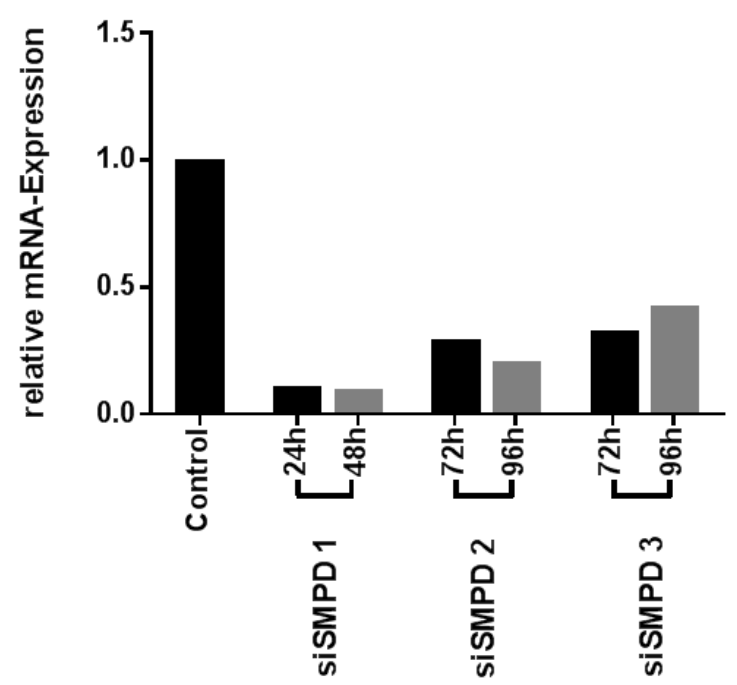

Abbildung 3.3: Bestimmung der geeigneten Inkubationszeit. A: Zeitreihe nach SMasen-KD im WesternBlot von SMPD1, SMPD2 und SMPD3. B: Relative Proteinexpression nach KD von SMPD1, SMPD2 und SMPD3 nach 24 h, 48 h, 72 h und 96 h gemessen im Western-Blot. Die Bandendichte aus Abb. 3.3: A wurde mit Image J quantifiziert und auf die Kontrolle normalisiert. $(n=1) C$ : Relative mRNA-Expression nach KD von SMPD1, SMPD2 und SMPD3 nach unterschiedlich langer Inkubationszeit gemessen mittels RTqPCR. Die Werte wurden auf die Kontrolle normalisiert. $(n=1)$

\subsubsection{Messung der mRNA-Transkription nach Knock-Down in der RTqPCR}

Parallel zum o. g. Versuch wurde die Herunterregulation der jeweiligen mRNA durch die drei siRNAs (siSMPD1, siSMPD2 und siSMPD3) analysiert. Um den KD überprüfen, wurden die mRNAs nach $24 \mathrm{~h}, 48 \mathrm{~h}, 72 \mathrm{~h}$ und $96 \mathrm{~h}$ isoliert und mittels RTqPCR quantifiziert. Die erhaltenen Resultate entsprachen denen der Western-Blots. Auch auf mRNA-Ebene war der KD suffizient und bis zu $96 \mathrm{~h}$ stabil (Abb. 3.3: C).

\subsubsection{Keine Beeinträchtigung der Zellviabilität durch Knock-Down von SMPD1, SMPD2 und SMPD3}

Da es möglich schien, dass der KD von für die Zelle so zentralen Genen wie SMPD1, SMPD2 und SMPD3 die Zellviabilität beeinträchtigen könnte, wurde diese mittels des MTT-Assays überprüft. Dazu wurden die Zellen nach $48 \mathrm{~h}$ und nach $96 \mathrm{~h}$ lysiert und die Konversion des Tetrazoliumsalzes MTT in Formazan photometrisch bestimmt. Verglichen mit der Kontrolle war die Viabilität sowohl nach $48 \mathrm{~h}$ als auch nach $96 \mathrm{~h}$ durch die Transfektion bei den mit siSMPD1, siSMPD2 und siSMPD3 behandelten Zellen nicht beeinträchtigt (Abb.3.4). 


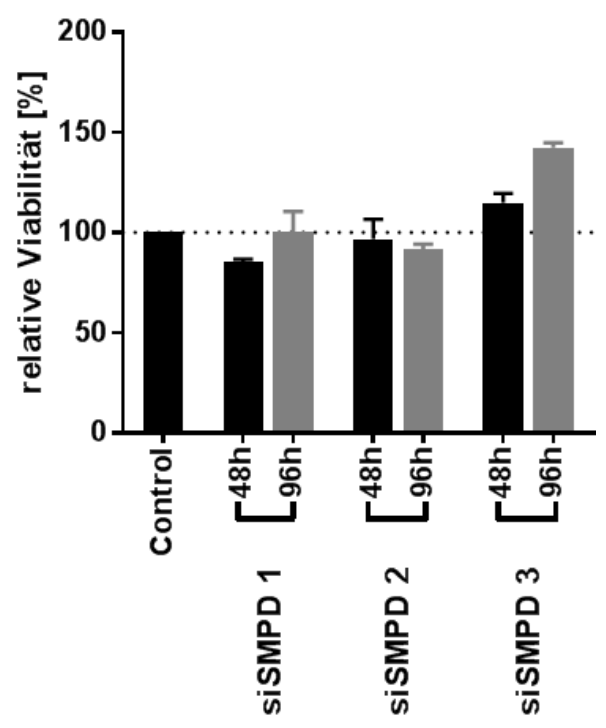

Abbildung 3.4: Bestimmung der Zellviabilität. Relative Viabilität von SK-BR-3 nach KD von SMPD1, SMPD2 und SMPD3 nach $48 \mathrm{~h}$ und $96 \mathrm{~h}$ Inkubationszeit gemessen mittels MTT-Viabilitätstest. Die Absorption des MTT-Farbstoffes wurde je auf die Kontrolle normalisiert. $(n=2)$

\subsection{Vesikelisolation}

Für die Vesikelisolation wurde ein Protokoll der Arbeitsgruppe verwendet (s. Kapitel 2.2.2.1). Da per Ultrazentrifugation keine absolute Trennung in Exo und MV gelingen kann und immer eine Restüberschneidung der beiden Subpopulationen übrig bleibt, ist es sinnvoll, die EV auf ihre Marker zu untersuchen. In dieser Arbeit wurde jedoch auf eine Trennungsüberprüfung mit einem Nachweis von gängigen EV-Markern verzichtet, da die Vorergebnisse der Arbeitsgruppe (Menck et al. 2017) einen solchen Nachweis und somit die hinreichende Trennung der EV mit der gleichen Trennmethode bestätigen konnten. Zusätzlich gibt auserdem das NTA Auskunft über die Größenverteilung der gemessenen Partikel, welche ebenso als Kontrolle dient. In Abb. 3.5 ist beispielhaft die Größen- und Konzentrationsverteilung einer Exo- und einer MV-Probe dargestellt. Es zeigt sich, dass die Exo (Abb. 3.5: A) wie erwartet kleiner ausfallen als die MV (Abb. 3.5: B). 

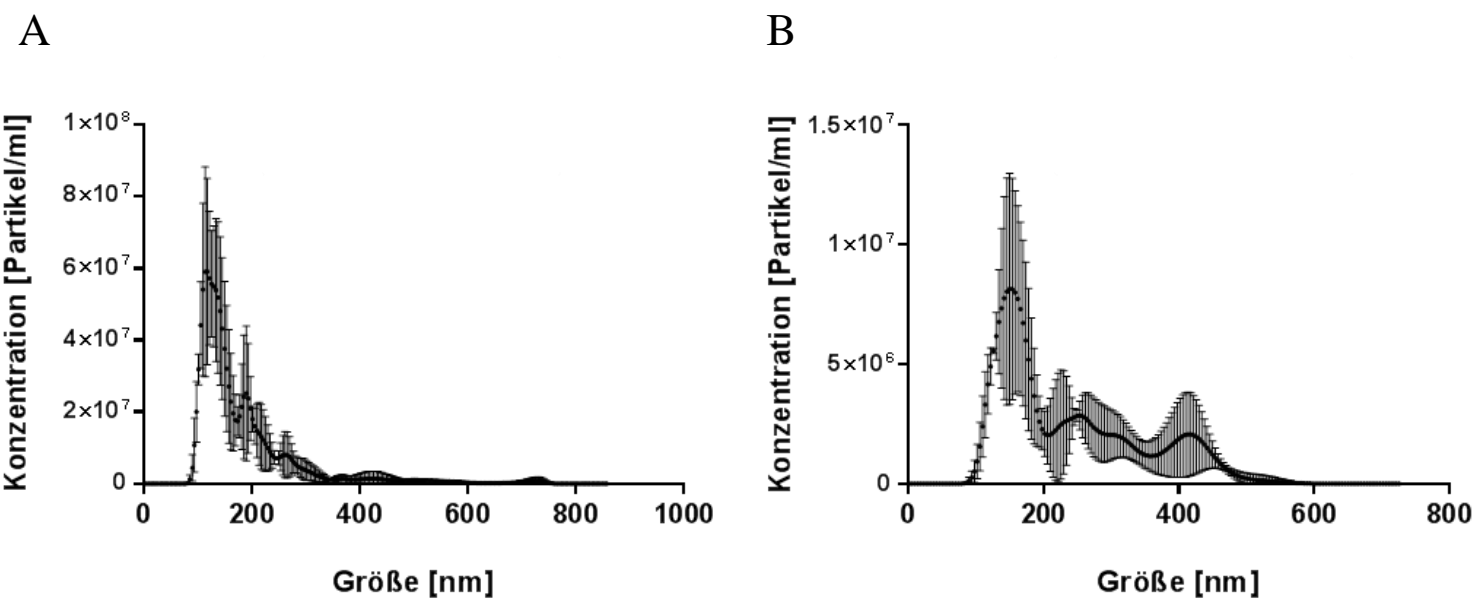

Abbildung 3.5: Beispielhafte Kurve zur Konzentrations- und Größenverteilung gemessener Exo (A) und MV (B) nach Transfektion mittels NTA. Die Kurve zeigt Mittelwert (mean) \pm Standardabweichung (SD), n=3

\subsection{Einfluss des Knock-Downs auf MV und Exo}

\subsubsection{Einfluss des Knock-Downs auf MV- und Exo-Sekretion}

Die Auswirkungen des KD von SMPD1, SMPD2 und SMPD3 auf die Produktion von MV und Exo wurde mittels NTA untersucht. Dafür wurden SK-BR-3-Zellen jeweils mit siSMPD1, siSMPD2 und siSMPD3 transfiziert und nach $48 \mathrm{~h}$ mit Exo- und MV-freien Medium versetzt, um die sezernierten EV zu sammeln. Per Ultrazentrifugation konnten Exo und MV voneinander getrennt und mittels NTA quantifiziert werden. Die gemessenen Proben zeigen einen signifikanten Abfall der Exo-Sekretion unter KD der aSMase SMPD1 (Exo-siSMPD1), bei gleichzeitig signifikanter Zunahme der MVSekretion (MV-siSMPD1) (Abb 3.6: A/B). Der KD der nSMasen SMPD2 und SMPD3 hingegen führte zu keiner signifkanten Änderung der Exo-Sekretion. Die Anzahl der sezernierten MV nahm zwar - wie aus den Vorversuchen erwartet - deutlich zu. Aufgrund der geringen Anzahl der Replikate erreichten die Änderungen jedoch nicht das Signifkanzniveau. 
A

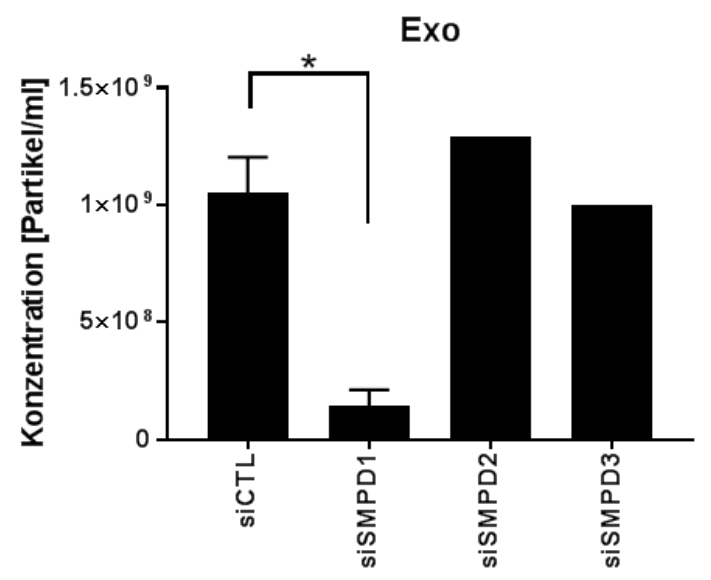

$\mathrm{C}$

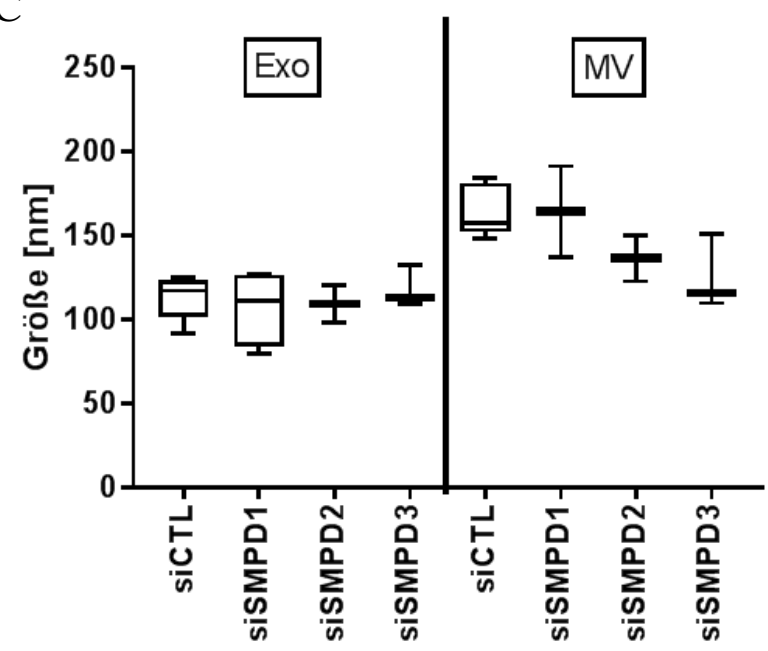

B

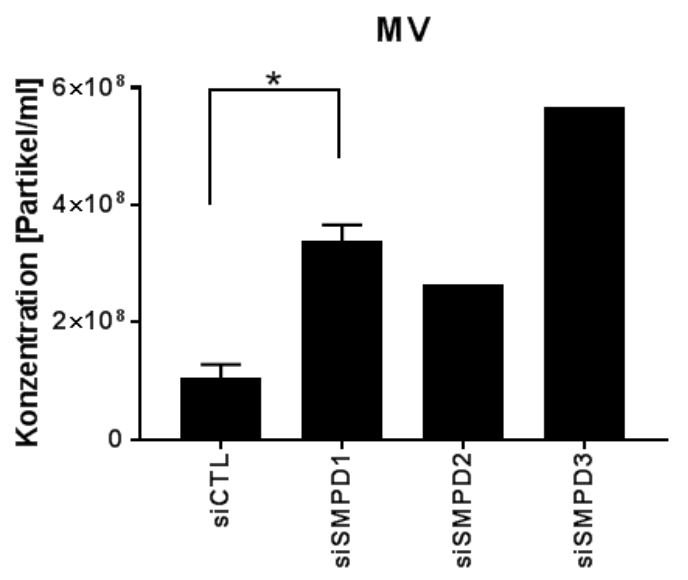

Abbildung 3.6: Einfluss des Knock Downs auf die EV-Sekretion. A/B: Konzentration von Exo und MV nach siRNA-KD verschiedener SMasen gemessen im NTA. C: Durchschnittliche Exo- und MV-Größe nach siRNA-KD verschiedener SMasen gemessen im NTA (mean \pm SD, p-Wert >0,05).

\subsubsection{Einfluss des Knock-Downs auf die MV- und Exo-Größe}

Um zu untersuchen, ob sich außer der Konzentration der EV unter Einfluss des KD von SMPDI, SMPD2 und SMPD3 auch deren Größe verändert, kann ebenso wie für die Konzentrationsmessung die NTA verwendet werden. Da die Ultrazentrifugation die EV abhängig von ihrem Sedimentationskoeffizienten trennt und die EV unterschiedliche Dichte besitzen oder z. B. Exo auch größere Aggregate bilden können, ist keine absolute Trennung von Exo und MV möglich. Dennoch ermöglicht die Größenmessung der EV recht gute Überprüfung, ob Exo und MV hinreichend voneinander getrennt wurden.

Unter Berücksichtigung der o. g. Einschränkungen konnte mittels NTA gezeigt werden, dass der KD von SMPD1-3 keinen Einfluss auf die Exo-Größe hat, da Exo-siSMPD1, Exo-siSMPD2 und Exo- 
siSMPD3, verglichen mit der Kontrolle, eine vergleichbare Durchschnittsgröße besitzen (Abb 3.6: C). Ihre Größe entspricht der erwarteten von 50-150 nm. Bei Betrachtung der MV hingegen ergab sich unter KD der nSMase1 und nSMase2 eine gewisse Tendenz zur Produktion kleinerer MV. Dies war jedoch statistisch nicht signifikant.

\subsection{3 Überprüfung des suffizienten Knock-Downs}

Da eine generelle Aussage über den Einfluss der SMasen auf die EV-Produktion nur dann getroffen werden kann, wenn sichergestellt ist, dass der KD auch bei diesem Versuch tatsächlich funktioniert hat, ist eine Überprüfung mittels Western-Blot parallel zum aktuellen Versuch unerlässlich. Da man für die Isolierung von EV nur das Medium und nicht die Zellen selbst benötigt, kann in den verbleibenden Zellen die SMasen-Expression mittels Western-Blot und RT-qPCR untersucht werden. Dabei ließ sich bestätigen, dass die Proteinexpression von aSMase und nSMase 1 deutlich und die von nSMase2 ausreichend vermindert war (Abb 3.7: A,C). Parallel dazu lag die relative Expression der kodierenden mRNA für aSMase, nSMase1 und nSMase2 deutlich unter 30\%, wodurch man zusammengefasst von einem suffizienten KD in den in den vorigen Kapiteln geschilderten Versuchen ausgehen kann (Abb. 3.7: B). 


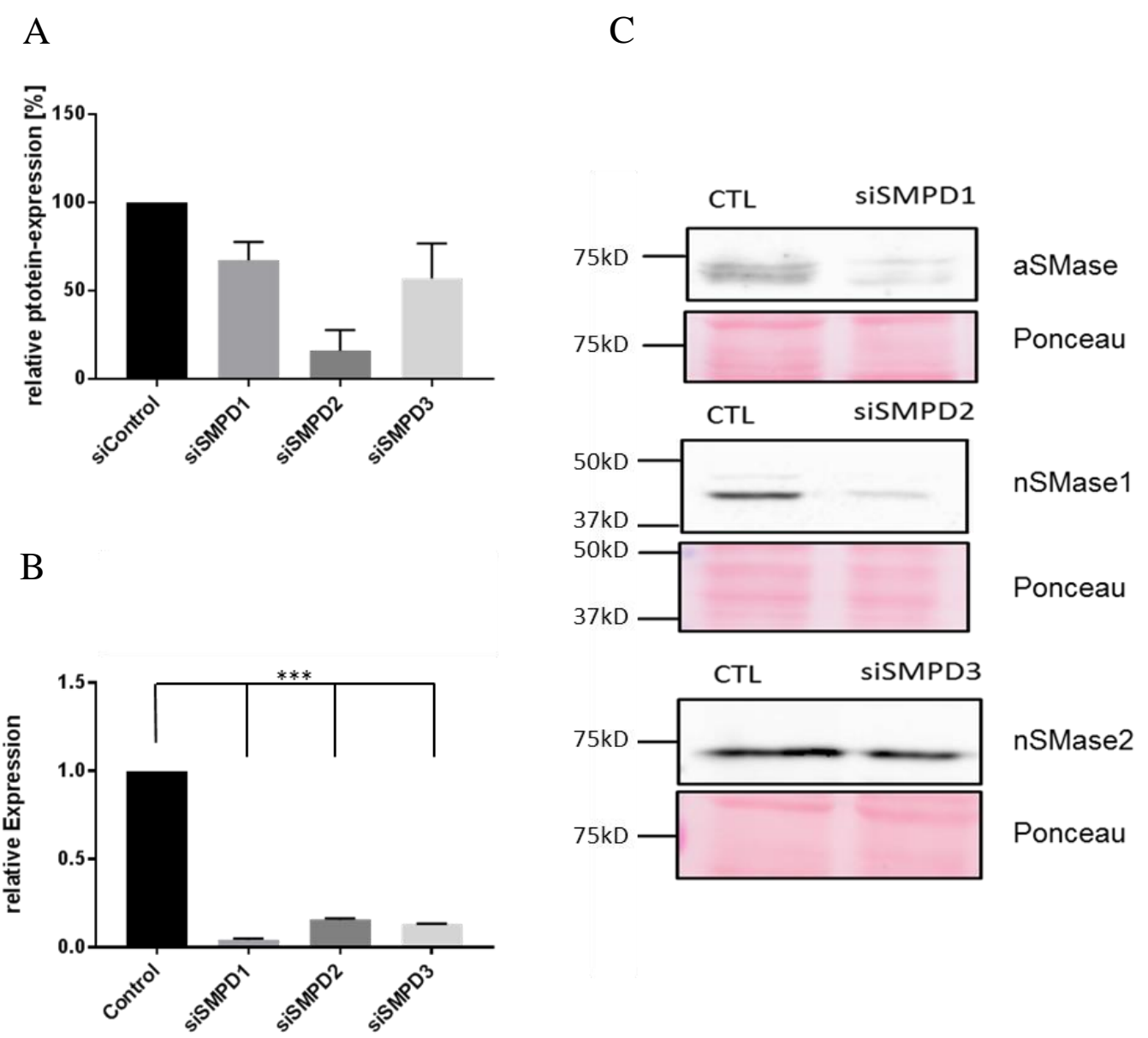

Abbildung 3.7: Überprüfung des suffizienten Knock-Downs. A: Relative Proteinexpression nach KD von SMPD1, SMPD2 und SMPD3 gemessen im Western-Blot. Die gemessenen Proben entstammen den gleichen Zellen, die für die EV-Messung herangezogen wurden. Die Bandendichte (s. Abbildung 3.5C) wurde mit Image J quantifiziert und auf die Kontrolle normalisiert. B: Relative mRNA-Expression nach KD von SMPD1, SMPD2 und SMPD3. Die Bandendichte wurde mit Image J quantifiziert und auf die Kontrolle normalisiert. Ein p-Wert < $0,005 \%$ wird durch $* * *$ abgebildet. Diagramme A \& B zeigen mean \pm SD, $n=3$ C: Western-Blot der SK-BR-3Zellen nach KD von SMPD1, SMPD2 und SMPD3 nach Isolation der sezernierten EV.

\subsection{Kein Einfluss des Knock-Downs einer SMase auf die Expression anderer SMasen}

Da durch den KD einer SMase die Aktivität des Enzyms reduziert wird, stellte sich die Frage, ob durch den KD einer SMase die anderen vermehrt exprimiert werden. Um diese Frage zu klären, wurde bei Zellen, die mit siRNA transfiziert wurden, mit Hilfe der RTqPCR die mRNA Expression gemessen.

Dabei ergab sich, dass der KD einer SMase keinen Einfluss auf die Expression der anderen ausübt (Abb. 3.8). In diesem Versuch wurden aus transfizierten SK-BR-3-Zellen Zelllysate aus 6-Well Zell- 
adhäsionsplatten erstellt und mit RTqPCR analysiert. Die Probe, die mit siSMPD1 transfiziert wurde, wurde so zum Beispiel anschließend auf ihre Expression von SMPD1-3 untersucht.

A

SMPD1

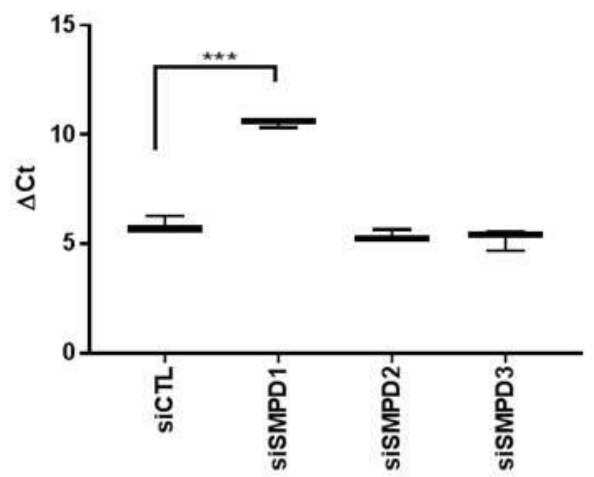

$\mathrm{C}$

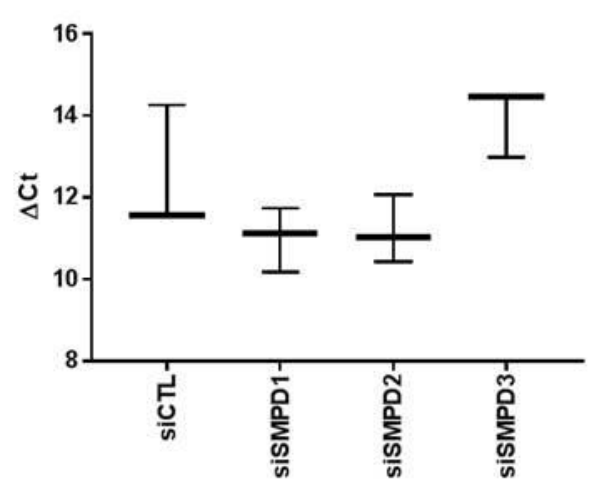

B

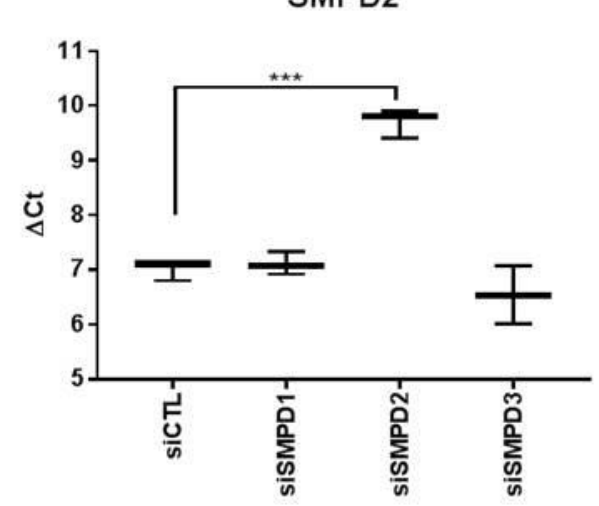

Abbildung 3.8: Einfluss des Knock-Downs einer SMase auf die Expression der anderen. Relative mRNAExpression nach KD von SMPD1, SMPD2 und SMPD3 gemessen in der RTqPCR und als $\triangle \mathrm{Ct}$-Wert (s. Kapitel 2.2.6.3) angegeben. A zeigt die Expression von SMPD1. B zeigt die Expression von SMPD2. C zeigt die Expression von SMPD3. Abgebildet sind je drei biologische Replikate. Die Diagramme zeigen mean $\pm \mathrm{SD}, \mathrm{n}=3$, ein $\mathrm{p}$-Wert $<0,005 \%$ durch *** abgebildet.

\subsection{Massenspektrometrische Analyse von Ceramiden und Sphingomyelinen}

Der Einfluss der SMasen als Hydrolasen von Sphingomyelinen auf die MV- und Exo-Sekretion ist am ehesten durch ihre maßgebliche Rolle im Ceramidsignaling begründet. Da sie wichtige Enzyme eines von zwei Ceramid produzierenden Wegen sind, ergibt sich die These, dass ihr Produkt Ceramid, welches, wie oben beschrieben, diverse Einflüsse auf Zellwachstum, Apoptose und Stressreaktionen 
von Zellen besitzt, eine Schlüsselposition einnimmt. Die Hemmung der SMasen führt zu Akkumulation von Sphingomyelinen und Verminderung von Ceramiden.

Mittels Massenspektrometrie wurden siSMPD1- und siSMPD2- Zellen auf ihren Gehalt von Ceramiden und Sphingomyelinen untersucht. Bei siSMPD1 konnte wie erwartet ein signifikanter Abfall des Ceramidgehalts nachgewiesen werden (Abb. 3.9: A/B). Der Sphingomyelingehalt ist nicht angestiegen (Abb. 3.9: C). Um jedoch zu klären, weshalb dieser nicht ansteigt, oder ob es daran liegt, dass der normale Grundgehalt des Sphingomyelins bereits sehr hoch ist, bzw. eine Gegenregulation durch andere Enzyme stattfindet, müssen weitere Versuche folgen.

A
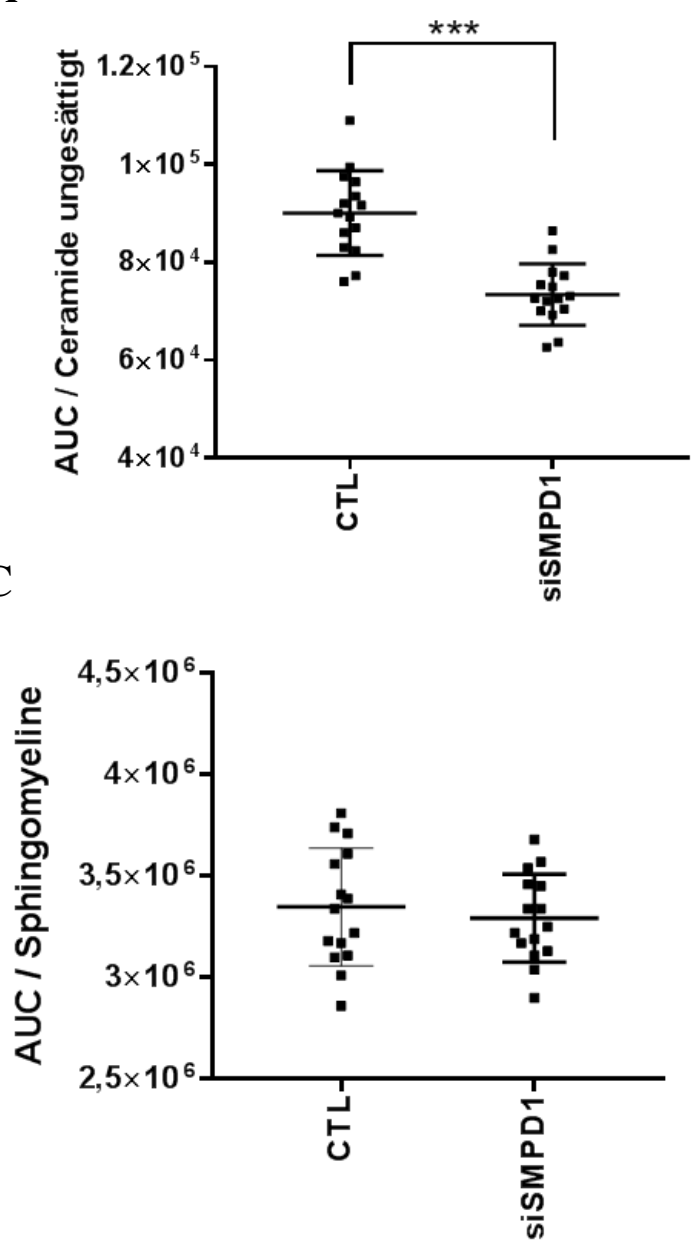

B

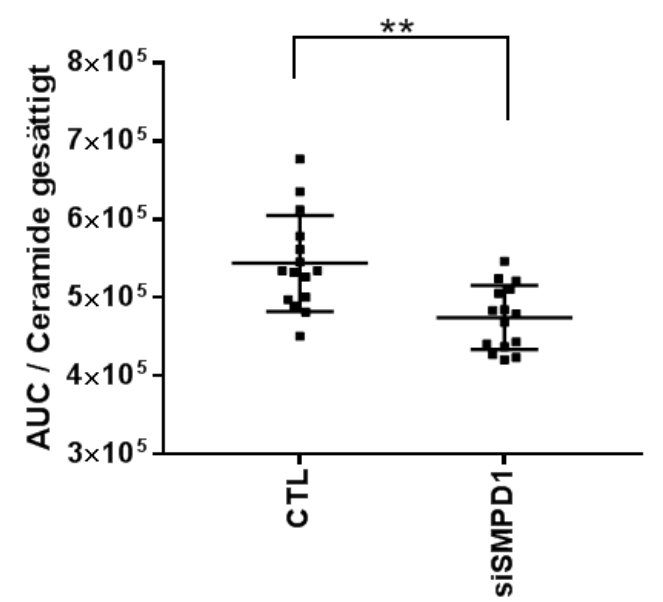

Abbildung 3.9: Messung des Ceramid- und Sphingomyelingehalts in SK-BR-3 nach Knock-Down von SMPD1. Ceramide ungesättigt (A), (B) Ceramide gesättigt und Sphingomyeline (C) wurden mit ihrem spezifischen Fragment Ion $262,2547 \mathrm{~m} / \mathrm{z}$ (A), 264,2687 m/z (B) und $184,0742 \mathrm{~m} / \mathrm{z}$ (C) mittels Massenspektrometrie gemessen. Dargestellt sind je fünf technische Replikate aus je drei biologischen Replikaten. Diagramme zeigen mean $\pm \mathrm{SD}, \mathrm{n}=15$, Ein $\mathrm{p}$-Wert $<0,5 \%$ wird durch $* *,<0,05 \%$ durch $* * *$ abgebildet. AUC, Fläche unter der Kurve, area under curve 
Da durch den KD von SMPD2 keine signifikante Änderung der Exo- und MV-Konzentrationen zu verzeichnen war, ergab sich die These, dass dieser keine Änderung der Ceramid- und Sphingomyelinmenge bewirkt. Wie erwartet konnte bei siSMPD2 keine signifikante Änderung der Ceramid- und Sphingomyelinkonzentrationen nachgewiesen werden (Abb. 3.10: A-C).

A

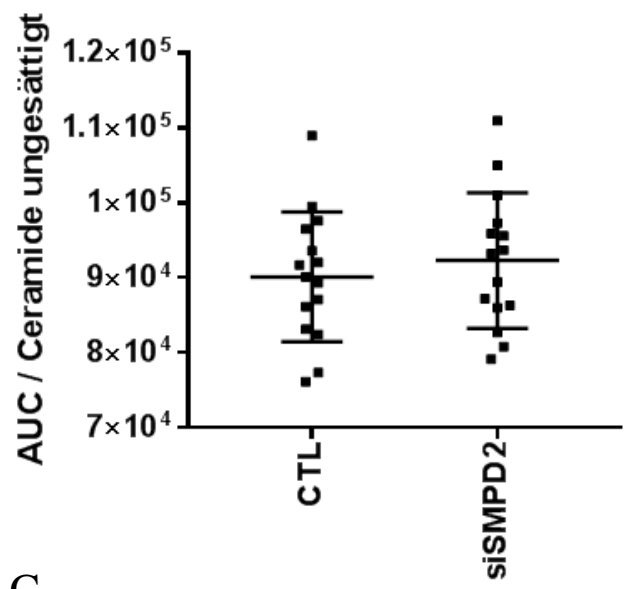

$\mathrm{C}$

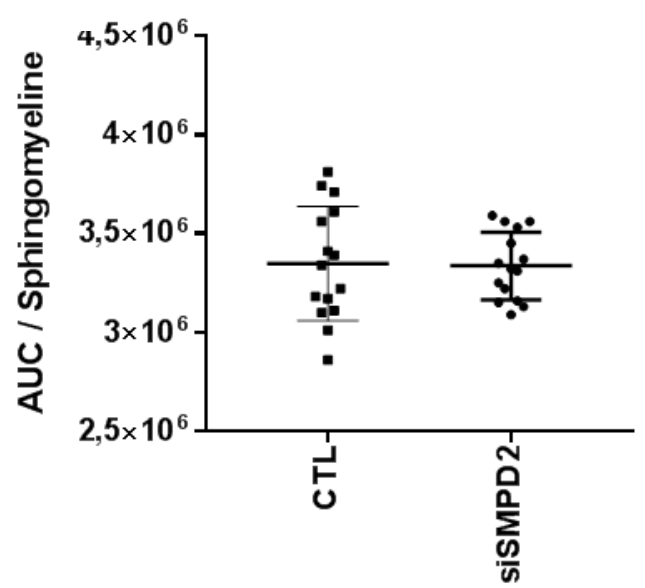

$\mathrm{B}$

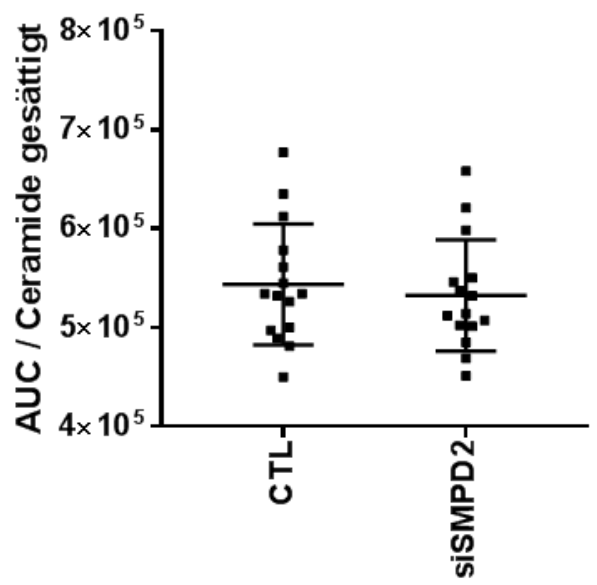

Abbildung 3.10 Messung des Ceramid- und Sphingomyelingehalts in SK-BR-3 nach Knock-Down von SMPD2. Ceramide ungesättigt (A), (B) Ceramide gesättigt und Sphingomyeline (C) wurden mit ihrem spezifischen Fragment Ion $262,2547 \mathrm{~m} / \mathrm{z}$ (A), 264,2687 m/z (B) und $184,0742 \mathrm{~m} / \mathrm{z}$ (C) mittels Massenspektrometrie gemessen. Dargestellt sind je fünf technische Replikate aus je drei biologischen Replikaten. Diagramme zeigen mean $\pm \mathrm{SD}, \mathrm{n}=15$ 


\section{Diskussion}

Schon länger ist bekannt, dass der Ceramid-Pathway und die Funktion der Sphingomyelinasen die Sekretion von EV beeinflussen. Vor Kurzem wurde außerdem beschrieben, dass sie sowohl die MVals auch die Exo-Sekretion modulieren (Trajkovic et al. 2008; Kucharzewska und Belting 2013; Menck et al. 2017). Da EV aktuell immer mehr in den Fokus neuer diagnostischer Methoden und therapeutischer Strategien rücken (Vader et al. 2014; Moloudizargari et al. 2018), ist ein besseres Verständnis von deren Sekretion und Produktion unerlässlich. In dieser Arbeit wurde untersucht, inwiefern die Familie der SMasen die EV-Sekretion beeinflusst und ob sich Anhaltspunkte für Ceramide als funktionelle Mediatoren finden lassen. Am eindeutigsten konnte dabei eine Rolle für die aSMase belegt werden, deren KD zu einem signifikanten Shift von der Exo- zur MV-Sekretion führt.

\subsection{Bestimmung der Rahmenverhältnisse für die Transfektion}

Da durch den KD mit siRNA die Sphingomyelinaseaktivität möglichst weit aufgehoben werden soll, ist es wichtig, die Konditionen der siRNA-Transfektion bzgl. Dosis und Zeitverlauf zu optimieren. Durch zu geringe Konzentration der siRNA, die in die SK-BR-3-Zellen aufgenommen werden, würde der KD nur unzureichend funktionieren und sich somit kaum oder keine Veränderungen im Zellmetabolismus ergeben. Da Zellen außerdem bemüht sind, die Beeinträchtigung durch die siRNA zu beseitigen, ist davon auszugehen, dass die siRNA-Wirkung nach einiger Zeit nachlässt und dadurch die Versuche unbrauchbar würden. Je nach Expression der SMasen ist auch vorstellbar, dass es unterschiedlich lang dauern kann, bis die maximale Wirkung der siRNA eingetreten ist. Die Bestimmung der optimalen Inkubationszeit und der siRNA-Konzentration ist somit für die Auswertung der darauf aufbauenden Versuche unerlässlich. Damit die herunterregulierten SMasen auch untereinander noch vergleichbar bleiben, musste des Weiteren eine siRNA-Konzentration und eine Inkubationszeit gewählt werden, die für alle zu untersuchenden Gene die besten Bedingungen liefert.

Da es sich bei den SMasen um für die SK-BR-3-Zellen lebenswichtige Enzyme handelt, musste auch überprüft werden, ob die Zellviabilität durch den KD eingeschränkt wird. Die Viabilität ist des Weiteren abhängig von der Zellkonfluenz in den Zellkulturplatten. Zu hohe, aber auch zu niedrige Zellkonfluenz verringert die Zellviabilität (Abo-Aziza und Zaki 2017). Mit dem MTT-Test konnte so gleichzeitig überprüft werden, ob der KD die eingesetzte optische Zellkonfluenz oder die Inkubationszeit die Viabilität der Zellen nachhaltig beeinflusst. Wie in den Ergebnissen 3.2 gezeigt, wurde die Viabilität durch die KD nicht beeinflusst und die Bedingungen von $10 \mathrm{nM}$ siRNAKonzentration, 50-60\% optische Zellkonfluenz und eine Inkubationszeit von 72 h gewählt. 


\subsection{Sphingomyelinasen beeinflussen die Exo- und MV-Sekretion}

In dieser Arbeit konnte für den KD der sauren Sphingomyelinase eine Veränderung sowohl in der MV- als auch in der Exo-Sekretion gefunden werden. Durch den KD ergab sich eine Abnahme der Exo- zugunsten einer Zunahme der MV-Sekretion. Diese Ergebnisse stehen im Einklang mit den Daten von Menck et. al. (2017), die durch die Inhibition von nSMasen mit GW4869 (welche die gleiche Reaktion katalysieren) die gleichen Effekte nachweisen konnten. Erst kürzlich erschien eine Arbeit von Hong et al. (2019), die eine verminderte Exo-Sekretion unter Inhibition der aSMase mit Amitryptilin verzeichneten. Bianco et al. (2009) beschrieben hingegen, dass durch Inhibition der aSMase eine Abnahme der MV-Sekretion bewirkt wird, während bei Menck und Mitarbeitern durch die Inhibition der nSMasen die MV-Sekretion zunimmt (Menck et al. 2017). Jedoch bezieht sich die Forschung Biancos (2009) auf die akuten Effekte von ATP-induzierter MV-Sekretion 20 min nach der $\mathrm{P} 2 \mathrm{X}_{7}$ Aktivierung in Gliazellen und Astrozyten. Da die Stimulation von Zellen mit ATP jedoch sowohl die MV- als auch die Exo-Sekretion ungleichmäßig erhöht (Drago et al. 2017) und die Ergebnisse von Menck et al. (2017) und dieser Arbeit von unstimulierten epithelialen Tumorzellen nach mehreren Stunden der Inhibition bzw. des KD stammen, sind die Ergebnisse Biancos im Bezug auf den Einfluss des SMase-KD mit denen Mencks und dieser Arbeit kaum vergleichbar. Es erscheint darüberhinaus durchaus denkbar, dass verschiedene Zellarten unterschiedliche EV-BiogeneseMaschinerien besitzen, die durch unterschiedliche Regulatoren gesteuert werden (van Niel et al. 2018). Ein Vergleich der mesenchymalen Glia- mit epithelialen Tumorzellen wäre dann nur schwer möglich.

Durch den KD der nSMasen konnte in dieser Arbeit keine Veränderung der Exo-Sekretion nachgewiesen werden. Bei den MV scheint sich durch den KD ein Trend zu einer gesteigerten MVProduktion abzuzeichnen. Diese Daten erreichen jedoch nicht das Signifkanzniveau. Ein Grund könnte die geringe Anzahl an Wiederholungen sein. Eine andere mögliche Erklärung könnte in der Tatsache liegen, dass stets nur eine der beiden nSMase1 oder nSMase2 herunterreguliert wurde. Menck et al. (2017) hatten hingegen den Inhibitor GW 4869 verwendet, der gleichzeitig beide nSMasen blockiert und $\mathrm{zu}$ einer stärkeren Hemmung führt, was auch an der deutlicheren Abnahme der Ceramidkonzentration in deren Arbeit abgelesen werden kann. Möglicherweise hätte in unseren Versuchen ein simultaner Doppel-KD von SMPD2 und SMPD3 ähnliche Ergebnisse erbracht.

Passend zu obiger Argumentationslinie ist die Beobachtung, dass in der vorliegenden Arbeit der KD jeweils nur partiell war. Wie in den Ergebnissen gezeigt, konnte die relative Expression der nSMasen auf mRNA-Ebene nur auf ca. $15 \%$ reduziert werden, die der aSMase jedoch auf ca. $4 \%$. Hier könnten weiterführende Experimente unter Anwendung der CRISPR/7Cas-Methodologie, die prinzipiell einen vollständigen Knock-Out von Genen erlaubt, Klärung bringen.

Außerdem ist sicherlich die subzelluläre Lokalisation der SMasen und der dort herrschende jeweilige pH-Wert für deren Einfluss auf die EV-Sekretion bedeutend. Während sich die aSMase mit einem 
sauren pH-Optimum in Lysosomen und auf der äußeren Schicht der Plasmamembran befindet, üben die nSMasen mit einem neutralen pH-Optimum ihre Funktion vor allem an der inneren Schicht der Plasmamembran aus (Zumbansen 2001; UniProt Consortium 2019a; 2019b). Je nach dem Milieu, in dem die Enzyme ihre Reaktionen katalysieren, verfügen sie über unterschiedliche katalytische Aktivität, woraus dann auch unterschiedliche intrazelluläre Produktkonzentrationen, in diesem Fall der Ceramide, resultieren. Nimmt man Ceramide als Mediatoren für die veränderte EV-Sekretion an, scheint es logisch, dass der KD der aSMase in Tumorzellen, in denen der $\mathrm{pH}$ aufgrund des veränderten (Glucose)-Metabolismus häufig saure Werte annimmt (Tannock und Rotin 1989) zu größeren EVSekretionsveränderungen führt, als der KD der nSMasen, deren katalytische Aktivität in einem sauren Milieu ohnehin reduziert ist. Die Tatsache, dass in dieser Arbeit mit Brustkrebszellen gearbeitet wurde, und somit ein pH-Wert näher am Optimum der aSMase postuliert werden muss, könnte erklären, weshalb für die aSMase eindeutigere Ergebnisse gefunden wurden. Gestützt wird diese These auch durch Forschungen, die darlegen konnten, dass die Exo-Sekretion in einem sauren pHMilieu zunimmt (Parolini et al. 2009). Sollte die aSMase für diesen Effekt verantwortlich sein, müsste die Exo-Sekretion bei aSMase-KD deutlich abnehmen, was in dieser Arbeit entsprechend gezeigt werden konnte.

Bereits früher konnten Ceramide als Mediatoren für die Beladung von Exosomen in die Multivesikulären Endosomen detektiert werden, was einen wichtigen Schritt in der Ausschleusung aus der Zelle darstellt (Trajkovic et al. 2008). Denkbar ist also, dass durch den KD der SMasen und die damit verbundene Abnahme der Ceramidkonzentration die Beladung der Multivesikulären Endosomen verringert wird und folglich auch keine bzw. weniger Exo entstehen können. Eine andere Möglichkeit wäre, dass der KD der aSMase nicht nur zur Entstehung von weniger Intraluminalen Vesikeln und somit auch weniger Exo führt, sondern bewirkt, dass mehr Multivesiküläre Endosomen mit Lysosomen verschmelzen und degradiert werden.

Menck et al. (2017) hatten vermutet, dass die Effekte der nSMasen-Inhibition auch auf die vermehrte Sphingomyelinmenge selbst zurückzuführen sei. Ihre Hypothese beruht darauf, dass die Vernetzung der inneren und äußeren Plasmamembranschicht Auswirkungen auf die Membrankrümmung, die sog. Kurvatur, hat (Tanasescu et al. 2016), wodurch die Bildung der EV erleichtert werden kann. Menck et al. (2017) hatten nachweisen können, dass durch die Inhibition der nSMasen Sphingomyeline akkumulieren. Da gleichzeitig die Sphingomyelin-abhängige Vernetzung der Schichten bei Abwesenheit von Cholesterol verstärkt wird (Róg et al. 2016), wäre es denkbar, dass der hohe Cholesterolgehalt in der Plasmamembran (van Meer et al. 2008) die Bildung von Vernetzungen verringert und damit die Bildung von MV verstärkt. Gleichzeitig würde der niedrige Cholesterolgehalt in der Membran der Multivesikülären Endosomen die Sphingomyelin-abhängigen Vernetzungen eher verstärken und somit die Bildung von Exo eher verringern. Bei ihrer elektronmikroskopischen Untersuchung von Zellen, in denen nSMase1 und nSMase2 inhibiert wurden, wurde jedoch keine 
Änderung in der Plasmamembranmorphologie sichtbar, sodass Menck et al. ihre Hypothese nicht beweisen konnten (Menck et al. 2017). In dieser Arbeit konnten durch KD der aSMase, wie bereits beschrieben, ähnliche Sekretionsveränderungen nachgewiesen werden wie durch die Inhibition der nSMasen bei Menck et al. (2017). Diese Veränderungen konnten auch bei nahezu gleichbleibenden Sphingomyelinkonzentrationen gezeigt werden. Daher ist der Einfluss von Sphingomyelin als direkter Mediator der EV-Sekretion auch nach dem Stand dieser Arbeit eher unwahrscheinlich. Dennoch müssten, wie auch von Menck et al. (2017) bereits angemerkt, hier weitere Forschungen erfolgen, um diese These zu prüfen.

\subsection{Detektion und Trennung der EV}

In dieser Arbeit wurde wurden EV mit Hilfe der Ultrazentrifugation isoliert und in MV und Exo bzw. P14 und P100 getrennt (s. Kapitel 2.2.2.1). Da die Ultrazentrifugation Partikel nach ihrem Sedimentationskoeffizienten separieren kann und die Vesikel auch innerhalb der Subpopulationen in Masse und Größe und somit auch im Sedimentationskoeffizienten variieren (Willms et al. 2016), ist es nicht möglich, eine Trennung der EV ohne geringfügige Überschneidungen mithilfe dieser Methode zu erreichen. Die 2017 veröffentlichten Voruntersuchungen der Arbeitsgruppe von Menck et al., bei denen die EV sowohl elektronenmikroskopisch hinsichtlich ihrer Größe als auch durch proteinchemischen Nachweis typischer Exo- bzw. MV-Marker charakterisiert wurden, konnten zeigen, dass sich bei dem verwendeten Trennprotokoll hauptsächlich MV in der P14 und Exo in der P100 Fraktion finden lassen. In dieser Arbeit wurde das gleiche, bereits gut ausoptimierte Trennprotokoll wie bei Menck et al. (2017) verwendet und somit auf eine erneute Markerkontrolle verzichtet.

Auch wenn die Ultrazentrifugation als Trennmethode in der aktuellen Forschung als „Goldstandard“ gilt (Muller et al. 2014; Doyle und Wang 2019), gibt es zur Zeit eine Vielzahl an Möglichkeiten, die EV voneinander zu trennen. So gibt es größenbasierte Methoden wie die Ultrafiltration oder chromatografische Methoden, verschiedene präzipitationsbasierte Techniken und - besonders für Exo - antikörperbasierte Techniken wie ELISA (Enzym linked Immunosorbent Assay) (Doyle und Wang 2019). All diese Techniken haben Vor- und Nachteile und sind untereinander kaum vergleichbar, wenn es um Konzentrations- und Größenmessungen von EV geht. Mehrere kürzlich erschienene Publikationen zeigen nämlich, dass sich die Partikelkonzentration, die durchschnittliche EV-Größe, die EV-Größenvarianz und auch die Proteinkonzentration auf den EV deutlich unterscheidet, wenn eine andere Isolationstechnik verwendet wurde (Muller et al. 2014; Doyle und Wang 2019; Patel et al. 2019). Es ist daher in dieser Arbeit nicht sinnvoll, von absoluten Konzentrationen zu sprechen, sondern stets das Verhältnis der Subpopulationskonzentrationen zueinander und zu der Kontrollgruppe zu berücksichtigen. 
Die mit NTA gemessene und in Kapitel 3.3.2 gezeigte durchschnittliche EV-Größe ist dennoch wichtig, um zu überprüfen, ob sich in der P14 und P100 Gruppe vornehmlich MV und Exo befinden, und um nachvollziehen zu können, wie gut die Trennung durchgeführt wurde. In dieser Arbeit konnte gezeigt werden, dass die P100-Fraktion kleinere Partikel enthält als die P14-Fraktion. Dennoch fanden sich in ersterer Fraktion z. T. etwas größere EV, sodass hier ein gewisses Maß an Überlappung mit der P14-Fraktion nicht auszuschließen ist, was die Ergebnisse verfälscht haben könnte. Die Partikel der P14-Fraktion von Kontrollgruppe und siSMPD1 entsprechen der erwarteten Partikelgröße mit einem Peak bei $200 \mathrm{~nm}$. Unter KD von SMPD2 bzw. SMPD3 hingegen sind die MV kleiner und ähneln mit ihrer Durchschnittsgröße eher der P100-Fraktion. Es ist also auch denkbar, dass in den EV unter siSMPD2 und siSMPD3 deshalb keine signifikanten Veränderungen detektiert werden konnten, da die si-induzierte Größenänderunng mit der Trenntechnik interferierte.

Ein weiterer Störfaktor könnte die Bildung von Apoptosekörpern sein, da der KD von SMasen die Zellhomöostase stört und die Zelle mit einem programmierten Zelltod reagieren könnte. Die Apoptosekörper, welche i. d. R. Zellorganellen beinhalten, sind jedoch mit 500-4000 nm (Elmore 2007; Akers et al. 2013) deutlich größer als die gemessenen MV und Exo. Dennoch entstehen auch während der Apoptose kleinere Apoptosevesikel mit einer Größe von 50-500 nm, welche sich direkt von der Plasmamembran abschnüren (Coleman et al. 2001; Sebbagh et al. 2001). Eine Verunreinigung der P100 und P14-Fraktionen durch Apoptosevesikel ist daher nicht ausgeschlossen. Da jedoch Sphingomyelinasen und auch Ceramide in der Entstehung der Apoptose eine grundlegende Rolle einnehmen, konnte bereits auch gezeigt werden, dass durch Inhibition der aSMase die Apoptoseinduktion stark verringert werden kann (Zhao et al. 2016; Niaudet et al. 2017). Da bei den Versuchen dieser Arbeit die aSMase herunterreguliert wurde, ist davon auszugehen, dass auch hier die Apoptoseinduktion verringert wurde und folglich Apoptosevesikel in nur geringer und irrelevanter Menge gebildet wurden. Gegen einen relevanten Einfluss der Apoptosekörper als Störfaktor sprechen außerdem noch zwei weitere Argumente. Erstens müssten die Apoptosekörper mit einer Größe von 50-500 nm in sowohl der MV-als auch der Exo-Fraktion zu finden sein, wodurch sich ihr Einfluss auf die gemessene Vesikelkonzentration im Exo- zu MV-Vergleich gegenseitig aufhebt. Zweitens konnte mit der Viabilitätstestung (s. Kapitel 3.2.3) gezeigt werden, dass die Zellen sowohl in der Kontrollgruppe als auch in den transfizierten Zellen keine deutliche Apoptoseinduktion stattfand. Die enstandenen Apoptosevesikel müssten demnach gleichermaßen in den transfizierten siCtl und siSMPD1-3 zu finden sein.

Alle Konzentrations- und Größenmessungen der EV wurden mit der Nanoparticle Tracking Analysis durchgeführt. An dieser Stelle sei angemerkt, dass die Methode sehr anfällig für Störfaktoren ist und die Handhabung auch durch verbesserte Software schwierig bleibt. Messungenauigkeiten durch bspw. externe Vibrationen, Temperaturschwankungen, Pippetierfehler und Partikelaggregationen sowie Luftblaseneinschlüsse (welche den Detektionslaser streuen) bleiben nicht aus, können allerdings 
minimiert werden (Gardiner et al. 2013). Bei der Messung ist es essenziell, auf die o. g. potenziellen Störfaktoren zu achten und im Zweifel die Messung zu wiederholen.

\subsection{Knock-Down einer SMase scheint die Expression der anderen nicht zu beeinflussen}

Es ist denkbar, dass Zellen alternative SMasen vermehrt exprimieren, wenn eine der SMasen durch den KD nicht ausrreichend aktiviert werden kann. Um das zu überprüfen, wurden, wie unter Kapitel 3.5 beschrieben, mittels RTqPCR die relativen Expressionen der einzelnen SMasen gemessen. Hierbei konnte für siSMPD1 und siSMPD2 eindrücklich gezeigt werden, dass zumindest auf mRNA-Ebene keine signifikante Zunahme der jeweils anderen SMasen zu verzeichnen ist. Dennoch konnte auch hier jeweils eine geringe tendenzielle vermehrte Expression nachgewiesen werden. Da die Expression von SMPD3 bei siSMPD2 jedoch so gering zunimmt, ist dadurch die kaum beeinträchtigte Ceramidkonzentration nicht erklärbar. Die Expression von SMPD2 bei siSMPD3 war auch tendenziell leicht erhöht. Da hier jedoch die Ceramid- und Sphingomyelinkonzentrationen nicht gemessen wurden, lässt sich hier keine Aussage über die veränderten Ceramidkonzentrationen machen. Auch durch den KD der aSMase ist keine vermehrte Expression von SMPD2 und SMPD3 zu verzeichnen.

Somit kann davon ausgegangen werden, dass vor allem der KD der aSMase die verminderte Ceramidkonzentration bewirkt. Da Ceramide jedoch auch über Ceramid-Synthasen entstehen können, wäre es für die abschließende Beurteilung noch notwendig zu untersuchen, ob diese CeramidSynthasen nicht über bisher unbekannte Mechanismen vermindert exprimiert werden, wenn die aSMase mit siRNA herunterreguliert wird. Dafür gibt es jedoch in der Literatur aktuell keinen Hinweis.

\subsection{Knock-Down der aSMase senkt die Ceramidkonzentration}

Interessanterweise konnte sich bei den Messungen in der Massenspektrometrie ein Abfall der Ceramide durch KD der aSMase finden lassen, während die Konzentration von Sphingomyelinen nahezu unverändert bleibt. Dieser Ceramid-Abfall könnte dann auch am ehesten die EVSekretionsveränderungen erklären. Ob Ceramid nun direkt in die EV-Biogenese der Exo und der MV eingreift oder über die Aktivierung und Deaktivierung anderer Enzyme seinen Einfluss auf die EVBiogenese ausübt, kann mit den durchgeführten Versuchen nicht geklärt werden. Unklar ist außerdem, wieso die Sphingomyelinmenge unverändert bleibt. Hintergrund könnte hier die Tatsache sein, dass Sphingomyeline um den Faktor zehn häufiger in Zellen vorkommen (Hannun und Obeid 2008) und daher eine veränderte Sphingomyelinmenge nicht so leicht messbar ist, wie die der Ceramide. Welche genaue Funktion Sphingomyeline in der Sekretion von EV besitzen, ist ebenfalls unbekannt. Da in 
dieser Arbeit jedoch bereits bei gleichbleibender Sphingomyelinmenge ein Effekt auf die EVSekretion zu verzeichnen war, scheint deren Einfluss zur Zeit eher vernachlässigbar.

Die massenspektrometrische Untersuchung bei siSMPD2-Zellen zeigte hingegen keine eindeutigen Veränderungen in der Ceramid- und Sphingomyelinkonzentrationen. Hier nahm entgegen der Erwartungen die Ceramidkonzentration eher zu, anstatt abzunehmen. Diese Tatsache könnte auch erklären, wieso keine signifikanten Veränderungen in der EV-Sekretion von siSMPD2-Zellen beobachtet werden konnten, wenn man Ceramide als hypothetische Modulatoren der EV-Sekretion annimmt. Offen bleibt hingegen, wieso sich keine verringerte Ceramidkonzentration finden lässt. Entweder hat der KD, wie oben beschrieben, nur unzureichend funktioniert und die nSMase1 konnte mit genügend Restaktivität ausreichend Ceramide bilden. Denkbar wäre aber auch eine kompensatorische Ceramidsynthese auf anderem Weg als über die Sphingomyelinase, bspw. über Ceramidsynthasen.

\subsection{Weitergehende Forschung}

Um die Frage ausführlich beantworten zu können, inwiefern die SMasen und vor allem auch ihr Produkt Ceramid an der Biogenese der EV beteiligt sind, müssen, wie oben beschrieben, noch weitere Versuche folgen. Zusätzlich zu den zuvor beschriebenen Ansatzpunkten ergibt die Thematik meines Erachtens nach noch viel Raum für weitergehende Forschung. Ich möchte im Folgenden kurz darlegen, welche Versuche unmittelbar auf diese Arbeit folgen könnten.

Zunächst wäre es interessant zu ergründen, weshalb in dieser Arbeit keine veränderte Exo-Sekretion durch KD der nSMasen gefunden werden konnte. In dieser Arbeit wurden die nSMasen nur einzeln herunterreguliert. Es wäre also interssant, den gleichen Versuchsaufbau zu verwenden, diesmal jedoch beide nSMasen gleichzeitig oder gar alle SMasen herunterzuregulieren. Weitaus stärkere Effekte müssten sich finden lassen, wenn man komplette Knock-Out-Versuche mit den entsprechenden Genen mittels der CRISPR-Cas-Methode durchführen würde. Voraussetzung hierbei ist natürlich, dass die Zellen diese genetischen Eingriffe im Bezug auf ihre Viabilität tolerieren. Da die SMasen und ihre Produkte Ceramide grundlegende Funktionen des Zellzyklus steuern, ist davon auszugehen, dass Zellen einen dreifachen KD nicht tolerieren und sterben.

Eine weitere Überlegung wäre es, die SMasen in den Zellen überzuexprimieren oder sie direkt mit Ceramiden zu inkubieren. Hier müssten theoretisch die gegenteiligen Effekte nachweisbar sein. Die Exo-Sekretion müsste zunehmen, während die MV-Sekretion abnimmt. Der Vorteil an einer direkten Ceramidinkubation wäre, dass die Wirkung der Ceramide gezielter, vor allem ohne den Einfluss weiterer Faktoren, wie beispielsweise dem Phosphocholin, welches bei der von den SMasen katalysierten Reaktion außerdem entsteht, untersucht werden könnte. 
Darüberhinaus wäre es interessant zu erfahren, wie sich die Komposition der EV durch den KD der SMasen verändert. Es liegt auf der Hand, dass sich die Lipidzusammensetzung bezogen auf die Ceramide und ihre Abkömmlinge Sphingomyeline und Sphingosin verändern muss. Genauso interessant wäre es jedoch zu erfahren, ob auch die Protein-, DNA- und RNA-Komposition verändert werden. Sollte sich die Komposition der EV ändern, müsste untersucht werden, inwiefern dadurch die Funktionen der EV beeinflusst werden.

\subsection{Relevanz der Arbeit in Bezug auf angewandte Medizin}

EV haben, wie in Kapitel 1.2 bereits angesprochen, diverse Funktionen und Einflüsse auf die Physiologie des Menschen. Hieraus ergeben sich diverse Möglichkeiten für diagnostische und therapeutische Anwendungen. Um jedoch erstens die Möglichkeiten der EV vollständig zu nutzen und zweitens eine sichere Diagnostik und Therapien zu ermöglichen, ist ein umfangreiches Wissen über die Mechanismen und Einflüsse der EV-Entstehung vonnöten. Im Folgenden möchte ich einige diagnostische und therapeutische Forschungsansätze diskutieren, und der Frage nachgehen, inwiefern die vorliegende Arbeit bei diesen Ansätzen helfen kann/könnte.

Seit einiger Zeit beschäftigen sich viele Forschungsgruppen mit der Möglichkeit, EV als Biomarker für verschiedene Krankheiten zu nutzen (Wu et al. 2017). Besonders aus der Onkologie ist bekannt, dass gerade Tumorzellen mehr EV sezernieren als ihre gesunden Äquivalenzzellen (Redzic et al. 2013). Darüberhinaus steigt die Anzahl der sezernierten EV außerdem mit dem Grad der Differenzierung (Taylor und Gercel-Taylor 2008; Sandvig und Llorente 2012). Durch Messung der im Blut, im Speichel oder in anderen Flüssigkeiten befindlichen EV können Aussagen über das Krankheitsstadium getroffen werden (Balaj et al. 2011). Abgesehen von der EV-Konzentration im Blut, die durch Tumoren zunimmt, verändert sich auch die EV-Komposition (Bryant et al. 2012). So sind z. T. auf Tumorzellen andere Proteine, RNA und DNA auf den EV nachzuweisen. Durch Charakterisierung dieser EV kann so in Zukunft die Tumordiagnostik erleichtert und verbessert werden. Tumoren sind meist Erkrankungen des höheren Alters und nicht selten mit anderen behandlungsbedürftigen Erkrankungen vergesellschaftet. Viele Medikamente gelten jedoch als funktionelle Inhibitoren der sauren Sphingomyelinase (sog. FIASMA). Hierunter fallen z. B. Flouxetin, Sertralin, Promethazin, Amlodipin, Doxepin, Amiodaron, Tamoxifen und viele andere (Kornhuber et al. 2008). In dieser Arbeit konnte der Einfluss der aSMase auf sowohl die Exo- als auch die MV-Sekretion gezeigt werden. Es muss daher untersucht werden, inwiefern sich sowohl die Anzahl als auch die Komposition der sezernierten EV in vivo verändert, wenn Patienten mit einem der FIASMA behandelt werden. Sollten ähnliche Effekte auf die EV-Biogenese wie in dieser Arbeit auch in vivo gefunden werden, wäre die diagnostische Aussagekraft nur noch eingeschränkt und die Gefahr der Über- und Unterdiagnostik gegeben. 
Ein möglicher Ansatzpunkt für weitere Forschung wäre es dieser Arbeit nach, einen aSMase-Inhibitor zu finden, der therapeutisch zur Anwendung kommt und effektiv die EV-Sekretion und damit indirekt die Angiogenese, Immunsuppression oder auch die EZM-Zersetzung reduziert (Yáñez-Mó et al. 2015; Wu et al. 2017). Ob die Inhibition der aSMase jedoch auch in vivo effektive EV-Sekretionsänderungen erzielt, und ob diese Änderung letztlich Auswirkungen auf die Tumorprogression besitzen, bleibt zum jetztigen Forschungsstand offen.

Einige EV sind in der Lage, das Immunsystem nicht zu unterdrücken, sondern es gezielt zu stimulieren (Raposo et al. 1996; Théry et al. 2002). Demnach gibt es Forschungsansätze, sich diese Funktion zunutze zu machen und EV therapeutisch als Immunstimuatoren einzusetzen. Neben der Möglichkeit EV als Medikment einzusetzen, ist es in Zukunft vielleicht möglich, SMase-Inhibitoren oder SMase-Aktivatoren für verschiedene Anwendungen einzusetzen, um die körpereigene EVSekretion zu verändern und auch von ihren protektiven Eigenschaften zu profitieren.

Unabhängig von den oben genannten Anwendungsmöglichkeiten der SMasen in Bezug auf die EVSekretion ist anzumerken, dass in dieser Arbeit lediglich mit einer Her2/neu positiven Mammakarzinomzelllinie gearbeitet wurde. Da die Forschung zur Zeit nahelegt, dass unterschiedliche Mechanismen für die EV-Biogenese in unterschiedlichen Zelltypen verantwortlich sind (van Niel et al. 2018), muss in Zukunft der Einfluss der SMase auch in ER-, und PR- positiven Mammakarzinomzelllinien untersucht werden. Darüberhinaus ist es wichtig, ihren Einfluss auch in anderen Tumor- und in Nicht-Tumorzellen zu untersuchen. Nur so können erstens allgemeine Aussagen getroffen, zweitens sichere Therapien gefunden und drittens die potenziellen Nebenwirkungen der EV-Therapie eingeschätzt werden. 


\section{Zusammenfassung}

Extrazelluläre Vesikel und ihre Subgruppen Mikrovesikel und Exosomen sind wichtige Vermittler der Zell-Zell-Kommunikation in physiologischen und in pathologischen Prozessen. Besonders in der Onkologie sind sie in den letzten Jahren in den Fokus gerückt, da sie sowohl diagnostisches sowie therapeutisches Potenzial besitzen. Auch wenn zum Teil schon einige Mechanismen der Exosomenund auch der Mikrovesikel-Biogenese entdeckt werden konnten, sind sie bislang noch nicht vollumfassend verstanden. Diverse Forschungsgruppen haben in der Vergangenheit den Sphingomyelinasen einen Einfluss auf die Exosomen-Sekretion zugesprochen. Die Vorergebnisse meiner Arbeitsgruppe ließen dann darauf schließen, dass die Sphingomyelinasen sowohl in der Exosomen- als auch in der Mikrovesikel-Biogenese involviert sind. Welchen Einfluss jedoch die einzelnen Sphingomyelinasen (saure und neutrale Sphingomyelinase 1 und 2) besitzen und welche molekularen Mechanismen dafür verantwortlich sind, wurde in dieser Arbeit untersucht.

Es konnte gezeigt werden, dass die Sphingomyelinasen, obwohl sie die gleiche Reaktion katalysieren, unterschiedliche Einflüsse auf die Produktion von extrazellulären Vesikeln ausüben. So bewirkt der Knock-Down der sauren Sphingomyelinase in Mammakarzinomzellen eine Zunahme der Mikrovesikel bei gleichzeitiger Abnahme der Exosomen. Der Knock-Down der neutralen Sphingomyelinasen führt ebenfalls tendenziell zu einer Zunahme der Mikrovesikel, jedoch zu einer unveränderten ExosomenSekretion. Für diese unterschiedlichen Effekte der Sphingomyelinasen sind am ehesten ihre jeweiligen intrazellulären Lokalisationen und ihre spezifischen $\mathrm{pH}$-Optima bedeutend. Außerdem ist $\mathrm{zu}$ vermuten, dass die Effekte der Sphingomyelinasen in unterschiedlichen Geweben variieren, was eine Verallgemeinerung der Ergebnisse erschwert. Ceramide, die Reaktionsprodukte der Sphingomyelinasen, scheinen wichtige Mediatoren der Knock-Down Effekte zu sein. In Zukunft muss geprüft werden, wie sich die Produktion der extrazellulären Vesikel verändert, wenn die Ceramidkonzentration auf anderem Wege verändert wird, welchen Einfluss dies auf andere Gewebe (physiologische und pathologische) hat und ob sich die Erkenntnisse über die EV-Biogenese auch in vivo reproduzieren lassen. Ein verbessertes Verständnis der Biogenese ist Voraussetzung für ihre Nutzung als diagnostische Biomarker ebenso wie ihre gezielte Beeinflussung im Rahmen von innovativen Therapie-Strategien. 


\section{Literaturverzeichnis}

Abo-Aziza FAM, Zaki AA (2017): The impact of confluence on bone marrow mesenchymal stem (BMMSC) proliferation and osteogenic differentiation. Int J Hematol-Oncol Stem Cell Res $\underline{11}, 121-$ 132

AGO (2019): Diagnosis and treatment of patients with early and advanced breast cancer. Leitlinie der Arbeitsgemeinschaft Gynäkologische Onkologie e. V. in der Deutschen Gesellschaft für Gynäkologie und Geburtshilfe e. V. sowie in der Deutschen Krebsgesellschaft e. V. https://www.agoonline.de/leitlinien-empfehlungen/leitlinien-empfehlungen/kommission-mamma, abgerufen am 31.07.2019

Akers JC, Gonda D, Kim R, Carter BS, Chen CC (2013): Biogenesis of extracellular vesicles (EV): exosomes, microvesicles, retrovirus-like vesicles, and apoptotic bodies. J Neurooncol $\underline{113}, 1-11$

Babst M (2005): A protein's final ESCRT. Traffic Cph Den $\underline{6}, 2-9$

Baietti MF, Zhang Z, Mortier E, Melchior A, Degeest G, Geeraerts A, Ivarsson Y, Depoortere F, Coomans C, Vermeiren E et al. (2012): Syndecan-syntenin-ALIX regulates the biogenesis of exosomes. Nat Cell Biol 14, 677-685

Balaj L, Lessard R, Dai L, Cho YJ, Pomeroy SL, Breakefield XO, Skog J (2011): Tumour microvesicles contain retrotransposon elements and amplified oncogene sequences. Nat Commun $\underline{2}$, 180

Bevers EM, Comfurius P, Dekkers DW, Zwaal RF (1999): Lipid translocation across the plasma membrane of mammalian cells. Biochim Biophys Acta 1439, 317-330

Bianco F, Perrotta C, Novellino L, Francolini M, Riganti L, Menna E, Saglietti L, Schuchman EH, Furlan R, Clementi E et al. (2009): Acid sphingomyelinase activity triggers microparticle release from glial cells. EMBO J $2 \underline{8}, 1043-1054$

Bobrie A, Colombo M, Raposo G, Théry C (2011): Exosome secretion: molecular mechanisms and roles in immune responses. Traffic Cph Den $\underline{12}, 1659-1668$

Bryant RJ, Pawlowski T, Catto JWF, Marsden G, Vessella RL, Rhees B, Kuslich C, Visakorpi T, Hamdy FC (2012): Changes in circulating microRNA levels associated with prostate cancer. Br J Cancer 106, 768-774

Cai H, Reinisch K, Ferro-Novick S (2007): Coats, tethers, Rabs, and SNAREs work together to 
mediate the intracellular destination of a transport vesicle. Dev Cell $\underline{12}, 671-682$

Cailleau R, Young R, Olivé M, Reeves WJ (1974): Breast tumor cell lines from pleural effusions. J Natl Cancer Inst $\underline{53}, 661-674$

Canals D, Perry DM, Jenkins RW, Hannun YA (2011): Drug targeting of sphingolipid metabolism: sphingomyelinases and ceramidases: Drug targeting, sphingomyelinases and ceramidases. $\mathrm{Br} \mathrm{J}$ Pharmacol 163, 694-712

Coleman ML, Sahai EA, Yeo M, Bosch M, Dewar A, Olson MF (2001): Membrane blebbing during apoptosis results from caspase-mediated activation of ROCK I. Nat Cell Biol $\underline{3}, 339-345$

Colombo M, Raposo G, Théry C (2014): Biogenesis, secretion, and intercellular interactions of exosomes and other extracellular vesicles. Annu Rev Cell Dev Biol 30, 255-289

Corrado C, Raimondo S, Chiesi A, Ciccia F, De Leo G, Alessandro R (2013): Exosomes as intercellular signaling organelles involved in health and disease: basic science and clinical applications. Int J Mol Sci 14, 5338-5366

Crescitelli R, Lässer C, Szabó TG, Kittel A, Eldh M, Dianzani I, Buzás EI, Lötvall J (2013): Distinct RNA profiles in subpopulations of extracellular vesicles: apoptotic bodies, microvesicles and exosomes. J Extracell Vesicles $\underline{2}, 20677$

Doyle LM, Wang MZ (2019): Overview of extracellular vesicles, their origin, composition, purpose, and methods for exosome isolation and analysis. Cells $\underline{8}, 727$

Drago F, Lombardi M, Prada I, Gabrielli M, Joshi P, Cojoc D, Franck J, Fournier I, Vizioli J, Verderio C (2017): ATP modifies the proteome of extracellular vesicles released by microglia and influences their action on astrocytes. Front Pharmacol $\underline{8}, 910$

D'Souza-Schorey C, Clancy JW (2012): Tumor-derived microvesicles: shedding light on novel microenvironment modulators and prospective cancer biomarkers. Genes Dev $\underline{26}, 1287-1299$

DuBridge RB, Tang P, Hsia HC, Leong PM, Miller JH, Calos MP (1987): Analysis of mutation in human cells by using an Epstein-Barr virus shuttle system. Mol Cell Biol 7, 379-387

Elmore S (2007): Apoptosis: a review of programmed cell death. Toxicol Pathol $\underline{35}, 495-516$

Figueroa-Magalhães MC, Jelovac D, Connolly R, Wolff AC (2014): Treatment of HER2-positive breast cancer. Breast Edinb Scotl 23, 128-136

Filipe V, Hawe A, Jiskoot W (2010): Critical evaluation of nanoparticle tracking analysis (NTA) by NanoSight for the measurement of nanoparticles and protein aggregates. Pharm Res $\underline{27}, 796-810$ 
Fogh J, Fogh JM, Orfeo T (1977): One hundred and twenty-seven cultured human tumor cell lines producing tumors in nude mice. J Natl Cancer Inst 59, 221-226

Gardiner C, Ferreira YJ, Dragovic RA, Redman CWG, Sargent IL (2013): Extracellular vesicle sizing and enumeration by nanoparticle tracking analysis. J Extracell Vesicles $\underline{2}, 19671$

Ginestra A, Miceli D, Dolo V, Romano FM, Vittorelli ML (1999): Membrane vesicles in ovarian cancer fluids: a new potential marker. Anticancer Res $\underline{19}, 3439-3445$

Gross JC, Zelarayán LC (2018): The mingle-mangle of Wnt signaling and extracellular vesicles: functional implications for heart research. Front Cardiovasc Med $\underline{5}, 10$

Gross JC, Chaudhary V, Bartscherer K, Boutros M (2012): Active Wnt proteins are secreted on exosomes. Nat Cell Biol 14, 1036-1045

Hannun YA, Obeid LM (2008): Principles of bioactive lipid signalling: lessons from sphingolipids. Nat Rev Mol Cell Biol $\underline{9}, 139-150$

Hashmi AA, Mahboob R, Khan SM, Irfan M, Nisar M, Iftikhar N, Siddiqui M, Faridi N, Khan A, Edhi MM (2018): Clinical and prognostic profile of Her2neu positive (non-luminal) intrinsic breast cancer subtype: comparison with Her2neu positive luminal breast cancers. BMC Res Notes $\underline{11}, 574$

Heijnen HF, Schiel AE, Fijnheer R, Geuze HJ, Sixma JJ (1999): Activated platelets release two types of membrane vesicles: microvesicles by surface shedding and exosomes derived from exocytosis of multivesicular bodies and alpha-granules. Blood 94, 3791-3799

Henry B, Ziobro R, Becker KA, Kolesnick R, Gulbins E (2013): Acid sphingomyelinase. Handb Exp Pharmacol 215, 77-88

Hong J, Bhat OM, Li G, Dempsey SK, Zhang Q, Ritter JK, Li W, Li P-L (2019): Lysosomal regulation of extracellular vesicle excretion during d-ribose-induced NLRP3 inflammasome activation in podocytes. Biochim Biophys Acta BBA - Mol Cell Res $\underline{1866}, 849-860$

Karakashian AA, Giltiay NV, Smith GM, Nikolova-Karakashian MN (2004): Expression of neutral sphingomyelinase-2 (NSMase-2) in primary rat hepatocytes modulates IL-beta-induced JNK activation. FASEB J Off Publ Fed Am Soc Exp Biol 18, 968-970

Kornhuber J, Tripal P, Reichel M, Terfloth L, Bleich S, Wiltfang J, Gulbins E (2008): Identification of new functional inhibitors of acid sphingomyelinase using a structure-property-activity relation model. J Med Chem 51, 219-237

Kucharzewska P, Belting M (2013): Emerging roles of extracellular vesicles in the adaptive response of tumour cells to microenvironmental stress. J Extracell Vesicles 2, 20304 
Lakkaraju A, Rodriguez-Boulan E (2008): Itinerant exosomes: emerging roles in cell and tissue polarity. Trends Cell Biol 18, 199-209

Lebeau A, Kriegsmann M, Burandt E, Sinn H-P (2014): Invasive breast cancer: the current WHO classification. Pathol $\underline{35}, 7-17$

Lee JY, Hannun YA, Obeid LM (1996): Ceramide inactivates cellular protein kinase Calpha. J Biol Chem $\underline{271}, 13169-13174$

Malvern (2019): Nanoparticle tracking Analysis. https://www.malvernpanalytical.com /de/products/technology/nanop article-tracking-analysis; abgerufen am 07.08.2019

Marchesini N, Luberto C, Hannun YA (2003): Biochemical properties of mammalian neutral sphingomyelinase 2 and its role in sphingolipid metabolism. J Biol Chem 278, 13775-13783

Marshall OJ (2004): PerlPrimer: cross-platform, graphical primer design for standard, bisulphite and real-time PCR. Bioinforma Oxf Engl 20, 2471-2472

Memorial Sloan Kettering (2019): SK-BR-3: Human breast cancer cell line (ATCC HTB-30) https://www.mskcc.org/research-advantage/support/technology/tangible-material/human-breast-cellline-sk-br-3, abgerufen am 08.08.2019

Menck K, Sönmezer C, Worst TS, Schulz M, Dihazi GH, Streit F, Erdmann G, Kling S, Boutros M, Binder C, Gross JC (2017): Neutral sphingomyelinases control extracellular vesicles budding from the plasma membrane. J Extracell Vesicles $\underline{6}, 1378056$

Möbius W, van Donselaar E, Ohno-Iwashita Y, Shimada Y, Heijnen HFG, Slot JW, Geuze HJ (2003): Recycling compartments and the internal vesicles of multivesicular bodies harbor most of the cholesterol found in the endocytic pathway. Traffic Cph Den $\underline{4}$, 222-231

Moloudizargari M, Asghari MH, Abdollahi M (2018): Modifying exosome release in cancer therapy: How can it help? Pharmacol Res $\underline{134}, 246-256$

Muller L, Hong CS, Stolz DB, Watkins SC, Whiteside TL (2014): Isolation of biologically-active exosomes from human plasma. J Immunol Methods $\underline{411}, 55-65$

Muralidharan-Chari V, Clancy J, Plou C, Romao M, Chavrier P, Raposo G, D’Souza-Schorey C (2009): ARF6-regulated shedding of tumor cell-derived plasma membrane microvesicles. Curr Biol CB $\underline{19}, 1875-1885$

NCBI (2019a): SMPD3 sphingomyelin phosphodiesterase 3, Gene ID: 55512. https://www.ncbi .nlm.nih.gov/gene? $\mathrm{Db}=$ gene $\& \mathrm{Cmd}=$ DetailsSearch $\&$ Term=55512\#gene-expression; abgerufen $\quad$ am 01.08.2019 
NCBI (2019b): Smpd2 sphingomyelin phosphodiesterase 2, Gene ID: 20598. https://www.ncbi .nlm.nih.gov/gene?Db=gene\&Cmd=DetailsSearch\&Term=20598; abgerufen am 01.08.2019

Niaudet C, Bonnaud S, Guillonneau M, Gouard S, Gaugler MH, Dutoit S, Ripoche N, Dubois N, Trichet V, Corre I, Paris F (2017): Plasma membrane reorganization links acid sphingomyelinase/ceramide to p38 MAPK pathways in endothelial cells apoptosis. Cell Signal $\underline{33}, 10$ 21

Parolini I, Federici C, Raggi C, Lugini L, Palleschi S, De Milito A, Coscia C, Iessi E, Logozzi M, Molinari A, et al. (2009): Microenvironmental pH is a key factor for exosome traffic in tumor cells. $\mathbf{J}$ Biol Chem 284, 34211-34222

Patel GK, Khan MA, Zubair H, Srivastava SK, Khushman M, Singh S, Singh AP (2019): Comparative analysis of exosome isolation methods using culture supernatant for optimum yield, purity and downstream applications. Sci Rep $\underline{9}, 5335$

Raposo G, Stoorvogel W (2013): Extracellular vesicles: Exosomes, microvesicles, and friends. J Cell Biol 200, 373-383

Raposo G, Nijman HW, Stoorvogel W, Liejendekker R, Harding CV, Melief CJ, Geuze HJ (1996): B lymphocytes secrete antigen-presenting vesicles. J Exp Med 183, 1161-1172

Ratajczak J, Miekus K, Kucia M, Zhang J, Reca R, Dvorak P, Ratajczak MZ (2006): Embryonic stem cell-derived microvesicles reprogram hematopoietic progenitors: evidence for horizontal transfer of mRNA and protein delivery. Leukemia $\underline{20}, 847-856$

Redzic JS, Kendrick AA, Bahmed K, Dahl KD, Pearson CG, Robinson WA, Robinson SE, Graner MW, Eisenmesser EZ (2013): Extracellular vesicles secreted from cancer cell lines stimulate secretion of MMP-9, IL-6, TGF- $\beta 1$ and EMMPRIN. PloS One $\underline{8}$, e71225

Rhiem K, Schmutzler RK (2015): Risikofaktoren und Prävention des Mammakarzinoms. Onkol 21, $202-210$

Róg T, Orłowski A, Llorente A, Skotland T, Sylvänne T, Kauhanen D, Ekroos K, Sandvig K, Vattulainen I (2016): Interdigitation of long-chain sphingomyelin induces coupling of membrane leaflets in a cholesterol dependent manner. Biochim Biophys Acta $\underline{1858}, 281-288$

Sandvig K, Llorente A (2012): Proteomic analysis of microvesicles released by the human prostate cancer cell line PC-3. Mol Cell Proteomics MCP 11, M111.012914

Schuchman EH, Levran O, Pereira LV, Desnick RJ (1992): Structural organization and complete nucleotide sequence of the gene encoding human acid sphingomyelinase (SMPD1). Genomics $\underline{12}$, 
$197-205$

Sebbagh M, Renvoizé C, Hamelin J, Riché N, Bertoglio J, Bréard J (2001): Caspase-3-mediated cleavage of ROCK I induces MLC phosphorylation and apoptotic membrane blebbing. Nat Cell Biol $\underline{3}, 346-352$

Simpson RJ, Lim JW, Moritz RL, Mathivanan S (2009): Exosomes: proteomic insights and diagnostic potential. Expert Rev Proteomics $\underline{6}, 267-283$

Soule HD, Vazguez J, Long A, Albert S, Brennan M (1973): A human cell line from a pleural effusion derived from a breast carcinoma. J Natl Cancer Inst $\underline{51}$, 1409-1416

Tanasescu R, Lanz MA, Mueller D, Tassler S, Ishikawa T, Reiter R, Brezesinski G, Zumbuehl A (2016): Vesicle origami and the influence of cholesterol on lipid packing. Langmuir ACS J Surf Colloids $\underline{32}$, 4896-4903

Tannock IF, Rotin D (1989): Acid pH in tumors and its potential for therapeutic exploitation. Cancer $\operatorname{Res} \underline{49}, 4373-4384$

Taylor DD, Gercel-Taylor C (2008): MicroRNA signatures of tumor-derived exosomes as diagnostic biomarkers of ovarian cancer. Gynecol Oncol $\underline{110}, 13-21$

Théry C, Duban L, Segura E, Véron P, Lantz O, Amigorena S (2002): Indirect activation of naïve CD4+ T cells by dendritic cell-derived exosomes. Nat Immunol 3, 1156-1162

Théry C, Amigorena S, Raposo G, Clayton A (2006): Isolation and characterization of exosomes from cell culture supernatants and biological fluids. Curr Protoc Cell Biol 30, 3.22.1-3.22.29

Théry C, Ostrowski M, Segura E (2009): Membrane vesicles as conveyors of immune responses. Nat Rev Immunol 9, 581-593

Trajkovic K, Hsu C, Chiantia S, Rajendran L, Wenzel D, Wieland F, Schwille P, Brügger B, Simons M (2008): Ceramide triggers budding of exosome vesicles into multivesicular endosomes. Science $\underline{319}, 1244-1247$

Trempe GL: Human breast cancer in culture. In: St-Arneault G, Band P, Israël L (Hrsg.): Recent Results in Cancer Research. Breast cancer a multidisciplinary approach. Springer, Berlin 1976, 33-41

Turturici G, Tinnirello R, Sconzo G, Geraci F (2014): Extracellular membrane vesicles as a mechanism of cell-to-cell communication: advantages and disadvantages. Am J Physiol Cell Physiol 306, C621-633

UniProt Consortium (2019a): Sphingomyelin phosphodiesterase, SMPD1. https://www.unip 
rot.org/uniprot/P17405; abgerufen am 01.08.2019

UniProt Consortium (2019b): Sphingomyelin phosphodiesterase 2, SMPD2. https://www.unip rot.org/uniprot/O60906; abgerufen am 01.08.2019

Vader P, Breakefield XO, Wood MJA (2014): Extracellular vesicles: emerging targets for cancer therapy. Trends Mol Med 20, 385-393

Van Meer G, Voelker DR, Feigenson GW (2008): Membrane lipids: where they are and how they behave. Nat Rev Mol Cell Biol $\underline{9}, 112-124$

Van Niel G, D’Angelo G, Raposo G (2018): Shedding light on the cell biology of extracellular vesicles. Nat Rev Mol Cell Biol 19, 213-228

Vanier MT (2013): Niemann-Pick diseases. Handb Clin Neurol 113, 1717-1721

Verheij M, Bose R, Lin XH, Yao B, Jarvis WD, Grant S, Birrer MJ, Szabo E, Zon LI, Kyriakis JM, et al. (1996): Requirement for ceramide-initiated SAPK/JNK signalling in stress-induced apoptosis. Nature $\underline{380}, 75-79$

Vidal M (2019): Exosomes: revisiting their role as „garbage bags“. Traffic 20, 815-828

Vidal M, Sainte-Marie J, Philippot JR, Bienvenue A (1989): Asymmetric distribution of phospholipids in the membrane of vesicles released during in vitro maturation of guinea pig reticulocytes: evidence precluding a role for „aminophospholipid translocase“. J Cell Physiol $\underline{140}, 455-462$

Waldenström A, Gennebäck N, Hellman U, Ronquist G (2012): Cardiomyocyte microvesicles contain DNA/RNA and convey biological messages to target cells. PloS One $\underline{7}$, e34653

Willms E, Johansson HJ, Mäger I, Lee Y, Blomberg KEM, Sadik M, Alaarg A, Smith CIE, Lehtiö J, El Andaloussi S, et al. (2016): Cells release subpopulations of exosomes with distinct molecular and biological properties. Sci Rep $\underline{6}, 22519$

Wollert T, Hurley JH (2010): Molecular mechanism of multivesicular body biogenesis by ESCRT complexes. Nature $\underline{464}, 864-869$

Wollert T, Wunder C, Lippincott-Schwartz J, Hurley JH (2009): Membrane scission by the ESCRT-III complex. Nature $\underline{458}, 172-177$

Wu BX, Clarke CJ, Hannun YA (2010): Mammalian neutral sphingomyelinases: regulation and roles in cell signaling responses. Neuromolecular Med $\underline{12}, 320-330$

Wu K, Xing F, Wu SY, Watabe K (2017): Extracellular vesicles as emerging targets in cancer: Recent development from bench to bedside. Biochim Biophys Acta Rev Cancer 1868, 538-563 
Yabu T, Shiba H, Shibasaki Y, Nakanishi T, Imamura S, Touhata K, Yamashita M (2015): Stressinduced ceramide generation and apoptosis via the phosphorylation and activation of nSMase1 by JNK signaling. Cell Death Differ 22, 258-273

Yáñez-Mó M, Siljander PRM, Andreu Z, Zavec AB, Borràs FE, Buzas EI, Buzas K, Casal E, Cappello F, Carvalho J, et al. (2015): Biological properties of extracellular vesicles and their physiological functions. J Extracell Vesicles $\underline{4}, 27066$

ZfKD (2019): Brustkrebs (Mammakarzinom) https://www.krebsdaten.de/Krebs/DE/Content/Krebs arten/Brustkrebs/brustkrebs_node.html; abgerufen am 02.08.2019

Zhao M, Pan W, Shi RZ, Bai YP, You BY, Zhang K, Fu QM, Schuchman EH, He XX, Zhang GG (2016): Acid sphingomyelinase mediates oxidized-LDL induced apoptosis in macrophage via endoplasmic reticulum stress. J Atheroscler Thromb $\underline{23}$, 1111-1125

Zumbansen M: Biochemische und molekularbiologische Studien zur Charakterisierung der murinen neutralen Sphingomyelinase in vitro und in vivo. Math. Nat. Diss. Köln. 2001

Zumbansen M, Stoffel W (2002): Neutral sphingomyelinase 1 deficiency in the mouse causes no lipid storage disease. Mol Cell Biol 22, 3633-3638 


\section{Danksagungen}

Für die großzügige Ermunterung und Unterstützung, die ich während der Arbeit an meiner Dissertation erfahren durfte, möchte ich mich herzlich bedanken.

Zuerst möchte ich meiner Doktormutter Frau Prof. Dr. Claudia Binder danken, die sich immer Zeit für mich nahm und die mich nicht besser hätte betreuen können. Ich danke für Ihr Vertrauen und ihre fachliche Unterstuitzung.

Für Anregungen und konstruktive Kritik danke ich auch Frau Prof. Dr. Christine Stadelmann-Nessler, die meine Dissertation als Gutachterin betreute.

Zudem möchte ich Frau Dr. Kerstin Menck dafür danken, dass Sie rund um die Uhr für theoretische und praktische Fragen erreichbar war und jeden Tag im Labor an meiner Seite stand.

$\mathrm{Zu}$ großem Dank verpflichtet bin ich auch den Mitarbeitern der Arbeitsgruppe Binder/Bleckmann. Besonderer Dank gebührt Matthias Schulz, Lena Ries und Meike Schaffrinski, die mich geduldig in methodischen Fragestellungen schulten und mir mit ihrer Berufserfahrung zur Seite standen.

Für die finanzielle Unterstützung während der Arbeit im Labor danke ich der „Studienstiftung des deutschen Volkes e. V.“ und der „Göttinger Gesellschaft zur Unterstützung der Krebsforschung und -therapie e.V.“.

Zum Schluss gilt mein Dank noch der Metabolomics Core Facility der UMG Göttingen, die im Rahmen einer Kooperation die Durchführung von Versuchen übernahm. 